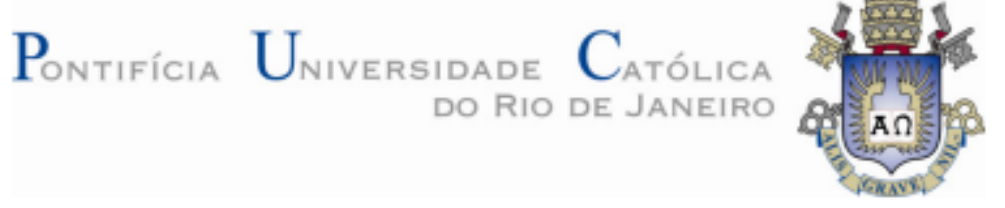

Raffael Capano de Arruda

Ensaios em Jogos Evolucionários com Aplicação ao Estudo da Interação entre Agências de Rating e Investidores

Dissertação de Mestrado

Dissertação apresentada como requisito parcial para obtenção do grau de Mestre pelo Programa de PósGraduação em Engenharia de Produção do Departamento de Engenharia Industrial da PUC-Rio.

Orientador: Prof. André Barreira da Silva Rocha 
Raffael Capano de Arruda

\section{Ensaios em Jogos Evolucionários com Aplicação ao Estudo da Interação entre Agências de Rating e Investidores}

Dissertação apresentada como requisito parcial para obtenção do grau de Mestre pelo Programa de PósGraduação em Engenharia de Produção do Departamento de Engenharia Industrial da PUC-Rio. Aprovada pela Comissão Examinadora abaixo assinada.

\section{Prof. André Barreira da Silva Rocha} Orientador Departamento de Engenharia Industrial - PUC-Rio

Prof. Carlos Patricio Samanez Departamento de Engenharia Industrial - PUC-Rio

Prof. Davi Michel Valladão Departamento de Engenharia Industrial - PUC-Rio

Prof. José Eugênio Leal

Coordenador Setorial do Centro Técnico Científico - PUC-Rio

Rio de Janeiro, 02 de setembro de 2015 
Todos os direitos reservados. É proibida a reprodução total ou parcial do trabalho sem autorização da universidade, do autor e do orientador.

\section{Raffael Capano de Arruda}

Possui graduação em Engenharia de Computação pela PUC-Rio (2011).

Ficha Catalográfica

Arruda, Raffael Capano de

Ensaios em jogos evolucionários com aplicação ao estudo da interação entre agências de rating e investidores / Raffael Capano de Arruda ; orientador: André Barreira da Silva Rocha. - 2015.

$$
95 \text { f. : il. (color.) ; } 30 \mathrm{~cm}
$$

Dissertação (mestrado) - Pontifícia Universidade Católica do Rio de Janeiro, Departamento de Engenharia Industrial, 2015.

Inclui bibliografia

1. Engenharia Industrial - Teses. 2. Teoria dos jogos evolucionários. 3. Agências de rating de crédito. 4. Estrutura de jogos. I. Rocha, André Barreira da Silva. II. Pontifícia Universidade Católica do Rio de Janeiro. Departamento de Engenharia Industrial. III. Título.

CDD: 658.5 
Ao meu pai, Tom, meu herói e amigo; pelo amor verdadeiro, pela formação do meu caráter e por todo esforço colocado em prol da minha educação. 


\section{Agradecimentos}

A Deus, pelo poder da vida; por me fornecer sabedoria, saúde e força para que eu siga sempre no caminho do bem.

Ao meu orientador, Professor André Barreira da Silva Rocha, pela oportunidade e pelo conhecimento transmitido.

À CAPES e a PUC-Rio, pelos auxílios concedidos, sem os quais este trabalho não poderia ter sido realizado.

Aos professores e funcionários da PUC-Rio, pela instrução e confiança; bases para este trabalho.

Ao Monsenhor Luiz Antônio Pereira Lopes, pela confiança e oportunidade.

Aos amigos do mestrado, Ali, Erick, Anna, Maurício e Douglas, pela troca de experiências e pela ajuda recebida na execução deste trabalho.

À Fernanda Sanromã e Carmen Maria, por todo amor, carinho e apoio. Seria muito mais difícil sem vocês!

À minha família (em especial ao meu pai, Tom, minha madrasta, Penha, meu avô Gennaro, meu tio Giovanni e meu primo Gio) pelo amor incondicional e apoio nesta caminhada; por entenderem meus momentos de ausência na busca de um futuro próspero para todos nós. Vocês são a base de tudo!

Àqueles que, apesar da ausência física, estarão sempre presentes na minha memória e no meu coração. 


\section{Resumo}

Arruda, Raffael Capano de; Rocha, André Barreira da Silva (Orientador). Ensaios em Jogos Evolucionários com Aplicação ao Estudo da Interação entre Agências de Rating e Investidores. Rio de Janeiro, 2015. 95 p. MSc. Dissertação - Departamento de Engenharia Industrial. Pontifícia Universidade Católica do Rio de Janeiro.

O papel das agências de rating de crédito no mercado de capitais tem evoluído ao longo dos últimos anos, passando de um provedor de informação aos agentes financeiros a um "quase-regulador" do mercado. Em princípio, supõe-se que as avaliações concedidas pelas agências de rating são imparciais e, consequentemente, indicadoras de qualidade de crédito dos mais diversos instrumentos financeiros. Porém, deve ser observado que à medida que esses instrumentos disponíveis no mercado foram se tornando mais complexos, o valor agregado das avaliações das agências diminuiu consideravelmente. A fim de analisar o problema da imparcialidade das agências de rating, conforme proposto por Hirth (2014), fez-se uso da estrutura espacial em comparação à solução analítica apresentada como condição de equilíbrio para o jogo evolucionário, com população well-mixed. Sendo assim, para a modelagem do problema apresentado, foi criado um programa computacional baseado a fim de apresentar uma solução compatível com a literatura sobre Teoria dos Jogos, expandindo seus conceitos e aplicações para uma Estrutura de Jogos Espaciais. Por fim, foi desenvolvida uma extensão ao programa, a qual, dentro do meu melhor conhecimento, representa uma inovação à literatura ao estender as abordagens de Chan et al. (2013), Hauert (2004) e Zhong et al. (2006), considerando a Estrutura de Jogos Espaciais, para o conceito de duas populações. A partir dos casos estudados, pode-se concluir que a população ser well-mixed ou estar disposta ao longo de um grid espacial não implica em diferenças significativas nos resultados para os mesmos valores dos parâmetros.

\section{Palavras-Chave}

Teoria dos Jogos Evolucionários; Agências de rating de crédito; Estrutura de Jogos Espaciais. 


\section{Abstract}

Arruda, Raffael Capano de; Rocha, André Barreira da Silva (Advisor). Essays on Evolutionary Games with Applications to the Study of Interactions between Rating Agencies and Investors. Rio de Janeiro, 2015. 95 p. MSc. Dissertation - Departamento de Engenharia Industrial. Pontifícia Universidade Católica do Rio de Janeiro.

The role of the credit rating agencies in the capital market has evolved in the last years, turning from a data provider to financial agents into a market "quasiregulator". Primarily, it is supposed that the evaluations provided by the rating agencies are impartial and, consequently, indicative of credit quality of a wide range of financial instruments. Nevertheless, it is important to note that as these instruments available in the market became more complex, the aggregate value of evaluations of agencies decrease considerably. In order to analyze the rating agencies impartiality issues, as proposed by Hirth (2014), this study uses the spatial structure in comparison to the analytical solution presented as equilibrium condition to the evolutionary game, with well-mixed population. Therefore, in order to model the presented problem, this study presents a computational program that aims to present a solution that matches the Game Theory literature, expanding its concepts and applications to a Spatial Games Structure. Finally, we created an extension of the program, which, in my best knowledge, is an innovation to the literature since it extends the approaches of Chan et al. (2013), Hauert (2004) e Zhong et al. (2006), regarding the Spatial Games Structure, to the concept of two populations. From the studied cases, we concluded that the fact of the population being well-mixed or disposed in a spatial grid does not imply differences of significance in the results to the same parameters values.

\section{Keywords}

Evolutionary games; Structured Spatial Games; Credit rating agencies. 


\section{Sumário}

1. Introdução

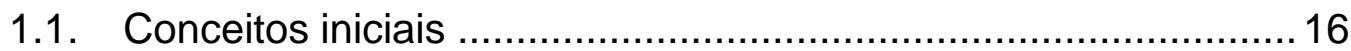

1.2. Objetivos e metodologia ............................................................. 17

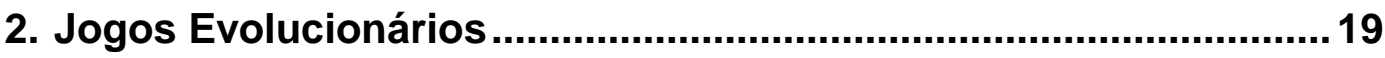

2.1. O Replicador Dinâmico ………………………………….......21

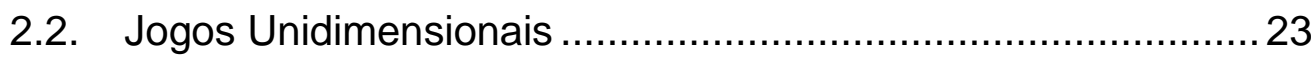

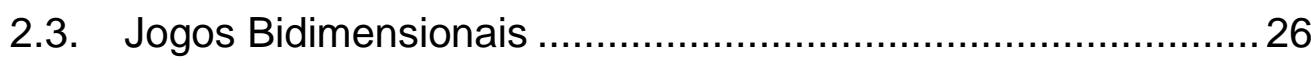

3. Métodos computacionais (agent-based simulation) ........................30

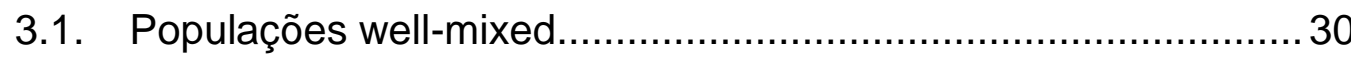

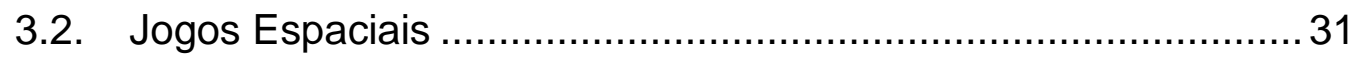

3.2.1. Dilema dos Prisioneiros e Snowdrift Game..............................31

3.2.2. A Dinâmica do Jogo Espacial .................................................33

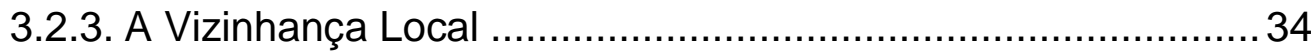

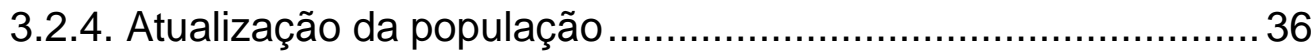

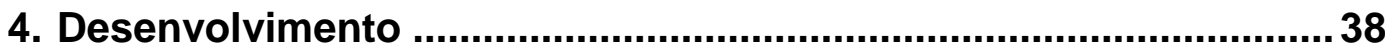

4.1. Jogos de uma população .........................................................38

4.1.1. Comparativo com o artigo "Evolutionary snowdrift game incorporating costly punishment in structured populations" ..... 43

4.1.1.1. Conceitos Iniciais .......................................................... 43

4.1.1.2. Resultados comparativos ................................................ 44

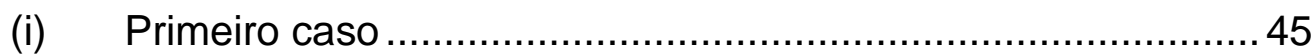

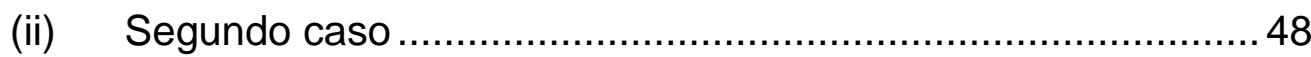

4.1.2. Comparativo com o artigo "Spatial structure often inhibits the evolution of cooperation in the snowdrift game" ...........................50

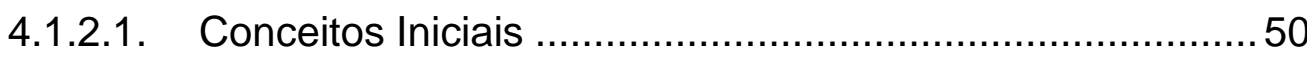


4.1.2.2. Resultados comparativos .............................................. 51

4.2. Jogos de duas populações........................................................ 55

4.2.1. Extensão do modelo computacional desenvolvido para

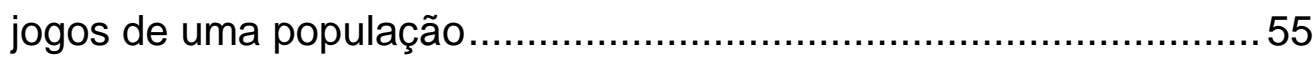

4.2.2. Análise sobre o artigo "Credit rating dynamics and

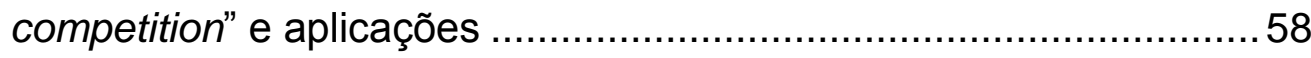

4.2.2.1. Agências de Rating …................................................... 58

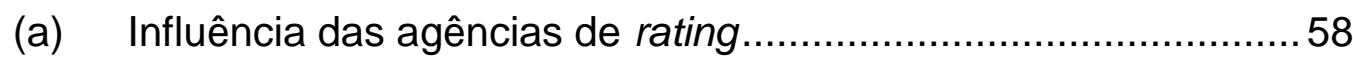

(b) Regras e objetivos das agências de rating..................................59

(c) O papel desempenhado pelas agências de rating nas

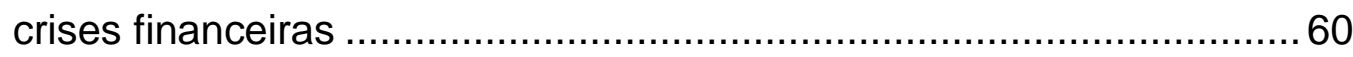

(d) Concorrência no segmento de agências de rating ........................62

(e) Regulação das agências de rating ............................................ 63

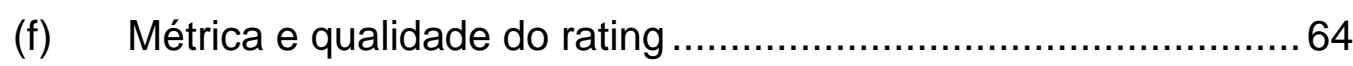

4.2.2.2. Conceitos Iniciais - Hirth (2014) ....................................... 65

4.2.2.3. Modelagem para a estrutura espacial .............................. 70

(a) Caso base: ponto fixo interior e dinâmica cíclica .......................70

i. Resultados alcançados ........................................................ 73

(b) Dinâmica sem ponto fixo interior ............................................... 76

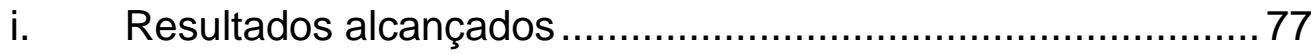

(c) Caso de sela: ponto fixo interior e duas bacias de atração.......81

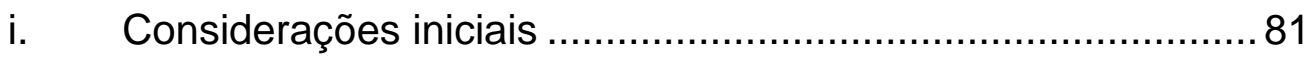

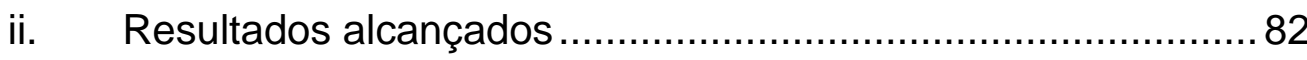

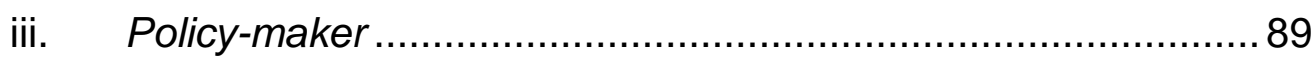

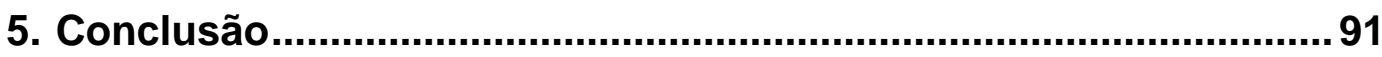

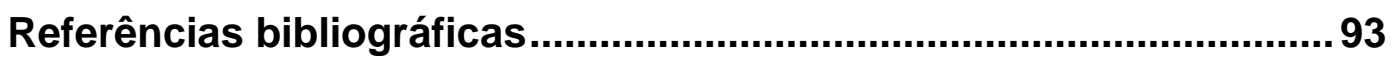




\section{Lista de figuras}

Figura 1 - Matriz de pagamentos para duas populações. 26

Figura 2 - Vizinhança de von-Neumann. 34

Figura 3 - Vizinhança de Moore. 35

Figura 4 - Alocação da população. 38

Figura 5 - Vizinhança de Von-Neumann para raio unitário. 39

Figura 6 - Matriz de pagamentos. 40

Figura 7 - Cálculo da matriz de payoffs. $\quad 40$

Figura 8 - Matriz populacional e de payoffs. 42

đ $\quad$ Figura 9 - Vizinhança de von-Neumann para indivíduos pertencentes às fronteiras da população. 43

Figura 10 - Matriz de pagamentos para o Snowdrift Game, incluindo agentes punidores.

Figura 11 - Evolução de frequências das estratégias da população. $r=0,02$.

Figura 12 - Evolução de frequências das estratégias da população. $r=0.02$.

Figura 13 - Composição da população. PMC = 1 (à esquerda).

$\mathrm{PMC}=10$ (à direita).

Figura 14 - Composição da população. PMC = 50 (à esquerda).

$P M C=100$ (à direita).

Figura 15 - Composição da população. PMC = 1000 (à esquerda).

$\mathrm{PMC}=5000$ (à direita).

Figura 16 - Evolução de frequências das estratégias da população. $r=0.6$.

Figura 17 - Evolução de frequências das estratégias da população. $r=0.6$.

Figura 18 - Composição da população. $\mathrm{PMC}=1$ (à esquerda).

$\mathrm{PMC}=10$ (à direita). 
Figura 19 - Composição da população. PMC = 50 (à esquerda).

$\mathrm{PMC}=250$ (à direita).

Figura 20 - Composição da população. PMC = 1000 (à esquerda).

$\mathrm{PMC}=5000$ (à direita).

Figura 21 - Frequência de cooperadores em função do custo-benefício. 51

Figura 22 - Frequência de cooperadores em função do custo-benefício. 52

Figura 23 - Composição da população no Snowdrift Game. $r=0.62 . \quad 53$

Figura 24 - Formação de filamentos na visão microscópica no

'Snowdrift Game'.

Figura 25 - Composição da população no 'Snowdrift Game'. r = 0.62. 54

Figura 26 - Formação de filamentos na visão microscópica no

'Snowdrift Game'.

Figura 27 - Alocação inicial das populações.

Figura 28 - Cálculo do payoff. Duas populações.

Figura 29 - Comparação entre indivíduos para cada população. 57

Figura 30 - Matriz de Pagamentos.

Figura 31 - Probabilidade do investidor comprar o investimento dado que este foi avaliado como 'bom'.

Figura 32 - Taxa esperada pela agência de rating.

Figura 33 - Parâmetros para o Caso Base - Ponto fixo interior e dinâmica cíclica.

Figura 34 - Caso Base: ponto fixo interior e dinâmica cíclica.

A figura representa a evolução dinâmica da fração da população, onde $\alpha$ representa a fração dos investidores confiantes (em vez dos sofisticados) e $\beta$ representa a fração das agências de rating honestas (em vez das inflacionárias).

Figura 35 - Caso Base: ponto fixo interior e dinâmica cíclica.

Figura 36 - Frequência da população de investidores.

Figura 37 - Frequência da população de agências de rating.

Figura 38 - Evolução espacial da população de investidores (investidores confiantes em vermelho e sofisticados em azul). 
$\mathrm{PMC}=1$ (à esquerda). $\mathrm{PMC}=50$ (à direita).

Figura 39 - Evolução espacial da população de investidores (investidores confiantes em vermelho e sofisticados em azul).

$P M C=500$ (à esquerda). PMC = 1000 (à direita).

Figura 40 - Evolução espacial da população de agências de rating (agências honestas em verde e inflacionárias em amarelo).

$\mathrm{PMC}=1$ (à esquerda). $\mathrm{PMC}=10$ (à direita).

Figura 41 - Evolução espacial da população de investidores (agências honestas em verde e inflacionárias em amarelo). $\mathrm{PMC}=50$ (à esquerda). $\mathrm{PMC}=500$ (à direita).

Figura 42 - Equilíbrio: Investidor confiante/ Agência inflacionária. $\lambda=0.71$.

Figura 43 - Frequência da população de investidores.

Figura 44 - Frequência da população de agências de rating.

Figura 45 - Evolução espacial da população de investidores (investidores confiantes em vermelho e sofisticados em azul). $P M C=1$ (à esquerda); PMC = 10 (à direita).

Figura 46 - Evolução espacial da população de investidores (investidores confiantes em vermelho e sofisticados em azul). $\mathrm{PMC}=30$ (à esquerda); PMC = 300 (à direita) .

Figura 47 - Evolução espacial da população de agências de rating (agências honestas em verde e inflacionárias em amarelo).

$\mathrm{PMC}=1$ (à esquerda); $\mathrm{PMC}=10$ (à direita).

Figura 48 - Evolução espacial da população de agências de rating (agências honestas em verde e inflacionárias em amarelo).

$\mathrm{PMC}=30$ (à esquerda); PMC = 300 (à direita).

Figura 49 - Equilíbrios de Nash para o caso: $\rho_{S}-\rho_{T}+(1-\lambda) . \Phi<0 . \quad 82$

Figura 50 - Parâmetros: caso de sela.

Figura 51 - Diagrama de fases. Caso de sela.

Figura 52 - Diagrama de fases para os pontos testados. (2014).

Figura 53 - Evolução das frequências para a população de investidores. Condição inicial: $(\alpha=0.13 ; \beta=0.8)$.

Figura 54 - Evolução das frequências para a população de agências 
de rating. Condição inicial: $(\alpha=0.13 ; \beta=0.8)$.

Figura 55 - Evolução das frequências para a população de investidores. Condição inicial: $(\alpha=0.15 ; \beta=0.8)$.

Figura 56 - Evolução das frequências para a população de agências de rating. Condição inicial: $(\alpha=0.15 ; \beta=0.8)$.

Figura 57 - Evolução das frequências para a população de investidores. Condição inicial: $(\alpha=0.14 ; \beta=0.8)$. Primeira simulação. 86

Figura 58 - Evolução das frequências para a população de agências de rating. Condição inicial: $(\alpha=0.14 ; \beta=0.8)$.

Primeira simulação.

Figura 59 - Evolução das frequências para a população de investidores. Condição inicial: $(\alpha=0.14 ; \beta=0.8)$. Segunda simulação.

Figura 60 - Evolução das frequências para a população de agências de rating. Condição inicial: $(\alpha=0.14 ; \beta=0.8)$.

Primeira simulação.

Figura 61 - População de investidores (investidores confiantes em vermelho e sofisticados em azul). $\mathrm{PMC}=1$ (à esquerda).

$\mathrm{PMC}=80$ (à direita).

Figura 62 - População de investidores (investidores confiantes em vermelho e sofisticados em azul). PMC $=180$ (à esquerda). $\mathrm{PMC}=250$ (à direita).

Figura 63 - População de agências de rating (agências de rating honestas em verde e inflacionárias em amarelo).

$\mathrm{PMC}=1$ (à esquerda). $\mathrm{PMC}=80$ (à direita).

Figura 64 - População de agências de rating (agências de rating honestas em verde e inflacionárias em amarelo).

$P M C=180$ (à esquerda). PMC = 250 (à direita).

Figura 65 - Efeitos da consideração de uma nova agência de rating no mercado. 


\section{Lista de siglas e abreviaturas}

$\begin{array}{ll}\text { EEE } & \text { Equilíbrio Evolucionariamente Estável } \\ \text { EN } & \text { Equilíbrio de Nash } \\ \text { HFA } & \text { Hedge Funds Association } \\ \text { IAIS } & \text { International Association of Insurance Supervisors } \\ \text { NRSRO } & \text { Nationally Recognized Statistical Rating Organization } \\ \text { PMC } & \text { Passo de Monte Carlo } \\ \text { SEC } & \text { Securities and Exchange Commission } \\ \text { VBA } & \text { Visual Basic for Application }\end{array}$




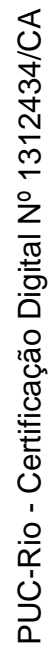

"A grandeza não consiste em receber honras, mas em merecê-las."

Aristóteles 


\section{Introdução}

\subsection{Conceitos iniciais}

O papel das agências de rating $^{1}$ de crédito no mercado de capitais tem evoluído ao longo dos últimos anos, passando de um provedor de informação aos agentes financeiros a um "quase-regulador" do mercado. De acordo com Pattberg (2005), as agências de rating são empresas privadas, que recebem uma comissão sempre que avaliam um ativo como grau de investimento, e surgiram para eliminar a assimetria de informação entre os diferentes atores do mercado financeiro. Deste modo, os emissores de títulos, investidores e tomadores de empréstimo, utilizam as informações providas por estas agências para sua tomada de decisão financeira. Em princípio, supõe-se que as avaliações concedidas pelas agências de rating são imparciais e, consequentemente, indicadoras de qualidade de crédito dos mais diversos instrumentos financeiros. Porém, deve ser observado que à medida que esses instrumentos disponíveis no mercado foram se tornando mais complexos, o valor agregado das avaliações das agências diminuiu consideravelmente. As avaliações fornecidas pelas agências, em boa parte, tornaram-se reativas às tendências econômicas observadas - e não mais preditivas de tais comportamentos. Considera-se que a crise do subprime - culminada em 2008 - foi impulsionada pela avaliação propositalmente inflada de ativos ruins, sendo estes classificados como grau de investimento pelas agências de rating.

Neste contexto, tem-se estudado formas eficientes de melhorar a qualidade das informações prestadas por tais agências. De acordo com o exposto em Bolton et al. (2012), o aumento da competição entre as agências não é eficiente. Hirth (2014), através da Teoria dos Jogos Evolucionários - inicialmente apresentada por Friedman (1991) para contextos econômicos similares ao discutido aqui - analisa sob quais circunstâncias as agências com baixo market share ${ }^{2}$ podem melhorar suas posições. Para tal, considera uma nova agência de rating entrante neste mercado, cujos padrões éticos e práticas comerciais são notoriamente distintos das empresas incumbentes.

\footnotetext{
${ }^{1}$ Classificação do crédito.

${ }^{2}$ Grau de participação da agência de rating no mercado.
} 
Em seu artigo, Hirth (2014) desenvolveu um modelo onde as agências podem adotar um comportamento do tipo honest, avaliando corretamente os investimentos, ou inflating, superestimando a qualidade do investimento. Os investidores podem ser do tipo trusting, que acreditam piamente nas notas emitidas pelas agências, ou sophisticated, dispondo de conhecimento e informação suficiente para avaliar se o investimento é, de fato, grau de investimento ou não. As Agências tendem a superestimar suas avaliações para os investidores trusting, pois o benefício de conseguirem mais comissões supera qualquer custo de reputação para o caso em que são pegas inflando suas notas.

Por outro lado, os investidores trusting mudam seu comportamento à medida que percebem que estão num mercado dominado por agências que inflam suas recomendações. Isso ocorre, pois os investidores sophisticated são mais bem sucedidos nesse ambiente. Os investidores sophisticated têm um custo de monitoramento das avaliações feitas pelas agências, ao passo que os investidores trusting economizam esse custo, mas incorrem em perdas significativas quando adquirem produtos ruins avaliados como bons.

Sendo assim, a maior contribuição desta dissertação foi modelar jogos de duas populações, assim como o apresentado por Hirth (2014), utilizando a estrutura de Jogo Espacial.

\subsection{Objetivos e metodologia}

A fim de analisar o problema da imparcialidade das agências de rating, conforme proposto por Hirth (2014), fez-se uso da estrutura espacial em comparação à solução analítica para populações well-mixed apresentada como condição de equilíbrio para o jogo evolucionário.

Sendo assim, para a modelagem do problema apresentado, foi criado um programa computacional baseado em linguagem de programação Visual Basic for Applications a fim de apresentar uma solução compatível com a literatura sobre Teoria dos Jogos, expandindo seus conceitos e aplicações para uma Estrutura de Jogos Espaciais. As simulações são realizadas de modo a replicar os resultados alcançados por Hauert (2004) e Chan et al. (2013) para os tradicionais jogos de uma população, como o Dilema dos Prisioneiros e Snowdrift Game, bem como as 
suas adaptações. É importante destacar que Hauert (2004) quebrou paradigmas ao mostrar que nem sempre a introdução da Estrutura de Jogos Espaciais favorece a cooperação, como no caso do jogo O Dilema dos Prisioneiros.

Por fim, foi desenvolvida uma extensão ao programa, a qual, dentro do meu melhor conhecimento, representa uma inovação à literatura ao estender as abordagens de Chan et al. (2013), Hauert (2004) e Zhong et al. (2006), considerando a Estrutura de Jogos Espaciais, para o conceito de duas populações. 


\section{Jogos Evolucionários}

O fenômeno das interações cooperativas entre os animais tem intrigado os biólogos desde Darwin. No entanto, os conceitos teóricos que fundamentam o estudo da cooperação apareceram apenas um século depois, e teve sua origem em Economia e Ciências Políticas em vez da Biologia.

John von-Neumann e Oskar Morgenstern desenvolveram um modelo matemático chamado Teoria dos Jogos, o qual descreve as interações entre os indivíduos. Esta teoria surgiu na segunda guerra mundial e seu uso foi destinado principalmente para usos militares. John Nash, posteriormente, contribuiu com o desenvolvimento da teoria através da introdução e desenvolvimento do conceito de Equilíbrio de Nash (EN).

O EN é alcançado no jogo quando a estratégia escolhida por cada jogador é uma melhor resposta ao perfil de estratégias escolhido por seus oponentes. Sendo assim, em um EN, nenhum jogador tem incentivo para desviar unilateralmente da sua estratégia escolhida para jogar.

Algumas décadas depois, John Maynard-Smith e George R. Price engenhosamente relacionaram o conceito econômico da função de payoff ${ }^{3}$ com a aptidão evolucionária, como o único fator relevante na evolução. Além disso, Maynard-Smith aperfeiçoou o conceito de EN em um contexto evolutivo e introduziu a noção de Equilíbrio Evolucionariamente Estável (EEE), que representa um subconjunto do conceito de equilíbrio proposto por Nash (1950). Em outras palavras, um EEE, na verdade, pode ser visto como um refinamento da teoria clássica, ao passo que acrescenta requisitos de estabilidade, ou seja, apresenta uma Estratégia Evolucionariamente Estável. Segundo Rocha et al. (2011), tem-se esta configuração quando a estratégia não pode ser invadida por um indivíduo mutante. Tal estratégia deve ser uma melhor resposta a si mesma, e fornece um payoff estritamente maior do que qualquer estratégia que é uma melhor resposta à Estratégia Evolucionariamente Estável.

Mais tarde, com o intuito de aprimorar as limitações da Teoria dos Jogos clássica, Taylor e Jonker (1978) interpretou tal teoria em um contexto populacional. Dessa

\footnotetext{
${ }^{3}$ Pagamento ou resultado para uma determinada combinação de estratégias.
} 
forma, o modelo de Teoria dos Jogos deixou de ser analisado de forma estática e passou a ser analisado de forma dinâmica. Na forma estática havia o pressuposto de que os jogadores se encontrariam em um único momento, e com a introdução do pensamento dinâmico pôde-se estender este conceito para o longo prazo, com um número suficientemente grande de iterações e, ainda, com a possibilidade de terem suas estratégias imitadas por seus oponentes, indicando que estes possuíam capacidade de aprendizado.

Um dos fatores principais que deram base à Teoria dos Jogos Evolucionários é que os jogadores não necessariamente sejam racionais. Nowak et al. (2000) afirma que o processo de adaptação das estratégias dos jogadores acontece, na maioria das vezes, de forma direta, ou seja, não necessariamente os jogadores estão racionalmente maximizando seus payoffs. $\mathrm{O}$ autor ainda afirma que os jogadores podem ser animais, bactérias, plantas, células, etc; Dessa forma, suas estratégias apenas representam padrões operacionais codificados em seus genes, instinto ou imitação.

O processo de adaptação dos jogadores é um tópico fundamental para a compreensão da Teoria dos Jogos Evolucionários. Na literatura clássica, um jogador interagia com seu oponente de uma forma estática. Já na abordagem evolucionária, tem-se um jogo onde dois indivíduos de uma ou mais populações suficientemente grandes, são escolhidos aleatoriamente e programados para adotar uma determinada estratégia pura, não necessariamente ótima, contra seu oponente, introduzindo assim o conceito de racionalidade limitada. Este procedimento ocorre em uma grande quantidade de iterações e, a cada iteração, o percentual da população com probabilidade de jogar uma das estratégias disponíveis é modificado de acordo com os pagamentos alcançados pelos indivíduos que compõem o jogo. Estes resultados não dependem somente da função de pagamento, mas também do estado da população, isto é, da frequência de agentes que adotam determinada estratégia. É importante salientar que os indivíduos de uma determinada população são simétricos em suas preferências, ou seja, possuem conjunto (não vazio) de estratégias idêntico.

A dinâmica da Teoria dos Jogos Evolucionários pode, em muitas vezes, eliminar alguns dos Equilíbrios de Nash alcançados na Teoria dos Jogos Clássica de forma a alcançar um único equilíbrio, o Equilíbrio Evolucionário. 


\subsection{O Replicador Dinâmico}

O replicador dinâmico - apresentado por Taylor e Jonker (1978) - consiste em modelar como a população evolui dinamicamente ao longo do tempo através de um sistema não linear de equações diferenciais a fim de determinar o estado da população que constitui um equilíbrio de longo prazo.

Analisando o replicador dinâmico em um contexto biológico, quando considera-se populações de organismos programados para se comportarem da mesma forma, pode-se dizer que os grupos de genes que determinam tal comportamento são os replicadores.

No conceito de Jogos Evolucionários, o comportamento determinístico de cada jogador é determinado pelo replicador dinâmico, sendo este designado a cada jogador, de forma a caracterizar seus comportamentos. Sendo assim, a evolução das frequências de cada população possui relação direta com a dinâmica do replicador, de forma que tal dinâmica trata da lei de evolução das frequências.

Segundo Binmore (1992), o replicador dinâmico possui as seguintes características:

- Capacidade de auto-replicação;

- Determina um comportamento que corresponde a uma estratégia de um jogo;

Para deduzir a equação do replicador dinâmico é preciso entender o significado dos parâmetros fundamentais, conforme mostrado abaixo:

- $N(t)$ : O tamanho da população no instante de tempo $t$;

- $N_{i}(t)$ : O número de indivíduos adotando a estratégia $\mathrm{S}_{\mathrm{i}}$ no instante de tempo $t$;

- $p_{i}(t)=\left(N_{i}(t) / N(t)\right)$ : A proporção de indivíduos que adotam a estratégia $\mathrm{S}_{\mathrm{i}}$ no instante de tempo $t$; 
- $\quad d$ : A taxa de mortalidade (constante);

- $\mathrm{U}\left(\mathrm{S}_{\mathrm{i}} ; \sigma\right)$ : O número esperado de filhos de um indivíduo que adota $\mathrm{S}_{\mathrm{i}}$ quando compete em uma população em estado $\sigma(\mathrm{t})$.

Dessa forma, o número de indivíduos adotando $\mathrm{S}_{\mathrm{i}} \mathrm{em} \mathrm{t}+1$ é:

$$
N_{i}(t+1)=N_{i}(t)\left[1+\sum_{j=1}^{n} p_{j} U\left(s_{i}, s_{j}\right)-d\right]
$$

Generalizando para tempo contínuo:

$$
N_{i}(t+\Delta t)=N_{i}(t)\left[1+\Delta t\left(\sum_{j=1}^{n} p_{j} U\left(s_{i}, s_{j}\right)-d\right)\right]
$$

Portanto:

$$
\begin{aligned}
& \dot{N}_{i}(t)=N_{i}(t)\left[\sum_{j=1}^{n} p_{j} U\left(s_{i}, s_{j}\right)-d\right] \\
& \dot{N}_{i}(t)=N_{i}(t)\left[U\left(s_{i}, \sigma\right)-d\right]
\end{aligned}
$$

Para a população toda:

$$
N(t+\Delta t)=\sum_{i=1}^{n}\left\{N_{i}(t) \cdot\left[1+\Delta t\left(\sum_{j=1}^{n} p_{j} U\left(s_{i}, s_{j}\right)-d\right)\right]\right\}
$$

Dessa forma, tem-se que:

$$
\begin{aligned}
& \dot{N}(t)=N(t)\left\{\sum_{i=1}^{n} p_{i}\left[\sum_{j=1}^{n} p_{j} U\left(s_{i}, s_{j}\right)-d\right]\right\} \\
& \dot{N}(t)=N(t) \cdot[U(\sigma, \sigma)-d]
\end{aligned}
$$

Por fim, tem-se que: 
$\dot{p}_{i}(t)=\frac{d}{d t} \frac{N_{i}(t)}{N(t)}=p_{i}(t) \cdot[U(s i, \sigma)-U(\sigma, \sigma)]$

A equação acima representa a dinâmica do replicador, conforme mostrado por Friedman (1988). Tal equação compara o desempenho de um indivíduo da população que joga uma determinada estratégia 'i' com a de um indivíduo médio desta mesma população que joga qualquer uma das estratégias do vetor $\sigma$.

O problema da equação do replicador dinâmico é que esta não considera o efeito das mutações e funciona de forma eficiente apenas para populações muito grandes.

\subsection{Jogos Unidimensionais}

Como já mostrado na seção anterior, sabe-se que para demonstrar a tendência de comportamento de uma população ao longo do tempo é utilizado o replicador dinâmico.

Para exemplificar o seu uso, seguem abaixo alguns parâmetros de um jogo unidimensional:

- Matriz $A=\left[\begin{array}{ll}a_{11} & a_{12} \\ a_{21} & a_{22}\end{array}\right]$, que representa o pagamento esperado da população;

- Jogo de uma população e duas estratégias;

- Conjunto de estratégias: $\mathrm{S}=\left\{e_{1}, e_{2}\right\}$;

- $\mathrm{p}=$ proporção de indivíduos da população que joga a primeira estratégia do conjunto de estratégias, onde $p \in[0,1]$;

- $(1-p)=$ proporção de indivíduos da população que joga a segunda estratégia do conjunto de estratégias; 
Antes de começar a desenvolver o jogo, pode-se normalizar a matriz A, a fim de facilitar o desenvolvimento dos cálculos. A normalização da matriz não influencia o resultado final do jogo, visto que a estrutura de melhor resposta não se altera.

Sendo assim, temos que:

$$
\dot{p}=p \cdot\left[f\left(e_{1, S}\right)-f(S, S)\right]
$$

O desempenho de um indivíduo da população que joga a primeira estratégia do conjunto de estratégias pode ser representado por:

$f\left(e_{1}, S\right)=e_{1} \cdot A \cdot S$

$$
f\left(e_{1}, S\right)=\left[\begin{array}{ll}
1 & 0
\end{array}\right] \cdot\left[\begin{array}{cc}
0 & a_{1} \\
a_{2} & 0
\end{array}\right] \cdot\left[\begin{array}{c}
p \\
1-p
\end{array}\right]
$$

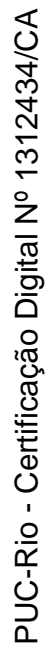

$$
f\left(e_{1}, S\right)=a_{1} \cdot(1-p)
$$

O desempenho de um indivíduo da população que joga qualquer uma das estratégias do vetor $\mathrm{S}$ pode ser representado por:

$$
f(S, S)=S \cdot A \cdot S
$$

$$
f(S, S)=\left[\begin{array}{ll}
p & 1-p
\end{array}\right] \cdot\left[\begin{array}{cc}
0 & a_{1} \\
a_{2} & 0
\end{array}\right] \cdot\left[\begin{array}{c}
p \\
1-p
\end{array}\right]
$$

$$
f(S, S)=\left[(1-p) \cdot a_{2} \quad p \cdot a_{1}\right] \cdot\left[\begin{array}{c}
p \\
1-p
\end{array}\right]
$$

$f(S, S)=a_{2} \cdot p \cdot(1-p)+a_{1} \cdot p \cdot(1-p)=\left(a_{1}+a_{2}\right) \cdot p \cdot(1-p)$

Dessa forma, voltando à equação do replicador dinâmico, temos que:

$$
\begin{aligned}
& \dot{p}=p \cdot\left[f\left(e_{1}, S\right)-f(S, S)\right] \\
& \dot{p}=p \cdot\left[\left(a_{1} \cdot(1-p)\right)-\left(\left(a_{1}+a_{2}\right) \cdot p \cdot(1-p)\right)\right]
\end{aligned}
$$


Após algumas simplificações, temos que:

$$
\dot{p}=p \cdot(1-p) \cdot\left[a_{1} \cdot(1-p)-a_{2} \cdot p\right]
$$

Com isso, para se obter o(s) equilíbrio(s) evolucionário(s) é fundamental, primeiramente, procurar pelos pontos estacionários. Dessa forma, temos que:

$$
\begin{aligned}
& \dot{p}=p \cdot(1-p) \cdot\left[a_{1} \cdot(1-p)-a_{2} \cdot p\right] \\
& \dot{p}=0
\end{aligned}
$$

Os primeiros pontos triviais obtidos são: $p=0$ e $p=1$. A fim de descobrir o terceiro ponto estacionário, tem-se que:

$$
a_{1} \cdot(1-p)-a_{2} \cdot p=0
$$

Logo:

$$
p=\frac{a_{1}}{a_{1}+a_{2}}
$$

Os pontos estacionários obtidos são:

$$
p=\left\{0,1, \frac{a_{1}}{a_{1}+a_{2}}\right\}
$$

Uma vez conhecidos, deve-se verificar a estabilidade dos pontos estacionários, aplicando $\frac{\partial \dot{p}}{\partial p}$ em cada um dos pontos estacionários.

Dessa forma, temos que:

$$
\begin{aligned}
& \frac{\dot{\partial p}}{\partial p}=(1-2 p)\left[a_{1}(1-p)-a_{2} p\right]-p(1-p)\left(a_{1}+a_{2}\right) \\
& \left.\frac{\dot{\partial p}}{\partial p}\right|_{p=0}=a_{1} ;\left.\quad \frac{\dot{\partial p}}{\partial p}\right|_{p=1}=a_{2} ;\left.\quad \frac{\dot{\partial p}}{\partial p}\right|_{p=\frac{a_{1}}{a_{1}+a_{2}}}=-\frac{a_{1} \cdot a_{2}}{a_{1}+a_{2}}
\end{aligned}
$$


A partir dos resultados obtidos acima, é possível analisar cada uma das derivadas parciais obtidas acima e verificar quais pontos são, de fato, assintoticamente estáveis, ou seja, quais pontos possuem:

$$
\text { - }\left.\quad \frac{\partial p}{\partial p}\right|_{p=p i}<0
$$

e com isso representam o equilíbrio evolucionariamente estável.

\subsection{Jogos Bidimensionais}

Seguem abaixo os parâmetros considerados que exemplificam um jogo bidimensional:

- Matriz $\mathrm{A}=\left(\mathrm{a}_{\mathrm{ij}}\right)_{2 \times 2}$, que representa o pagamento esperado para a população A e $B=\left(b_{i j}\right)_{2 \times 2}$, que representa o pagamento esperado para a população B. As matrizes estão intercaladas, conforme mostrado abaixo:

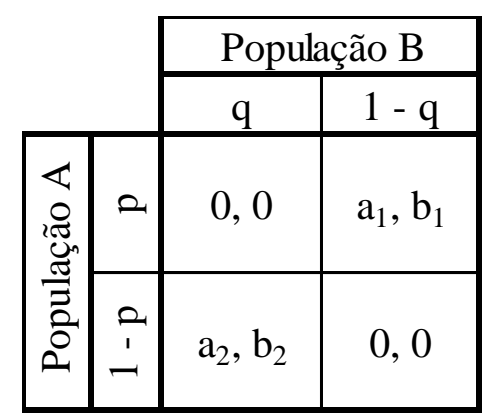

Figura 1 - Matriz de pagamentos para duas populações.

- Jogo de duas populações, cada uma possuindo duas estratégias;

- Conjunto de estratégias: $S^{A}=\left\{e_{1}^{A}, e_{2}^{A}\right\}$ e $S^{B}=\left\{e_{1}^{B}, e_{2}^{B}\right\}$;

- $\mathrm{p}=$ proporção de indivíduos da população A que joga a primeira estratégia do conjunto de estratégias;

- $(1-p)=$ proporção de indivíduos da população A que joga a segunda estratégia do conjunto de estratégias; 
- $\quad \mathrm{q}$ = proporção de indivíduos da população B que joga a primeira estratégia do conjunto de estratégias;

- $(1-q)=$ proporção de indivíduos da população B que joga a segunda estratégia do conjunto de estratégias;

Sendo assim, para a ótica do jogador linha (jogador da população A), temos que:

$$
\dot{p}=p \cdot\left[f\left(e_{1}^{A}, \delta\right)-f(\sigma, \delta)\right]
$$

onde $\sigma$ e $\delta$ são, respectivamente, os estados atuais das populações A e B.

O desempenho de um indivíduo da população que joga a primeira estratégia do conjunto de estratégias da população A, contra um indivíduo que joga qualquer uma das estratégias da população $\mathrm{B}$, de acordo com suas probabilidades de ocorrência:

$$
f\left(e_{1}^{A}, \delta\right)=e_{1}^{A} \cdot A \cdot \delta
$$

$$
f\left(e_{1}^{A}, \delta\right)=\left[\begin{array}{ll}
1 & 0
\end{array}\right] \cdot\left[\begin{array}{cc}
0 & a_{1} \\
a_{2} & 0
\end{array}\right] \cdot\left[\begin{array}{c}
q \\
1-q
\end{array}\right]
$$

$f\left(e_{1}^{A}, \delta\right)=a_{1} \cdot(1-q)$

Abaixo é mostrado o desempenho de um indivíduo da população A que joga qualquer uma das suas estratégias, contra um indivíduo da população B, que também joga qualquer uma de suas estratégias, de acordo com as respectivas probabilidades de ocorrência:

$$
\begin{aligned}
& f(\sigma, \delta)=\sigma \cdot A \cdot \delta \\
& f(\sigma, \delta)=\left[\begin{array}{ll}
p & 1-p
\end{array}\right] \cdot\left[\begin{array}{cc}
0 & a_{1} \\
a_{2} & 0
\end{array}\right] \cdot\left[\begin{array}{c}
q \\
1-q
\end{array}\right] \\
& f(\sigma, \delta)=\left[a_{2} \cdot(1-p) \cdot q+a_{1} \cdot p \cdot(1-q)\right]
\end{aligned}
$$


Fazendo os cálculos de forma similar, sob a ótica do jogador coluna (população B), constata-se que:

$$
\begin{aligned}
& \dot{q}=q \cdot\left[f\left(\sigma, e_{1}^{B}\right)-f(\sigma, \delta)\right] \\
& f\left(\sigma, e_{1}^{B}\right)=b_{2} \cdot(1-p) \\
& f(\sigma, \delta)=\left[b_{2} \cdot(1-p) \cdot q+b_{1} \cdot p \cdot(1-q)\right]
\end{aligned}
$$

Sendo assim, temos que:

$$
\begin{aligned}
& \dot{p}=p \cdot(1-p) \cdot\left[a_{1} \cdot(1-q)-a_{2} \cdot q\right] \\
& \dot{q}=q \cdot(1-q) \cdot\left[b_{2} \cdot(1-p)-b_{1} \cdot p\right]
\end{aligned}
$$

O próximo passo agora é determinar os pontos estacionários e verificar suas estabilidades. Entretanto, diferentemente do que foi feito para o caso unidimensional, aqui temos um sistema de equações não-lineares. Dessa forma, aplica-se a matriz Jacobiana, de modo a analisar a estabilidade na vizinhança do ponto estacionário do sistema linearizado.

Com isso, a matriz Jacobiana possui a seguinte estrutura:

$$
J(p, q)=\left[\begin{array}{cc}
\frac{\partial \dot{p}}{\partial p} & \frac{\partial \dot{p}}{\partial q} \\
\frac{\partial \dot{q}}{\partial p} & \frac{\partial \dot{q}}{\partial q}
\end{array}\right]
$$

Com a matriz Jacobiana obtida, pode-se calcular o traço e o determinante:

$$
\begin{aligned}
& \operatorname{tr}(J(p, q))=\frac{\partial \dot{p}}{\partial p}+\frac{\partial \dot{q}}{\partial q} \\
& \operatorname{det}(J(p, q))=\left(\frac{\partial \dot{p}}{\partial p} \cdot \frac{\partial \dot{q}}{\partial q}\right)-\left(\frac{\partial \dot{p}}{\partial q} \cdot \frac{\partial \dot{q}}{\partial p}\right)
\end{aligned}
$$

Calculando as derivadas parciais da matriz Jacobiana, temos que: 


$$
\begin{aligned}
& \frac{\partial \dot{p}}{\partial p}=(1-2 p)\left(a_{1}(1-q)-a_{2} q\right) \\
& \frac{\partial \dot{p}}{\partial q}=-p(1-p)\left(a_{1}+a_{2}\right) \\
& \frac{\partial \dot{q}}{\partial p}=-q(1-q)\left(b_{1}+b_{2}\right) \\
& \frac{\partial \dot{q}}{\partial q}=(1-2 q)\left(b_{2}(1-p)-b_{1} p\right)
\end{aligned}
$$

A partir de agora, pode-se encontrar os autovalores $(\lambda)$ da matriz Jacobiana. Com isso, temos que:

$\operatorname{det}(J(p, q)-\lambda * I)=0$

$\operatorname{det}(J(p, q)-\lambda * I)=\left[\begin{array}{cc}\frac{\partial \dot{p}}{\partial p}-\lambda & \frac{\partial \dot{p}}{\partial q} \\ \frac{\partial \dot{q}}{\partial p} & \frac{\partial \dot{q}}{\partial q}-\lambda\end{array}\right]=0$

$\operatorname{det}(J(p, q)-\lambda * I)=\left(\frac{\partial \dot{p}}{\partial p}-\lambda\right) \cdot\left(\frac{\partial \dot{q}}{\partial q}-\lambda\right)-\left(\frac{\partial \dot{p}}{\partial q}\right) \cdot\left(\frac{\partial \dot{q}}{\partial p}\right)=\lambda^{2}-t r J * \lambda+\operatorname{det} J=0$

Portanto, os autovalores são dados por:

$$
\lambda=\frac{t r J \pm \sqrt{(t r J)^{2}-4 \operatorname{det} J}}{2} .
$$




\section{Métodos computacionais (agent-based simulation)}

\subsection{Populações well-mixed}

Uma aplicação computacional usando agent-based simulation aplicado a uma população well-mixed ${ }^{4}$ foi explorado por Xu et al. (2011) com a inclusão de uma estratégia de punição na dinâmica do jogo. Considera-se um jogo em que os agentes podem escolher três estratégias: cooperar, desviar ou punir. Os agentes que escolhem a estratégia de punição podem ser vistos como altruístas, pois estão dispostos a abrir mão de parte de seu pagamento, com a finalidade que agentes que optem por desviar sejam penalizados, e que, dessa forma, tenham incentivo maior a adotar a estratégia de cooperação.

Sendo assim, o autor realizou um estudo analítico e numérico com relação à evolução e dinâmica do jogo envolvendo uma população do tipo "bem misturada".

Neste tipo de jogo, é considerada uma população que, em seu estágio inicial, é composta pelos indivíduos que estão dispostos a jogar cada uma das estratégias do jogo. Esta população possui um número muito grande de indivíduos, sendo que cada um dos indivíduos interage com todos os outros indivíduos da população com a mesma probabilidade.

A cada passo evolucionário é dada a oportunidade para que todos os indivíduos tenham, em média, uma chance de trocar de estratégia. Com isso, um agente focal compete com um oponente, ambos escolhidos aleatoriamente dentro da população e o agente focal obtém um payoff $\mathrm{V}(\mathrm{i})$. Da mesma forma, um agente referência compete com outro oponente, ambos escolhido aleatoriamente dentro da população, e obtém um payoff $\mathrm{V}(\mathrm{j})$. O agente focal compara o seu payoff com o do agente referência. Caso o payoff do agente focal seja maior ou igual ao payoff do agente referência, o agente focal mantém a sua estratégia, caso contrário, o agente focal imitará a estratégia do seu oponente com uma determinada probabilidade.

\footnotetext{
${ }^{4}$ Conceito de populações bem misturadas. Todos os indivíduos da população interagem entre si.
} 
Sendo assim, quando todos os indivíduos, em média, tiverem a oportunidade de modificar suas estratégias, termina-se um passo evolucionário e um novo passo evolucionário se inicia de forma a repetir a dinâmica do jogo.

\subsection{Jogos Espaciais}

O surgimento de comportamento cooperativo em sociedades humanas e de animais é um dos problemas fundamentais da Biologia e Ciências Sociais. A cooperação leva a grandes transições da história da vida: moléculas agregadas em protocélulas, genes organizados em cromossomos, células em forma de organismos complexos, ou indivíduos formados em sociedades, por exemplo. Todos os exemplos citados possuem algo em comum. Todos estes aparentam ser uma contradição com a seleção Darwiniana, porque são propensos à exploração.

Em ciências do comportamento, a essência de várias interações entre seres humanos e animais pode ser modelada pelos chamados jogos 2 x 2. Tais jogos descrevem as interações de pares de indivíduos com duas estratégias comportamentais a serem escolhidas. O indivíduo obtém um determinado payoff dependendo do seu comportamento - estratégia assumida. Na Biologia, tal payoff é geralmente relacionado com o sucesso de sua reprodução. Em certas aplicações, é conveniente modelar a população distribuída espacialmente, com os indivíduos ocupando pontos específicos no espaço. Em tal situação, os indivíduos interagem apenas com seus vizinhos imediatos, diferentemente de uma população wellmixed, onde cada vizinho é vizinho de todos os demais indivíduos.

\subsubsection{Dilema dos Prisioneiros e Snowdrift Game}

Segundo Hauert (2001), o estilo de jogo mais representativo que explica as interações entre os indivíduos no âmbito dos jogos espaciais é o Dilema dos Prisioneiros. Este jogo explica o surgimento do comportamento cooperativo altruísta entre indivíduos desconexos e egoístas.

De forma sucinta, o Dilema dos Prisioneiros representa uma situação em que dois indivíduos são presos pela polícia. Como a polícia não tem provas para condenálos, os indivíduos são colocados em salas separadas e lhes são oferecidos o 
mesmo acordo: se um dos prisioneiros, confessando, testemunhar contra o outro e esse outro permanecer em silêncio, o que confessou sai livre enquanto o cúmplice - silencioso - cumpre sua sentença. Se ambos ficarem em silêncio, a polícia só pode condená-los a um prazo inferior ao prazo da condenação caso um indivíduo confesse e o outro fique em silêncio. Se ambos traírem o comparsa, cada um é condenado por um prazo intermediário com relação os dois citados anteriormente. Cada prisioneiro faz a sua decisão sem saber que decisão o outro vai tomar. $\mathrm{O}$ objetivo do problema é entender o comportamento dos prisioneiros.

Um dos principais resultados teóricos que foi obtido a partir de variações de configuração do Dilema dos Prisioneiros afirma que qualquer forma de interação associativa favorece a cooperação. A cooperação, especialmente, pode prosperar no jogo espacial do Dilema dos Prisioneiros, onde os indivíduos estão confinados em um determinado espaço onde seja possível, somente, interagir com a sua vizinhança local.

Apesar das conquistas teóricas, alguns estudos experimentais foram realizados e mostraram que, em muitas vezes, é difícil avaliar os payoffs para diferentes padrões de comportamento. As condições rigorosas do Dilema dos Prisioneiros não puderam ser satisfeitas em muitas situações naturais reais. Sendo assim, em uma alternativa biologicamente viável surgiu o Snowdrift Game, jogo este que se refere, da mesma forma que o anterior, a interações cooperativas, mas sob condições diferentes, como em populações bem distribuídas e com encontros aleatórios entre cooperadores e desertores configurando um equilíbrio estável, contrastando com o jogo do Dilema dos Prisioneiros, onde os indivíduos que optam por escolher a estratégia que busca a cooperação são extintos.

O Snowdrift Game, na forma espacial, em contraste com o Dilema dos Prisioneiros, na mesma forma, não beneficia a cooperação. De fato, a estrutura espacial tende a reduzir o comportamento cooperativo relativamente a populações bem distribuídas. No Dilema dos Prisioneiros espacial, os cooperadores podem prosperar através da formação de aglomerados compactos de indivíduos que jogam a mesma estratégia, e as perdas de cooperadores contra desertores ao longo da fronteira são compensadas por ganhos de interações dentro do próprio cluster $^{5}$.

\footnotetext{
${ }^{5}$ Agrupamento de indivíduos que jogam a mesma estratégia.
} 
Em contrapartida, este comportamento não acontece no Snowdrift Game espacial. De forma um pouco contraditória, a razão definitiva para que isto aconteça é o comportamento cooperativo em populações bem distribuídas.

O Snowdrift Game também é conhecido como o jogo do Falcão e Pombo. Neste jogo existem duas estratégias de equilíbrio, em que o jogador escolhe ser 'pombo' ou ser 'falcão'. Essa escolha irá definir o seu comportamento perante uma situação de conflito; caso o indivíduo escolhe ser falcão, tem uma atitude mais agressiva e ataca. Caso escolhe ser 'pombo' adota uma estratégia mais segura e desiste do confronto. Se ambos os jogadores escolhem ser 'pombo' presencia-se uma situação benéfica, pois não há qualquer confronto, mas também os indivíduos não obtém payoff positivo. Caso ambos os jogadores escolhem ser 'falcão' há um confronto do qual ninguém sai beneficiado. Sendo assim, se o benefício de vencer for maior que o custo de perder, a melhor estratégia é optar por ser 'falcão', pois o 'falcão' sempre tem payoff melhor que o 'pombo'. No entanto, se o custo de confronto for elevado será melhor ser 'pombo'.

\subsubsection{A Dinâmica do Jogo Espacial}

A população do jogo espacial é representada por um grid $^{6}$ de tamanho N x N. Em contraste com o jogo well-mixed - em que cada um dos indivíduos da população interage com todos os demais jogadores - no jogo espacial, os indivíduos somente interagem com os que estão contidos na sua vizinhança local. Cada indivíduo acumula um payoff médio que é obtido pelo resultado das interações com todos seus vizinhos locais.

Em cada geração - ou a cada passo de Monte Carlo - cada indivíduo da população pode ter a oportunidade de se comparar com um de seus vizinhos e imitar a sua estratégia, o que é conhecido na literatura como "Replication by Imitation".

\footnotetext{
${ }^{6}$ Grelha ou matriz populacional.
} 


\subsubsection{A Vizinhança Local}

Assim como já introduzido anteriormente, a vizinhança local contém os indivíduos que estão situados ao redor do jogador 'focal', que é aquele sob o qual está sendo realizada a análise.

Os tipos de vizinhança mais utilizados na literatura - apresentado por Hauert (2004) e Chan et al. (2013) em suas simulações - são a Vizinhança de vonNeumann e a Vizinhança de Moore. O conceito de Vizinhança de von-Neumann surgiu juntamente com o de 'Autômato Celular', que é um modelo discreto estudado na Biologia Teórica, Matemática e Teoria da Recursão. Tal conceito consiste de uma grade infinita e regular de células, cada uma podendo estar em um número finito de estados, que variam de acordo com regras determinísticas. Dessa forma, a Vizinhança de von-Neumann consiste de quatro células ortogonais ao redor de uma célula central em uma grade bidimensional, conforme mostrado na figura abaixo:
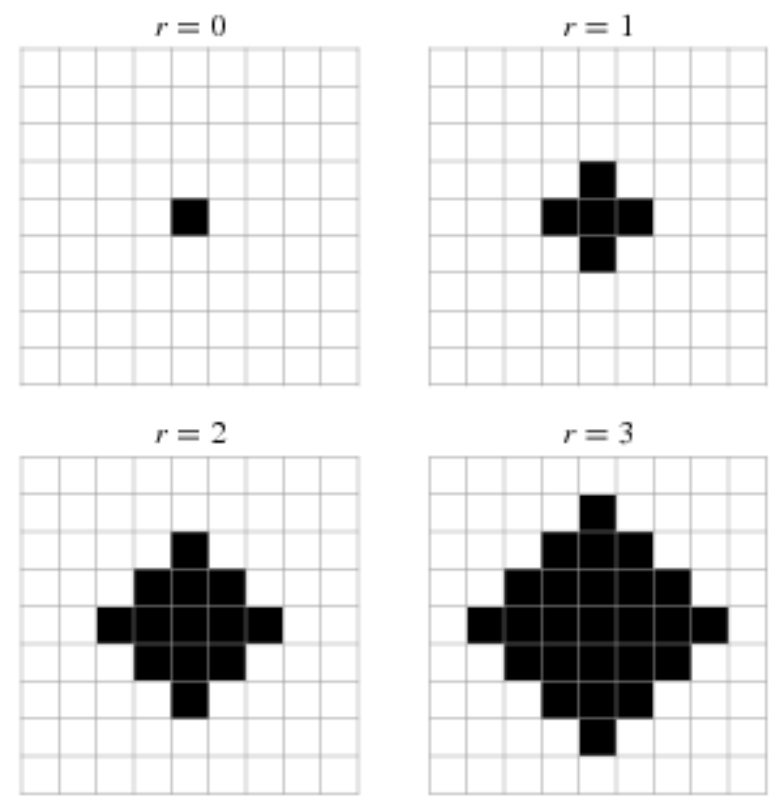

Figura 2 - Vizinhança de von-Neumann. Fonte: Gray (2003).

Da figura acima pode-se observar que a vizinhança de von-Neumann existe para diferentes raios, conforme explicado abaixo: 
- $\quad \mathrm{r}=0$ : o indivíduo não interage com os seus vizinhos.

- $\quad r=1$ : o indivíduo interage somente com os seus vizinhos imediatos.

- $\quad r>1$ : o agente focal interage com uma vizinhança mais distante, além dos seus vizinhos imediatos. Quanto maior o valor de 'R', maior é a quantidade de vizinhos com os quais o agente focal interage.

O outro tipo de vizinhança bastante utilizado na modelagem de jogos espaciais é a Vizinhança de Moore. A Vizinhança de Moore consiste de oito células ao redor de uma célula central, conforme mostrado na figura abaixo. A vizinhança foi nomeada desta forma em homenagem à Edward F. Moore, um pioneiro da teoria dos autômatos celulares.
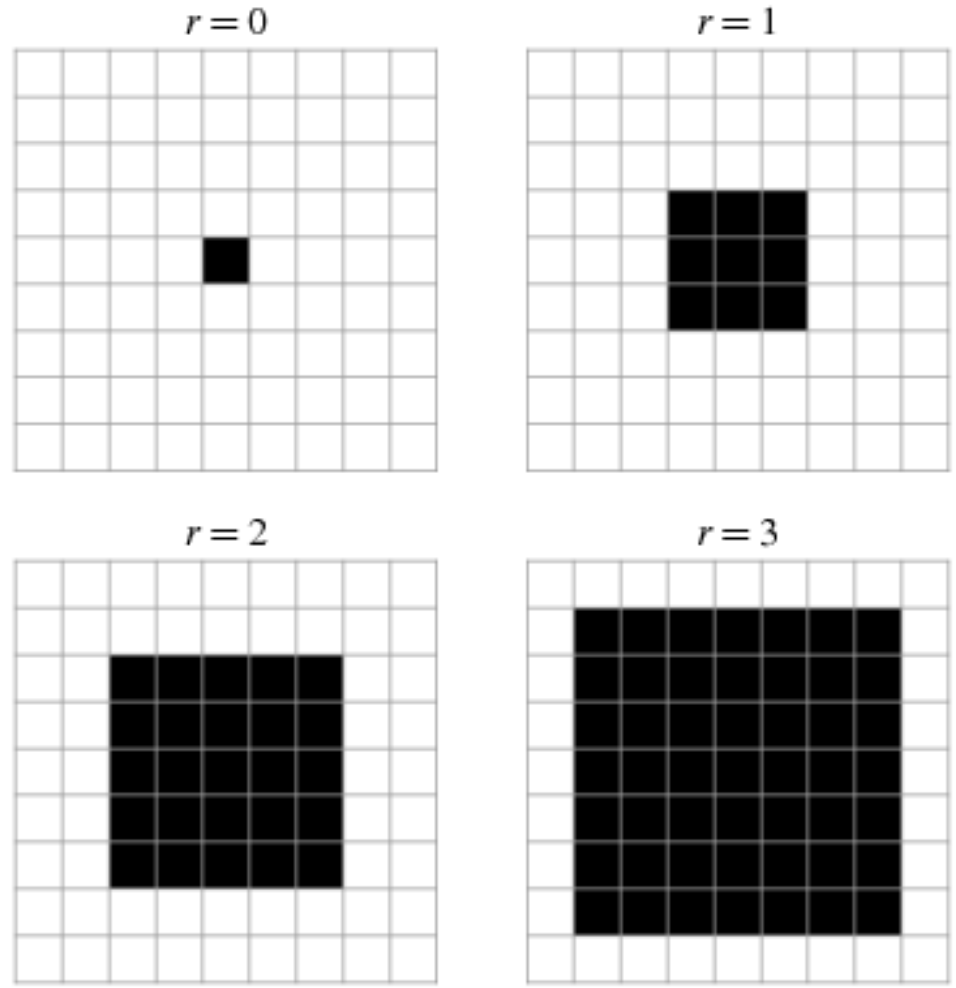

Figura 3 - Vizinhança de Moore. Fonte: Gray (2003). 


\subsubsection{Atualização da população}

A população pode ser atualizada na forma síncrona ou assíncrona. Segundo Hauert (2001), na forma de atualização síncrona, a população somente é atualizada para uma nova composição de indivíduos, após todos os indivíduos terem a oportunidade de jogar com seus vizinhos locais. Dessa forma, todos os agentes tem a oportunidade de se adaptarem em um determinado passo de Monte Carlo, no entanto, somente ao final do passo de Monte Carlo - onde todas as interações ocorreram - é que, simultaneamente, os jogadores adotam a estratégia do seu vizinho local.

$\mathrm{Na}$ forma de atualização assíncrona, existe a possibilidade de se imitar a estratégia do vizinho local após cada iteração. Ou seja, um determinado indivíduo não espera todos os demais terem a oportunidade de se comparar com os vizinhos para imitar ou não a estratégia deste último.

Cada indivíduo possui um payoff médio, que é encontrado pela média aritmética dos payoffs obtidos em cada interação com os seus vizinhos locais, sendo assim, sabe-se que:

$$
\text { - } \quad V i=\frac{\sum_{i=1}^{n} v i}{n} .
$$

Dessa forma, o jogador focal compara o seu payoff médio com o payoff médio do jogador referência, que é escolhido aleatoriamente dentre os indivíduos pertencentes à vizinhança do jogador focal. O payoff médio do jogador referência, que é utilizado na comparação com o jogador focal, é obtido como resultado das interações que o jogador referência realiza com os seus vizinhos locais, em que até mesmo o jogador focal está incluído. Dessa forma, o payoff médio obtido pelo jogador referência pode ser entendido como:

$$
\text { - } \quad V j=\frac{\sum_{i=1}^{n} v j}{n} .
$$

Após o cálculo dos payoffs, deve-se realizar o seguinte procedimento: caso $V i \geq V j$, o jogador focal mantém sua estratégia, visto que o payoff do jogador referência não é maior do que seu próprio payoff. Com isso, não há possibilidade de replicação por imitação, visto que não há expectativa de melhora em seu 
desempenho. Entretanto, caso $V i<V j$, o jogador focal tem a possibilidade de melhorar sua estratégia. O jogador focal imitará a estratégia do seu oponente com a seguinte probabilidade:

$$
\text { - } \quad w=\frac{(V j-V i)}{m a ́ x},
$$

em que o parâmetro "máx" representa o máximo valor na matriz de pagamentos do jogo. Com isso, sabe-se que: $w \in(0,1]$. Note que quanto pior for o desempenho do jogador focal relativamente ao jogador referência, maior é a probabilidade do primeiro imitar a estratégia do último. 


\section{Desenvolvimento}

\subsection{Jogos de uma população}

A fim de verificar a dinâmica espacial para jogos de uma população, foi criado um programa na linguagem de programação Visual Basic for Applications (VBA) realizando interface com o Microsoft Excel (qualquer versão disponível). Os resultados encontrados na simulação computacional foram comparados aos obtidos por Chan et al. (2013) e Hauert (2004).

$\mathrm{Na}$ inicialização do programa, o usuário define - dentre outros parâmetros específicos de cada jogo estudado - o tamanho da população e sua composição inicial. A composição inicial da população é definida pelo usuário de forma que este atribui um percentual correspondente à proporção de indivíduos, que, inicialmente, opta por jogar uma determinada estratégia.

Após a escolha das proporções iniciais das estratégias, é criado um vetor - com o mesmo tamanho da população - de números aleatórios.

O preenchimento da população e escolha das estratégias que a compõe ocorre serialmente de forma a preencher toda a matriz populacional comparando-se os números aleatórios com o percentual definido pelo usuário, assim como mostrado na figura (4) abaixo:
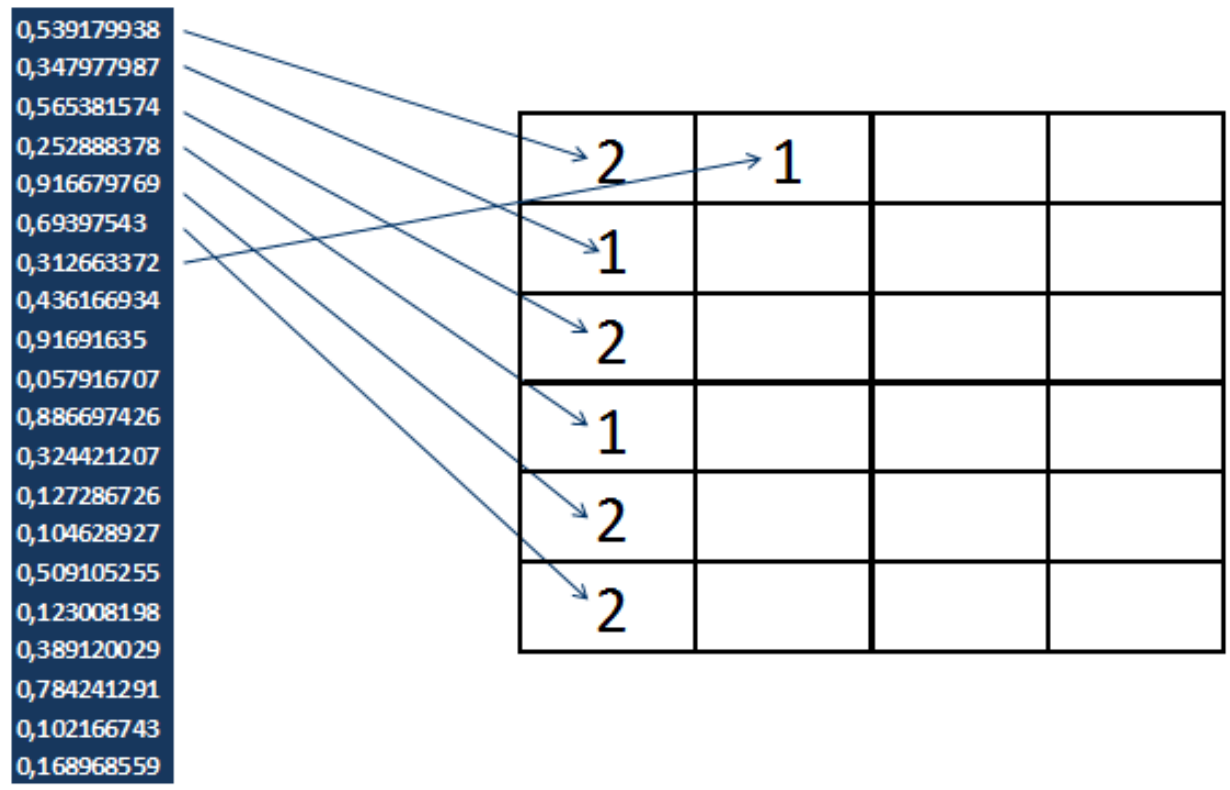

Figura 4 - Alocação da população. 
No exemplo acima foi considerado uma frequência inicial definida pelo usuário de 0.5 .

Como existe um fator aleatório na escolha das estratégias que compõem a população no estado inicial, nem sempre o programa cria a população exatamente conforme previsto pelo usuário, existindo então uma margem de erro. Quanto maior é o tamanho da população, menor é essa diferença. A fim de contornar esse problema, foi criado um teste que verifica se a população foi composta de acordo com os parâmetros de entrada. Caso a proporção de indivíduos - para qualquer uma das estratégias - se distancie de $1 \%$ para o parâmetro de entrada, uma nova população é gerada.

Com a população inicializada, o próximo passo é calcular o payoff de cada indivíduo da população.

É importante salientar que o programa pode ser executado nas formas síncrona e assíncrona. No entanto, de acordo com Chan et al. (2013) e Hauert (2004) os resultados são similares para ambas as formas, na maioria dos casos estudados. $\mathrm{O}$ que pode ser verificado em um exemplo, mostrado posteriormente, no presente estudo.

Sendo assim, a explicação adiante sobre a metodologia computacional está embasada para a implementação do programa na forma de atualização síncrona.

O programa percorre a matriz populacional de forma sequencial calculando o payoff de cada indivíduo e colocando o resultado do payoff em uma matriz de payoffs. Assim, a matriz de payoffs se completa quando o cálculo do payoff é realizado para todos os indivíduos. Para este cálculo foi considerada a vizinhança de von-Neumann, de raio unitário, de acordo com a figura abaixo.

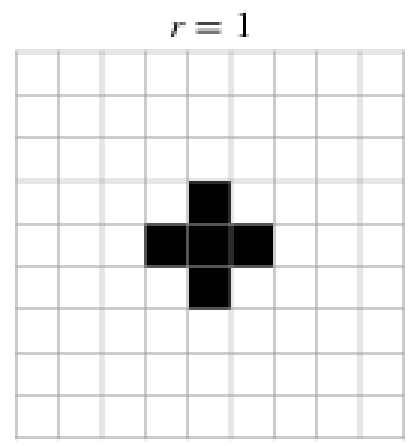

Figura 5 - Vizinhança de Von-Neumann para raio unitário. Fonte: Gray (2003). 
Dessa forma, o payoff alocado para cada indivíduo corresponde à soma dos payoffs obtidos na interação com cada um dos seus vizinhos. Na figura acima, o elemento central representa o agente 'focal', e os outros quatro indivíduos (à esquerda; acima; à direita e abaixo) representam os quatro vizinhos. Assim, o agente 'focal' interage com cada vizinho pertencente a sua vizinhança local.

Segue abaixo um exemplo que ilustra o procedimento citado anteriormente:

- Considere a seguinte matriz de pagamentos:

\begin{tabular}{|ccc} 
& Est. 1 & Est. 2 \\
\hline Est. 1 & 3.5 & 3 \\
Est. 2 & 5 & 4.5 \\
\hline
\end{tabular}

Figura 6 - Matriz de pagamentos.

No exemplo elaborado, os jogadores podem adotar as estratégias puras 1 ou 2 . Dessa forma, o procedimento de cálculo dos payoffs acontece da seguinte forma:

Matriz Populacional $v_{i=\frac{\sum_{i=1}^{n}}{n}}^{\text {Matriz de Payoffs }}$
\begin{tabular}{|c|c|c|c|c|c|c|c|c|c|c|}
\hline 1 & 1 & 1 & 2 & 2 & 1 \\
\hline 2 & 2 & 1 & 2 & 2 & 1 \\
\hline 1 & 2 & 1 & 2 & 1 & 2 \\
\hline 2 & 1 & 2 & 2 & 1 & 2 \\
\hline 1 & 2 & 1 & 1 & 1 & 1 \\
\hline 1 & 2 & 2 & 2 & 2 & 2 \\
\hline
\end{tabular}

Figura 7 - Cálculo da matriz de payoffs.

Da figura acima observa-se que o agente focal observado na cor 'verde' interage com os demais indivíduos pertencentes a sua vizinhança local, que são os 4 indivíduos em 'amarelo' ao seu redor. Dessa forma, o payoff médio é obtido como resultado da interação do agente focal com seus vizinhos locais. 
Após o cálculo do payoff para todos os agentes, é realizada a comparação entre os indivíduos.

Um agente é escolhido aleatoriamente na população. Para esse agente, é escolhido - também de forma aleatória - um dos seus vizinhos para que ocorra a interação. A interação ocorre de forma que o agente focal 'i' compara o seu payoff $(V i)$ com o payoff do agente referência $(V j)$. Caso o payoff do agente focal seja maior ou igual ao payoff do agente referência $(V i \geq V j)$, não há motivos para a troca de estratégia, visto que o agente focal possui melhor desempenho com relação ao seu oponente. Não há razão para imitá-lo, visto que isso gera piora no seu desempenho. Caso o payoff do agente focal seja menor do que o payoff do agente referência $(V i<V j)$, há uma oportunidade probabilística de replicação por imitação. O jogador focal imita a estratégia do jogador referência com a seguinte probabilidade:

- $\quad w=\frac{(V j-V i)}{m a ́ x}$,

onde o parâmetro 'máx' representa o máximo valor obtido na matriz de pagamentos do jogo estático, ou seja, representa o maior payoff obtido para qualquer interação entre as estratégias. Infere-se que: $w \in(0,1]$.

Assim, sorteia-se um número aleatório entre zero e um e compara-se o mesmo com ' $w$ '. Se o número aleatório sorteado for menor que ' $w$ ', há troca de estratégia. Dessa forma, existe uma probabilidade $(1-w)$ de não haver troca de estratégia.

Segue abaixo um exemplo que ilustra esse procedimento:

- Considere, como exemplo, as seguintes matrizes: 
Matriz Populacional

\begin{tabular}{|l|l|l|l|l|l|}
\hline 1 & 1 & 1 & 2 & 2 & 1 \\
\hline 2 & 2 & 1 & 2 & 2 & 1 \\
\hline 1 & 2 & 1 & 2 & 1 & 2 \\
\hline 2 & 1 & 2 & 2 & 1 & 2 \\
\hline 1 & 2 & 1 & 1 & 1 & 1 \\
\hline 1 & 2 & 2 & 2 & 2 & 2 \\
\hline
\end{tabular}

Matriz de Payoffs

\begin{tabular}{|l|l|l|l|l|l|}
\hline 3,75 & 4,20 & 3,75 & 3,13 & 3,13 & 4,20 \\
\hline 4,20 & 4,20 & 4,20 & 3,75 & 3,13 & 3,13 \\
\hline 3,13 & 3,75 & 3,13 & 3,13 & 4,20 & 3,75 \\
\hline 3,13 & 4,00 & 4,50 & 3,13 & 4,50 & 3,13 \\
\hline 3,75 & 4,20 & 3,75 & 4,50 & 3,13 & 3,75 \\
\hline 3,13 & 4,50 & 4,50 & 3,75 & 3,13 & 3,13 \\
\hline
\end{tabular}

Figura 8 - Matriz populacional e de payoffs.

Da figura acima observa-se que foi escolhido aleatoriamente, dentro da população, um agente focal, e um agente referência que pertença a vizinhança de von-Neumann correspondente ao agente focal.

Sendo assim, observa-se que o payoff médio do agente referência é maior do que o payoff médio do agente focal. Com isso, deve-se calcular o ' $w$ ', que irá definir se haverá, ou não, troca de estratégias entre os indivíduos. De acordo com os dados do exemplo (ainda considerando a matriz de payoffs da figura (6), temos que:

$$
\text { - } \quad w=\frac{(V j-V i)}{\operatorname{máx}}=\frac{(4.20-3.75)}{5}=0.09
$$

O próximo passo é sortear um número aleatório e compará-lo com ' $w$ '. Caso ' $w$ ', seja maior que tal número, deve-se efetuar a troca entre as estratégias, caso contrário, não há qualquer alteração nas matrizes.

O programa repete esse procedimento de comparação tantas vezes quanto for o tamanho da população, de forma que cada jogador tenha tido a oportunidade, em média, de trocar sua estratégia uma vez.

Após o passo anterior, pode-se dizer que o programa concluiu um passo evolucionário, ou, um passo de Monte Carlo.

Sendo assim, o programa repete o procedimento completo citado até o momento que corresponde a um passo de Monte Carlo - tantas vezes quantas forem necessárias para que as frequências das estratégias se tornem estáveis e o jogo 
convirja para um determinado equilíbrio, dependendo da característica do jogo estudado.

Deve-se tomar o cuidado devido ao considerar os indivíduos que pertencem à fronteira da população. O problema ocorre quando um determinado indivíduo está na fronteira da população e tenta interagir com seus vizinhos, conforme mostrado na figura abaixo:

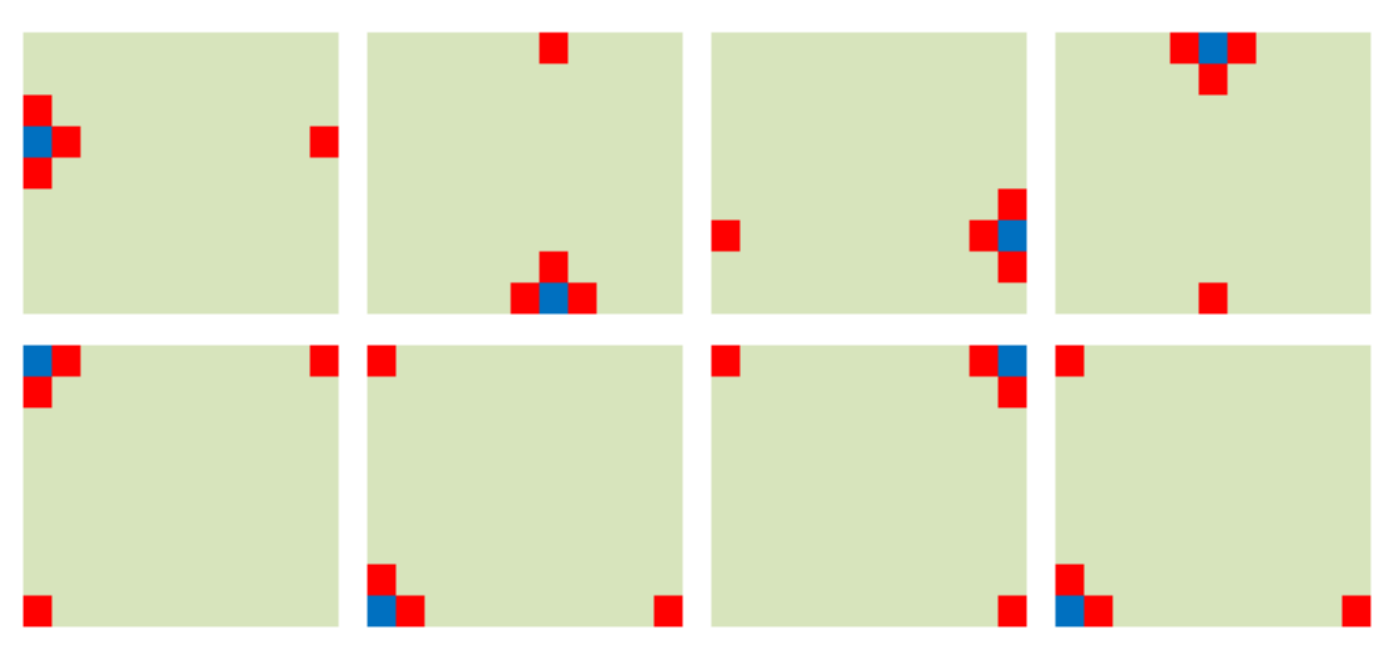

Figura 9 - Vizinhança de von-Neumann para indivíduos pertencentes às fronteiras da população.

A figura acima é intuitiva. O indivíduo 'focal' está representado na cor azul, enquanto que os indivíduos do tipo 'referência' estão representados em vermelho. Sendo assim, o programa deve estar implementado de modo a considerar adequadamente a vizinhança para esses casos, conforme mostrado acima, ou seja, admitimos que a grelha possui 'periodic boundary conditions'.

\subsubsection{Comparativo com o artigo "Evolutionary snowdrift game incorporating costly punishment in structured populations"}

\subsubsection{Conceitos Iniciais}

Sabe-se que o Snowdrift Game tem sido utilizado como um modelo para estudar o surgimento da cooperação em populações concorrentes, visto que este tipo de jogo reflete um dilema social conforme explicado anteriormente nesta dissertação. Por outro lado, existem outras estratégias em situações na vida real. Existem punidores que atuam cooperativamente quando competem com agentes 
cooperadores, em contrapartida pagam um custo para punir agentes não cooperativos, ou desertores. Sendo assim, tal agente promove um comportamento altruísta.

A matriz de pagamentos utilizada por Chan et al. (2013), considerando a inclusão dos agentes punidores, pode ser visualizada na figura abaixo:

$$
\begin{gathered}
C \\
D \\
P
\end{gathered}\left(\begin{array}{ccc}
1 & 1-r & P \\
1+r & 0 & 1+r-\beta \\
1 & 1-r-\alpha & 1
\end{array}\right)
$$

Figura 10 - Matriz de pagamentos para o Snowdrift Game, incluindo agentes punidores. Fonte: Chan et al. (2013).

onde ' $r$ ' é a razão entre o custo e o benefício líquido de cooperar, conforme bem definido na literatura por Doebeli e Hauert (2005).

Dessa forma, quando um indivíduo punidor compete com um indivíduo cooperador, esse comporta como se fosse um indivíduo cooperador, recebendo o mesmo pagamento. De outra forma, quando um indivíduo punidor compete com um indivíduo desertor, incorre em um custo $\alpha$ de modo a levar um dano $\beta$ para o indivíduo desertor, onde $\beta>\alpha$, de forma a tornar a ação de punir racional. Portanto, nesse contexto de jogos evolucionários, os jogadores mantém racionalidade limitada.

\subsubsection{Resultados comparativos}

Para estudar os efeitos do jogo espacial, o autor considerou a vizinhança de vonNeumann e utilizou uma população de tamanho 90 x 90. Os valores de $\alpha$ e $\beta$ foram definidos pelo autor em 0.01 e 0.05 respectivamente. Além disso, o autor realizou as simulações nas formas de atualização síncrona e assíncrona. Conforme mencionado no artigo, o autor obteve resultados similares para ambas as configurações.

Sendo assim, para efeitos de comparação, dois casos foram estudados nesta dissertação - na forma síncrona - e com as mesmas configurações citadas pelo autor. 


\section{(i) Primeiro caso}

Para o primeiro caso, em que $r=0.02$, percebe-se que, em um primeiro momento, a frequência de desertores diminui enquanto que as frequências de punidores e cooperadores possuem, aproximadamente, os mesmos valores e aumentam na mesma proporção até o ponto que corresponde, aproximadamente, ao centésimo passo de Monte Carlo. Isso acontece pois, neste estágio inicial ainda existe uma proporção suficiente de desertores ao redor dos cooperadores e punidores, como vizinhos locais, resultando em um payoff menor. Após o centésimo passo de Monte Carlo, a frequência de desertores continua a cair e se torna muito pequena, e somente a frequência de cooperadores continua a aumentar. Essa dinâmica ocorre porque, além da troca direta de desertores para cooperadores, acontece a troca indireta de desertores para cooperadores, com os punidores como intermediários. Assim, os desertores se tornam punidores, e estes, que outrora eram desertores, se tornam cooperadores. Isto acontece quando a frequência de desertores é muito pequena, e existe muita interação entre cooperadores e punidores. Quando o par cooperador-punidor pertence a um ambiente de competição em que existe o mesmo número de desertores nas suas vizinhanças, os punidores tem um payoff menor que os desertores devido ao custo de punição. Assim, quando um indivíduo punidor compete com um indivíduo cooperador, existe uma probabilidade elevada para que o indivíduo punidor se torne cooperador.

A presença de indivíduos desertores é importante para a dinâmica de evolução da população, visto que, quando a população de desertores se extingue, não há incentivo para haver troca de estratégias entre punidores e cooperadores, visto que ambos possuem o mesmo payoff em caso de competição.

Abaixo segue o gráfico que representa a evolução de frequência para cada estratégia da população: 


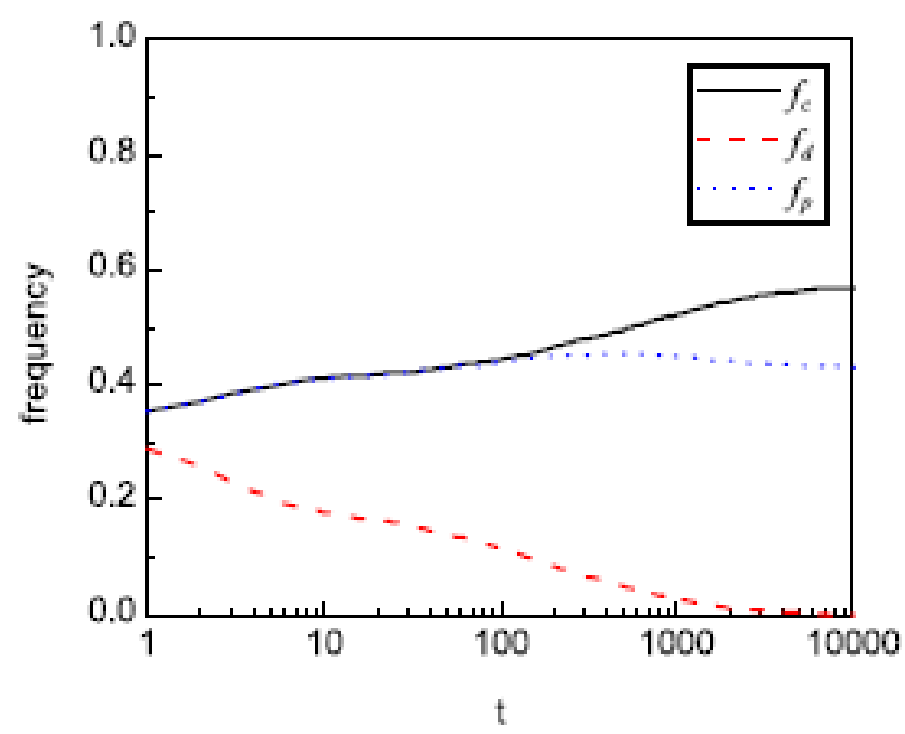

Figura 11 - Evolução de frequências das estratégias da população. $r=0,02$. Fonte: Chan et al. (2013).

Segue abaixo o gráfico comparativo, obtido como resultado do estudo de caso.

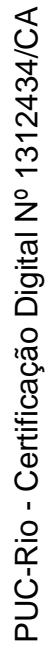

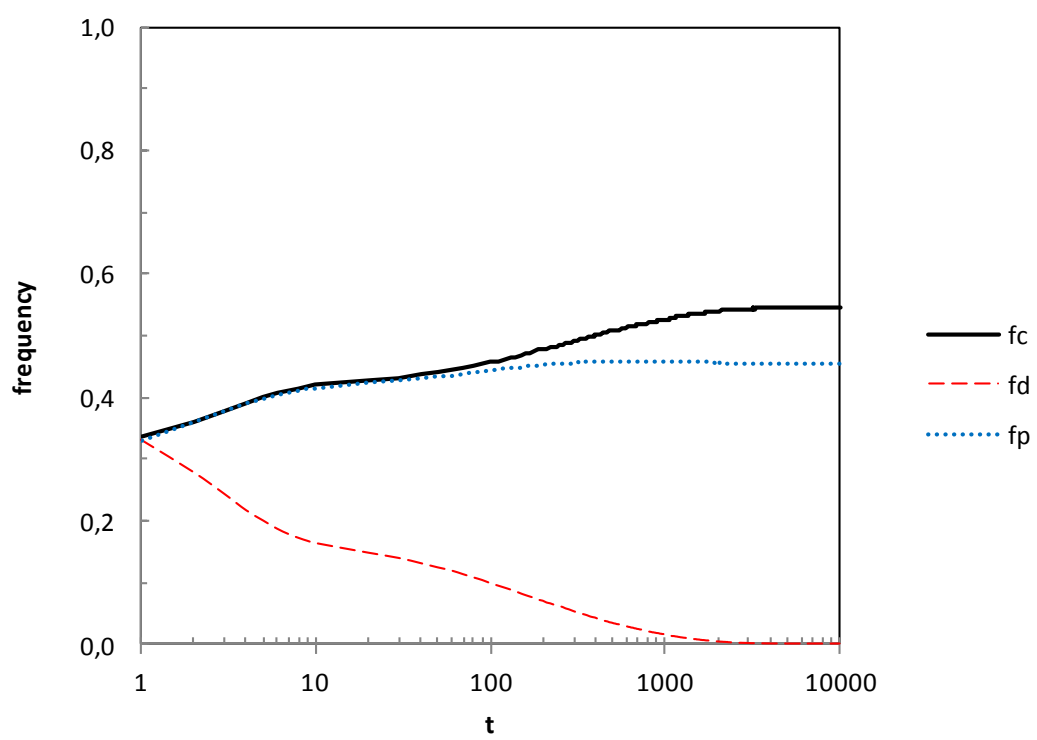

Figura 12 - Evolução de frequências das estratégias da população. $r=0.02$.

Segue abaixo a representação da evolução da população de acordo com a estrutura espacial: 

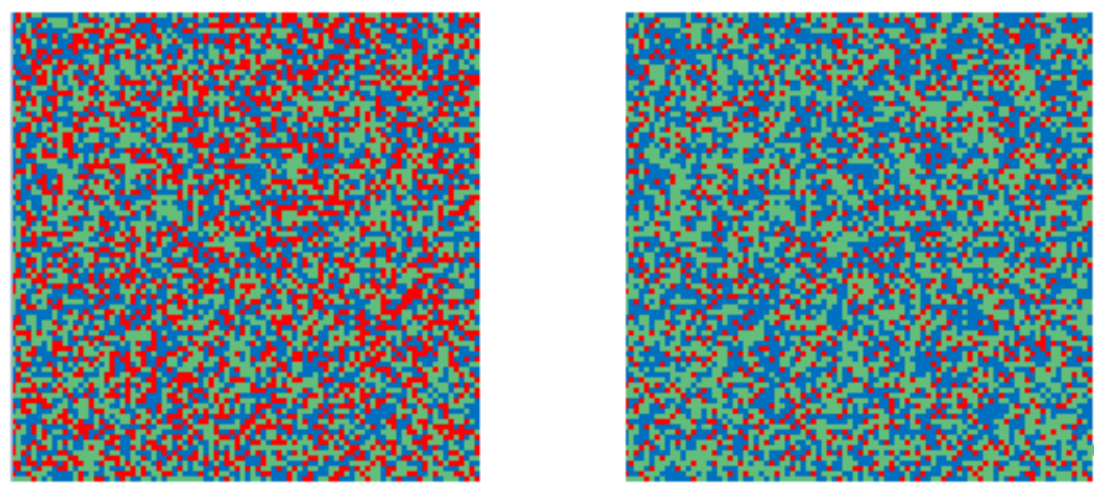

Figura 13 - Composição da população. PMC = 1 (à esquerda). PMC = 10 (à direita).
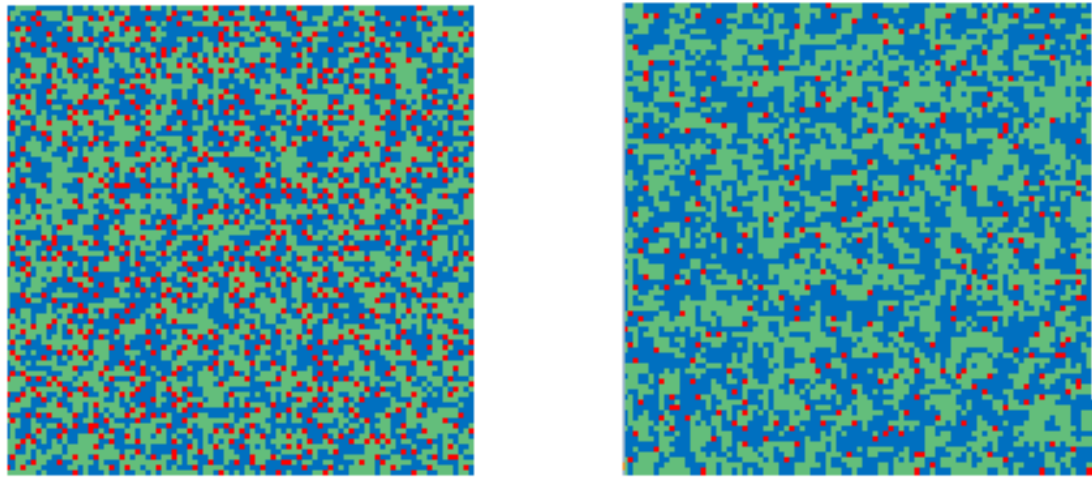

Figura 14 - Composição da população. PMC = 50 (à esquerda). PMC = 100 (à direita).
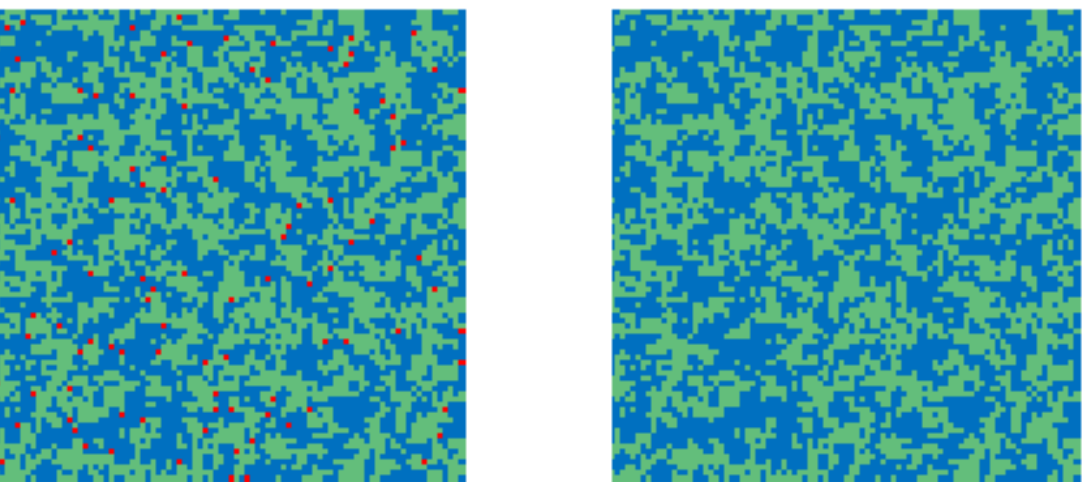

Figura 15 - Composição da população. PMC = 1000 (à esquerda). PMC = 5000 (à direita).

Os pontos em vermelho representam os indivíduos desertores, enquanto que os pontos em azul e verde representam, respectivamente, os indivíduos cooperadores e punidores. Cada figura representa o estado da população para um determinado passo de Monte Carlo (PMC).

Não foi possível realizar a comparação da composição da população sobre o enfoque espacial visto que o autor não apresentou tal resultado em seu artigo, mas 
observa-se a formação de clusters bem definidos de cooperadores e punidores ao mesmo tempo em que os desertores vão sendo eliminados.

\section{(ii) Segundo caso}

Este segundo caso foi estudado alterando-se o parâmetro ' $r$ ' de forma a possuir o seguinte valor: $r=0.6$. Todos os outros parâmetros e configurações permanecem iguais aos do primeiro caso.

No primeiro momento, o alto valor de ' $r$ ' (custo de cooperar elevado em relação ao benefício) leva à dinâmica de troca de indivíduos dos tipos cooperadores e punidores para indivíduos desertores. Esta dinâmica acontece até o centésimo passo de Monte Carlo, aproximadamente. Percebe-se que após este estágio existem muitos indivíduos desertores; é importante lembrar que, quando desertores competem com desertores, possuem o menor payoff dentre todos. Neste período acontecem trocas de desertores para punidores e de cooperadores para desertores. $\mathrm{O}$ efeito líquido é um aumento na frequência de punidores, próximo ao centésimo passo de Monte Carlo, à custa de cooperadores. Após esse período, a população de cooperadores desaparece e a população fica composta por desertores e punidores, com uma frequência muito baixa do último, conforme mostra o gráfico abaixo.

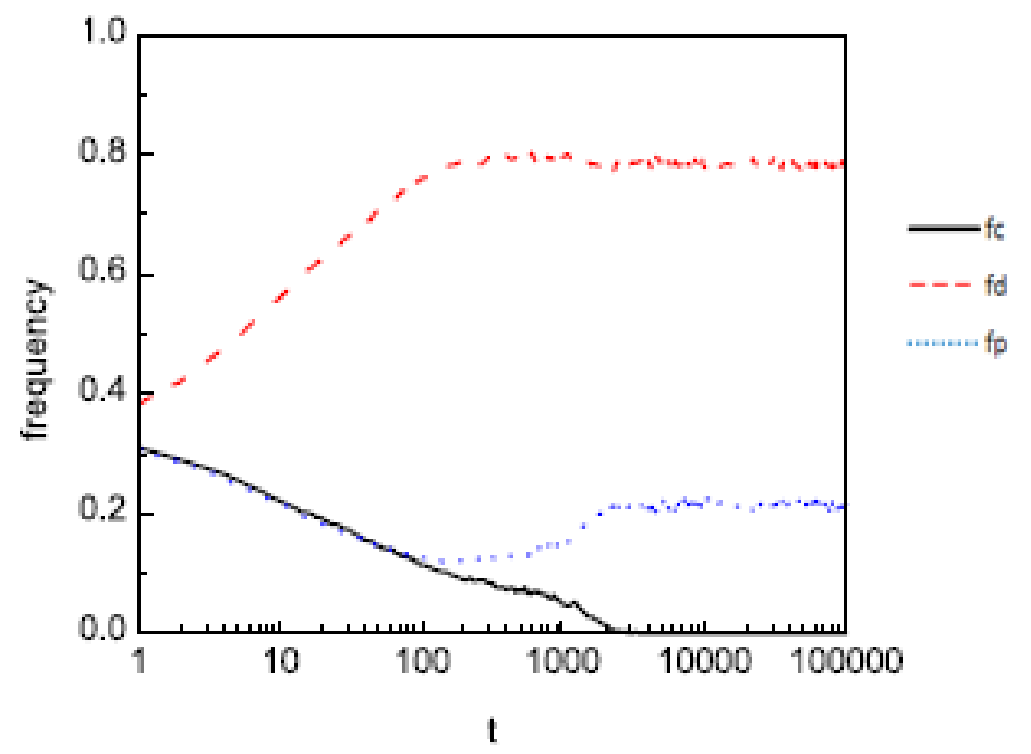

Figura 16 - Evolução de frequências das estratégias da população. $r=0.6$. Fonte: Chan et al. (2013). 
Segue abaixo o gráfico comparativo, obtido como resultado do estudo de caso.

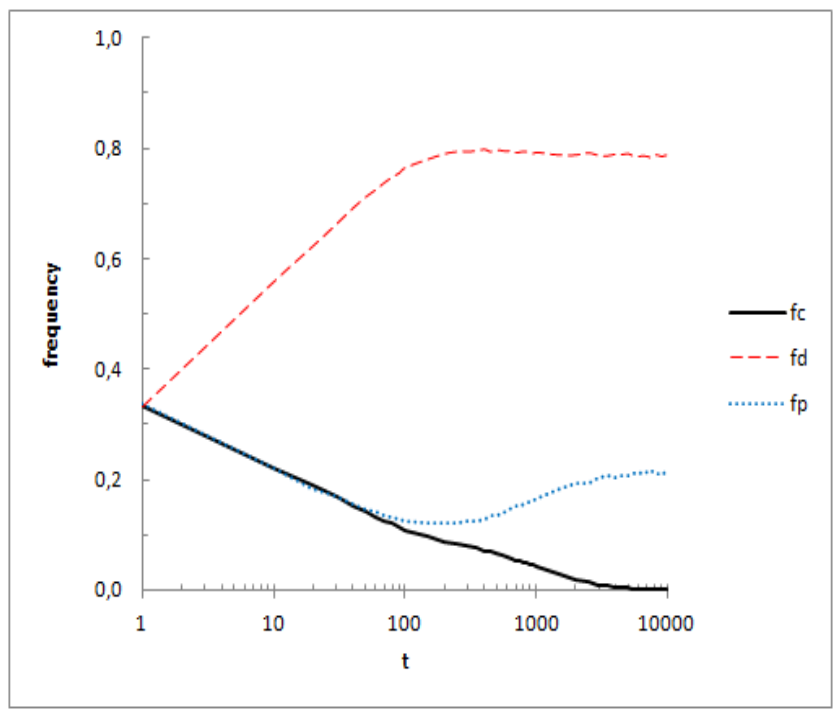

Figura 17 - Evolução de frequências das estratégias da população. $r=0.6$.

Segue abaixo a representação da evolução da população de forma espacial:
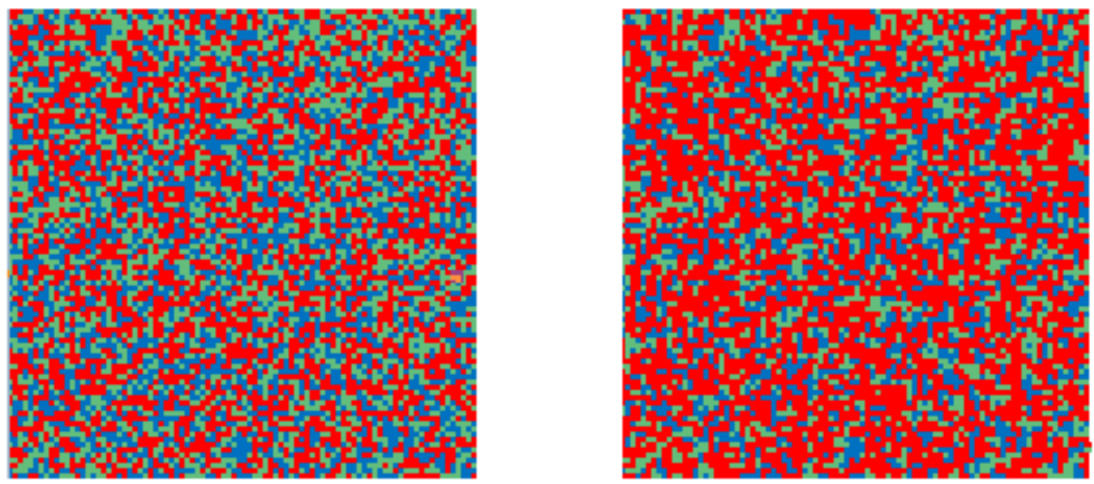

Figura 18 - Composição da população. PMC = 1 (à esquerda). PMC = 10 (à direita).
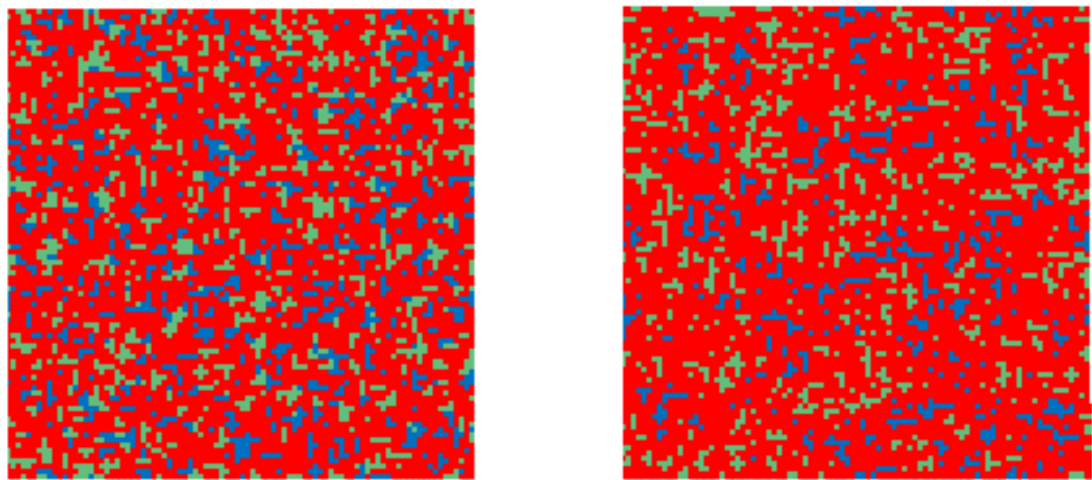

Figura 19 - Composição da população. PMC = 50 (à esquerda). PMC = 250 (à direita). 

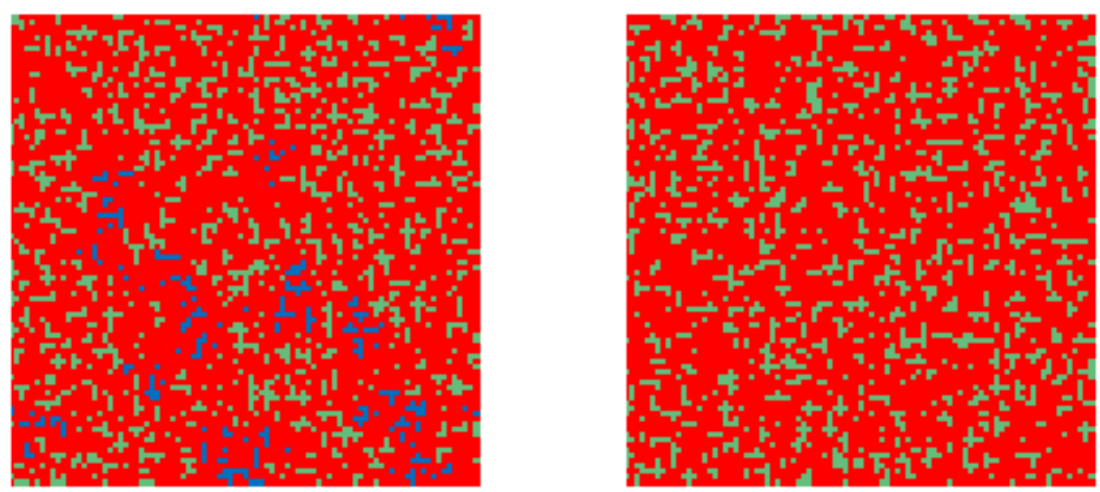

Figura 20 - Composição da população. PMC = 1000 (à esquerda). PMC = 5000 (à direita).

Conforme explicado no primeiro caso, os pontos em vermelho representam os indivíduos desertores, enquanto que os pontos em azul e verde representam, respectivamente, os indivíduos cooperadores e punidores. Cada figura representa o estado da população para um determinado passo de Monte Carlo (PMC).

Não foi possível realizar a comparação da composição da população sobre o enfoque espacial visto que o autor não apresentou tal resultado em seu artigo. Diferentemente do primeiro caso simulado, pode ser observado que os clusters formados pelos punidores não são compactos, tendo uma estrutura filamentar que favorece a exploração pelos desertores, efeito similar àquele explicado por Hauert (2004), o qual será abordado melhor na próxima subseção.

Por fim, conforme observado, pode-se constatar que os resultados alcançados são similares aos apresentados por Chan et al. (2013).

\subsubsection{Comparativo com o artigo "Spatial structure often inhibits the evolution of cooperation in the snowdrift game"}

\subsubsection{Conceitos Iniciais}

Hauert (2004) abordou os jogos "Dilema dos Prisioneiros" e "Snowdrift Game" sob a modelagem de estrutura espacial. Sabe-se que, no primeiro, o equilíbrio estável é representado pelo estado de não-cooperação, o que inspirou diversas investigações e extensões sobre como o estado cooperativo poderia persistir sem ser extinto. A estrutura espacial promove a evolução da cooperação para este tipo de jogo.

Com relação ao Snowdrift Game, sabe-se que níveis intermediários de cooperação persistem. No entanto, conforme mostrado pelo autor, a estrutura espacial reduz a 
frequência de cooperadores para uma ampla gama de parâmetros. Em geral, a estrutura espacial elimina a cooperação se o custo-benefício de cooperar for alto. Os resultados obtidos pelo autor alertam contra o que normalmente se acreditava naquela altura, que a estrutura espacial é necessariamente benéfica para o comportamento cooperativo.

\subsubsection{Resultados comparativos}

No desenvolvimento do seu modelo, Hauert (2004) utilizou uma população de 10000 indivíduos, formando assim, uma matriz espacial de $100 \times 100$. O autor também realizou as simulações na forma síncrona e assíncrona, obtendo resultados similares para ambos os casos.

Sendo assim, para efeitos de comparação, foi estudado o caso síncrono para a vizinhança de von-Neumann.

No gráfico abaixo, pode-se observar as frequências finais de cooperadores quando se simula o Snowdrift Game e varia-se o parâmetro 'r', que representa o custobenefício, para o caso de uma estrutura espacial com vizinhança de von-Neumann.

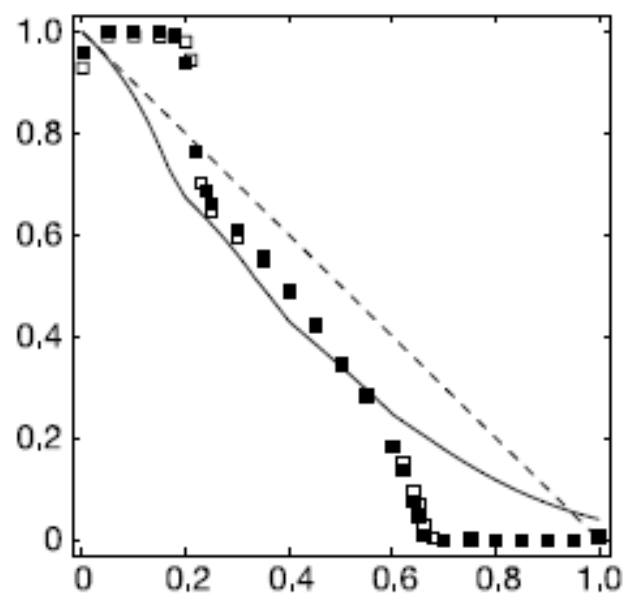

Figura 21 - Frequência de cooperadores em função do custo-benefício. Fonte: Hauert (2004).

Assim, pode-se perceber que para $r \approx 0.2$, a população deixa de ser composta somente de cooperadores e começa a possuir uma composição mista com desertores, o que acontece até $r \approx 0.65$, quando a população é composta somente de desertores, visto que o custo-benefício de cooperar é muito alto. Segue abaixo o gráfico comparativo obtido na simulação dessa pesquisa: 


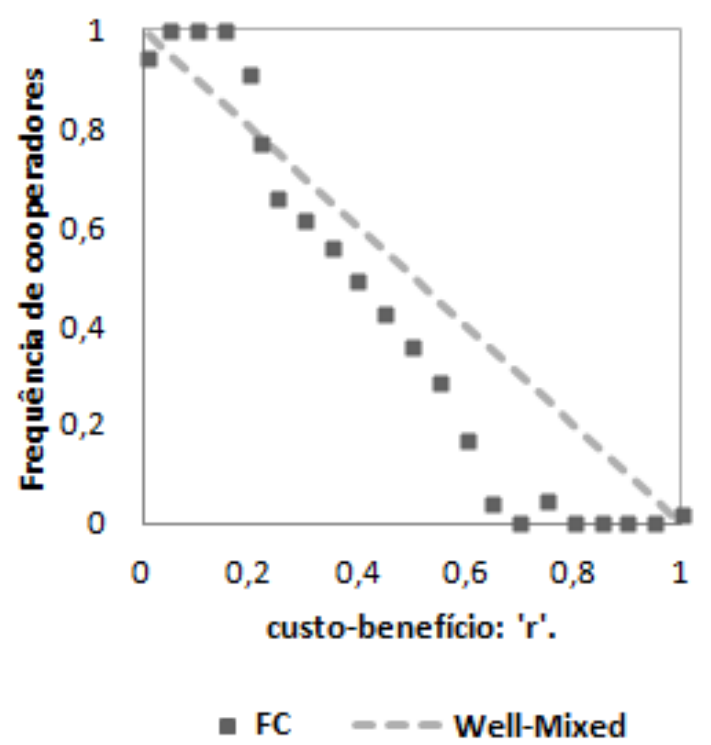

Figura 22 - Frequência de cooperadores em função do custo-benefício.

A figura acima mostra a frequência de cooperadores obtida como resultado do jogo espacial quando se simula o Snowdrift Game e varia-se o parâmetro 'r', conforme explicado anteriormente. A linha tracejada corresponde às frequências de cooperadores, no equilíbrio, quando é considerada uma população well-mixed. Ou seja, menor é a frequência de cooperadores o quão maior é o valor do parâmetro ' $r$ ',

Sendo assim, observa-se que, para $r>0.2$ (aproximadamente) a não-cooperação é favorecida de acordo com a estrutura espacial.

Segue abaixo o snapshot ${ }^{7}$ obtido pelo autor, para $\mathrm{r}=0.62$, considerando o Snowdrift Game:

\footnotetext{
${ }^{7}$ Registros da população em um dado instante de tempo.
} 


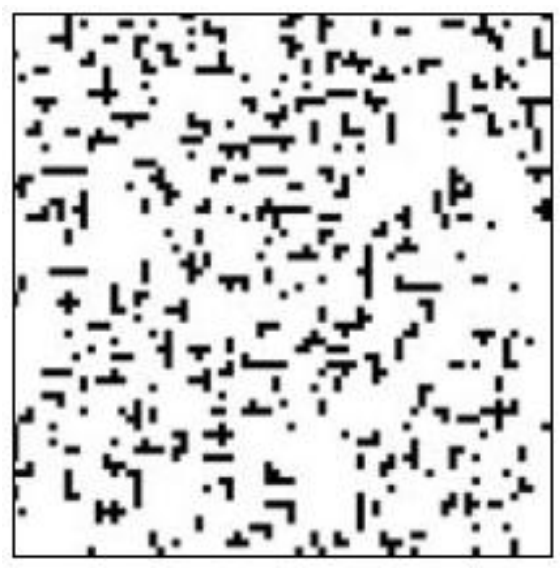

Figura 23 - Composição da população no Snowdrift Game. $r=0.62$. Fonte: Hauert (2004).

A partir da figura acima percebe-se que os cooperadores sobrevivem formando pequenos filamentos. Em consonância com o resultado apresentado na figura |22|, percebe-se que, para valores elevados de custo-benefício, a frequência de cooperação é menor do que a obtida como resultado do jogo considerando população well-mixed, devido à formação de clusters filamentares que favorecem a ação dos desertores.

Esses pequenos filamentos são mostrados pelo autor na forma microscópica, conforme a figura abaixo:
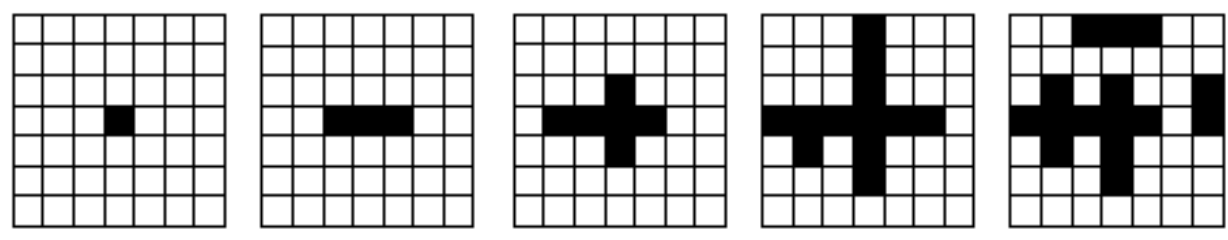

Figura 24 - Formação de filamentos na visão microscópica no 'Snowdrift Game'. Fonte: Hauert (2004).

Segundo o autor, no caso do Snowdrift Game, um indivíduo cooperador pode crescer no sentido de uma linha de cooperadores e então formar outro filamento perpendicular, cruzando esta linha; no entanto, cooperadores não podem se expandir no sentido de formarem clusters compactos, como no caso do Dilema dos Prisioneiros para a estrutura espacial, porque a estrutura de payoff protege os desertores nos cantos. Eventualmente, cooperadores formam o que o autor chama 
de 'esqueleto dendrítico'. Ocasionalmente, tais dendritos se rompem para formar novas sementes.

Por fim, esses padrões espaciais geram uma vantagem para os desertores, devido ao aumento da zona de competição entre os dois tipos de indivíduos, o que leva a uma redução global de cooperadores.

Segue abaixo o gráfico resultante obtido em comparação ao o estudo realizado por Hauert (2004):

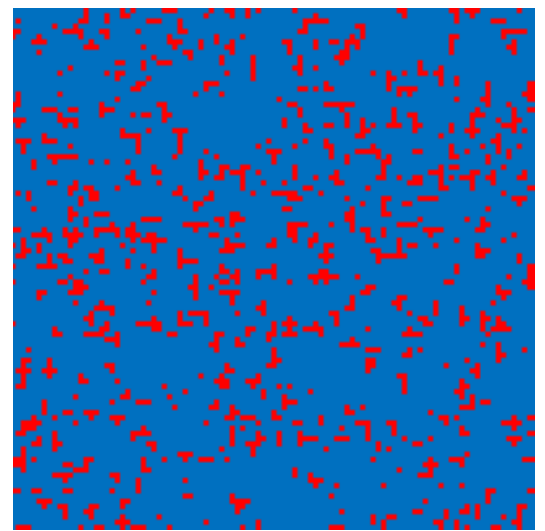

Figura 25 - Composição da população no 'Snowdrift Game'. r = 0.62.

A figura acima refere-se ao 'Snowdrift Game'. Conforme explicado anteriormente, pode-se observar que a população de cooperadores (em vermelho) formou pequenos filamentos.

Abaixo, pode-se observar microscopicamente como um pequeno filamento é formado:
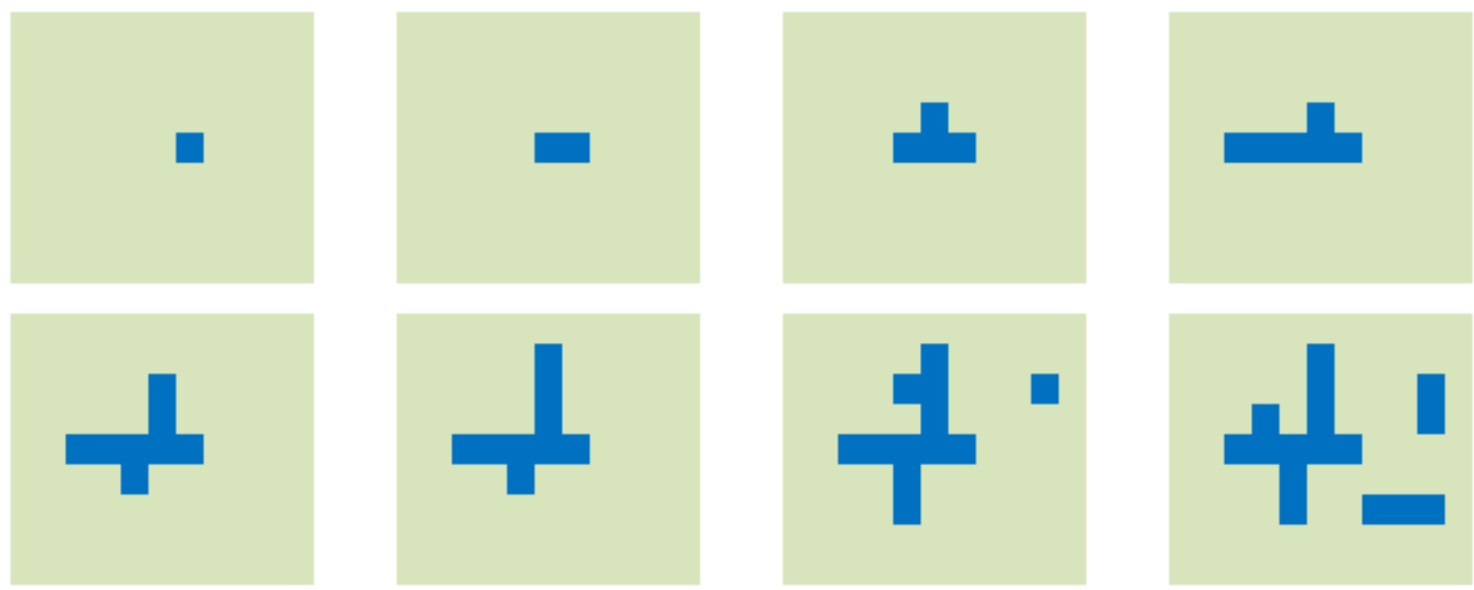

Figura 26 - Formação de filamentos na visão microscópica no 'Snowdrift Game'. 
Por fim, conforme observado, pode-se constatar que os resultados alcançados são similares os apresentados por Hauert (2004).

\subsection{Jogos de duas populações}

A fim de verificar a dinâmica espacial para jogos de duas populações, foi realizada uma extensão ao programa outrora criado para suportar jogos de uma população. É importante salientar que o programa foi extensamente analisado e testado, conforme mostrado nas seções anteriores.

A extensão supracitada representa, dentro do meu melhor conhecimento, uma inovação à literatura ao estender as abordagens de Chan et al. (2013), Hauert (2004) e Zhong et al. (2006), considerando a Estrutura de Jogos Espaciais, para o conceito de duas populações.

\subsubsection{Extensão do modelo computacional desenvolvido para jogos de uma população}

A seguir, são explicados os passos referentes ao novo modelo computacional, atentando-se de forma a não ser redundante com o que já foi explicado para o modelo de uma população e que não tenha sofrido alteração, para suportar o jogo de duas populações.

Diferentemente do modelo anterior, no modelo atual, o usuário define - dentre outros parâmetros específicos de cada jogo estudado - o tamanho da população e a composição inicial de ambas as populações, obedecendo o mesmo procedimento descrito anteriormente. Após a escolha das proporções iniciais das estratégias, é criado um vetor - para cada população - de números aleatórios, assim como ilustra a figura (27) abaixo: 


\begin{tabular}{l}
0,539179938 \\
0,347977987 \\
0,565381574 \\
0,252888378 \\
0,916679769 \\
0,69397543 \\
0,312663372 \\
0,436166934 \\
0,91691635 \\
0,057916707 \\
0,886697426 \\
0,324421207 \\
0,127286726 \\
0,104628927 \\
0,509105255 \\
0,123008198 \\
0,389120029 \\
0,784241291 \\
0,102166743 \\
0,168968559 \\
\hline
\end{tabular}

0,917668812
0,724719924
0,523209204
0,503192747
0,126826099
0,972265712
0,072609769
0,608814114
0,159490555
0,096553437
0,610850929
0,173113351
0,616240216
0,892781427 $\quad$\begin{tabular}{|l|l|l|l|l|l|}
\hline 4 & -3 & & & & \\
\hline 4 & & & & & \\
\hline 4 & & & & & \\
\hline 4 & & & & & \\
\hline 4 & & & & & \\
\hline 4 & & & & & \\
\hline
\end{tabular}

0,892781427

0,102203551

0,480454256

0,033861592

0,794252046

0,655476462

0,042959907

0,034801540

Figura 27 - Alocação inicial das populações.

No exemplo acima foi considerado uma frequência inicial definida pelo usuário de 0.5 , para cada população.

Caso a proporção de indivíduos - para qualquer uma das estratégias e para cada população - seja maior do que $1 \%$ (um por cento) do que a definida pelo usuário, uma nova população é gerada.

Com as populações inicializadas, o próximo passo é calcular o payoff de cada indivíduo para cada população.

Duas matrizes são criadas contendo as estratégias jogadas pelos jogadores de cada população. O programa percorre as matrizes populacionais de forma sequencial, calculando o payoff de cada indivíduo e colocando o resultado do payoff em uma matriz de payoffs. Dessa forma, haverá duas matrizes de payoffs, uma para cada população. Para o cálculo do payoff é considerado a vizinhança de von-Neumann de raio unitário, conforme explicado anteriormente nesta dissertação.

Porém, diferentemente do que foi explicado para o jogo de uma população, aqui o indivíduo de uma população compete com os indivíduos da outra população, sendo assim, cada indivíduo, ao invés de competir com os seus quatro vizinhos locais, compete com os quatro vizinhos locais, que estão na mesma posição geográfica na outra população, e ainda compete com o indivíduo central, que é o indivíduo que está na mesma posição geográfica que o indivíduo focal, porém tal 
indivíduo está presente na outra população. Sendo assim, cada indivíduo, compete com cinco indivíduos, conforme mostrado na figura abaixo.

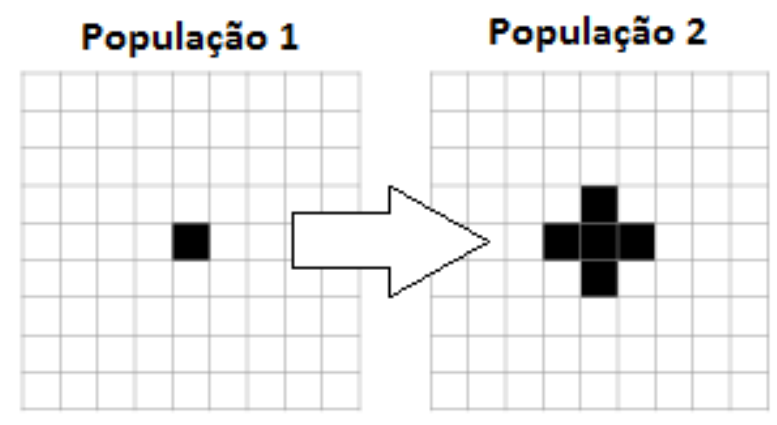

Figura 28 - Cálculo do payoff. Duas populações.

Após o cálculo do payoff para todos os agentes, é realizada a comparação entre os indivíduos. O procedimento de comparação é idêntico ao explicado para o jogo de uma população, visto que o indivíduo se compara com seus vizinhos locais, e dependendo da comparação, pode imitar a estratégia do seu oponente com uma dada probabilidade, assim como mostra a figura abaixo:

População 1
\begin{tabular}{|l|l|l|l|l|l|}
\hline 1 & 1 & 1 & 2 & 1 & 1 \\
\hline 2 & 2 & 1 & 2 & 2 & 1 \\
\hline 1 & 2 & 1 & 2 & 1 & 2 \\
\hline 2 & 1 & 2 & 2 & 1 & 2 \\
\hline 1 & 2 & 1 & 1 & 1 & 1 \\
\hline 1 & 2 & 2 & 2 & 2 & 2 \\
\hline
\end{tabular}

População 2
\begin{tabular}{|l|l|l|l|l|l|}
\hline 3 & 4 & 3 & 4 & 3 & 4 \\
\hline 4 & 3 & 4 & 3 & 4 & 3 \\
\hline 3 & 4 & 3 & 4 & 3 & 4 \\
\hline 4 & 3 & 4 & 3 & 3 & 4 \\
\hline 3 & 3 & 4 & 4 & 3 & 3 \\
\hline 4 & 4 & 4 & 3 & 4 & 4 \\
\hline
\end{tabular}

Figura 29 - Comparação entre indivíduos para cada população.

O programa repete esse procedimento de comparação tantas vezes quanto for o tamanho da população, de forma que cada jogador tenha tido a oportunidade, em média, de trocar sua estratégia uma vez.

Após o passo anterior, pode-se dizer que o programa concluiu um passo evolucionário, ou, um passo de Monte Carlo.

Sendo assim, o programa repete o procedimento completo citado até o momento que corresponde a um passo de Monte Carlo - tantas vezes quantas forem 
necessárias para que as frequências das estratégias, para ambas as populações, se tornem estáveis e o jogo convirja para um determinado equilíbrio evolucionário, dependendo da característica do jogo estudado.

\subsubsection{Análise sobre o artigo "Credit rating dynamics and competition" e aplicações}

\subsubsection{Agências de Rating}

As agências avaliadoras de risco, ou agências de rating, são empresas especializadas e independentes que avaliam o grau de risco das instituições e seus respectivos instrumentos de dívida, no que tange à capacidade de geração de fluxos de caixa suficientes para a perenidade do negócio da instituição e para a remuneração dos instrumentos de dívida que elas emitem. Essa avaliação se dá na forma de uma opinião seguida de uma nota.

Os investidores utilizam os serviços das agências de rating como forma de avaliar os riscos implícitos em determinados investimentos, e como forma de classificar os diferentes tipos de emissores. Já as empresas buscam as agências de rating como forma de indicar aos investidores, e ao mercado em geral, a qualidade de suas emissões através de uma avaliação independente.

O objetivo principal das agências de rating é promover uma avaliação de determinado tomador de recurso quanto ao risco de crédito, ou, simplesmente, a capacidade que o tomador tem de pagar dívidas.

\section{(a) Influência das agências de rating}

Ainda que os investidores possam usar os ratings de crédito em suas decisões de investimento, os ratings fornecidos pelas agências não indicam o mérito do investimento. Em suma, tais avaliações não são recomendações para comprar, manter ou vender, ou mesmo uma medida do valor do ativo, nem têm a intenção de sinalizar a adequação de um investimento. O rating trata de um aspecto da decisão de investimento - a qualidade de crédito - e, em alguns casos, pode 
mostrar o grau de recuperação esperado de investimento em uma situação de default ${ }^{8}$.

Em suas análises, os investidores deveriam levar em consideração, além da qualidade do crédito, a composição atual de suas carteiras, suas estratégias de investimento e horizonte de tempo, sua tolerância ao risco, e uma estimativa do valor relativo de um título em comparação com outros de sua eventual escolha.

Segundo Ivanovic et al. (2012), a finalidade das agências de rating de crédito é oferecer aos investidores informações valiosas sobre empresas, entidades, e títulos para financiamento.

As agências de rating surgiram de acordo com a necessidade dos investidores, devido à falta de qualidade e objetividade na informação. Dessa forma, havia uma necessidade que surgiu para começar a medir objetivamente a qualidade de crédito de países, negócios de entidades e seus títulos, a fim de tomar a decisão certa sobre o investimento. Outra importante função era fornecer padrão de comparação e escala de classificação, a partir dos quais poderia se construir uma carteira de títulos.

A partir destas duas últimas funções especificadas (padrão de comparação e escala de classificação) surgiu a necessidade de assegurar um padrão comum como método de apoio à decisão. Com a classificação padronizada, as agências podem reduzir a assimetria de informação no mercado de crédito.

\section{(b) Regras e objetivos das agências de rating}

A principal atividade das agências de rating é vender sua opinião como uma pontuação que mede a qualidade de crédito dos títulos, entidades empresariais ou governos. Como já mencionado anteriormente nesta dissertação, a agência de rating não presta serviços de consultoria em termos de recomendações para compra ou venda de valores mobiliários, que proporcione um parecer sobre a solvabilidade do emissor ou dos valores mobiliários.

Os investidores devem estar cientes de que a avaliação do risco não é uma garantia, mas apenas uma opinião sobre a capacidade de o devedor cumprir com

\footnotetext{
${ }^{8}$ Inadimplência ou atraso no pagamento, dependendo da metodologia utilizada por cada instituição.
} 
as obrigações da dívida. A avaliação e opinião com relação aos créditos são baseadas em análise de profissionais experientes com a função de analisar e interpretar as informações recebidas pelas agências de rating e de outras fontes confiáveis.

Em regra, existe uma relação inversamente proporcional entre a taxa de juros e a notação de risco de crédito, de forma que, quanto melhor for uma classificação de uma determinada entidade, menor será a taxa de juros cobrada para os empréstimos contraídos por tal entidade. O contrário também é verdadeiro, ou seja, caso uma entidade possua uma classificação de risco de crédito ruim, esta deverá pagar uma remuneração maior ao credor (caso o crédito seja concedido) a fim de compensá-lo pelo risco de empréstimo cuja probabilidade de inadimplência é mais alta que as demais empresas do ramo.

\section{(c) O papel desempenhado pelas agências de rating nas crises financeiras}

O crescimento dos mercados financeiros internacionais ao longo dos últimos anos teria sido impensável sem a presença das agências de rating. Segundo Utzig (2010), as agências de rating se esforçaram de modo a construir um sistema simples e facilmente compreensível, que permite a qualquer investidor entender as classificações de risco dos títulos internacionais para os quais não estavam familiarizados, promovendo dessa forma a diversificação das carteiras.

No mercado de produtos estruturados, o papel das agências de rating vai além de reduzir a assimetria da informação. $\mathrm{O}$ mercado de produtos estruturados não poderia ter se desenvolvido sem a garantia de qualidade fornecida pelas agências de rating, para investidores institucionais, sobre produtos financeiros inerentemente complexos.

No entanto, nos últimos anos, as agências de rating vêm tentando recuperar a credibilidade reduzida desde a crise de 2008, em que as agências de rating foram consideradas por diversas entidades financeiras ao redor do mundo como as principais culpadas.

A crise financeira mundial, que foi deflagrada em 2008 com a quebra do banco norte-americano Lehman Brothers, ainda impacta negativamente a população mundial por conta dos problemas nas contas públicas europeias. 
A quebra do banco, provocada exatamente pelo excesso de exposição a crédito de alto risco, conhecido nos Estados Unidos como subprime ${ }^{9}$, começou um questionamento sobre a verdadeira eficiência das agências de classificação de risco, visto que as agências deveriam alertar seus clientes sobre os perigos em investir em títulos com este nível de risco.

Segundo Utzig (2010), alguns elementos foram apontados como os principais fatores que influenciaram negativamente no trabalho das agências de rating:

- Excesso de confiança em metodologias matemáticas e estatísticas com base em dados inadequados;

- Consideração insuficiente de mercado e desenvolvimentos macroeconômicos como fatores, influenciando as notações de risco;

- Não consideração de interdependências;

- Não consideração de conflitos de interesses;

- Práticas de divulgação inadequada no tocante a modelos e pressupostos do modelo.

Em adição, Utzig (2010) afirma que os investidores também tiveram uma parcela de culpa ao aceitarem frequentemente ratings de forma acrítica e superestimando seu significado. Não foi dada a atenção devida ao fato de que as classificações de risco são apenas estimativas da probabilidade relativa de inadimplência ou perda esperada em um instrumento de dívida. As notações de risco não significam uma avaliação detalhada dos riscos e pouco dizem a respeito da qualidade do preço de um determinado instrumento ou sobre sua liquidez.

Por fim, o autor conclui que as classificações de risco não substituem as avaliações realizadas na gestão de risco dos investimentos, de forma que, as informações fornecidas pelas agências de rating são limitadas.

\footnotetext{
${ }^{9}$ Crédito hipotecário para o setor imobiliário destinado a tomadores de empréstimos que representam maior risco.
} 


\section{(d) Concorrência no segmento de agências de rating}

A falta de concorrência é um dos principais problemas para a regulação e desenvolvimento deste segmento do mercado. Segundo Schettini (2010), nessas condições, o preço pode se encontrar acima do que prevaleceria em um mercado competitivo, a qualidade do serviço pode ser comprometida e a estrutura de incentivos parece ainda não favorecer a inovação.

Esta falta de concorrência é consequência de outra crise nos Estados Unidos. Em decorrência da crise de crédito do início dos anos 1970, a partir de 1975 as regulamentações passaram a exigir que tais classificações fossem emitidas por Agências "nacionalmente reconhecidas" (Nationally Recognized Statistical Rating Organization - NRSRO, na sigla em inglês), sendo designadas como tais pela SEC (Securities and Exchange Commission), que é a Comissão de Títulos e Câmbio dos Estados Unidos. Apenas uma pequena parte das agências de rating foi classificada como NRSRO, sendo que por muitos anos não existiu uma definição clara e um critério conhecido para adquirir esse credenciamento.

Segundo Schettini (2010), existe um interessante fator relativo ao peso que a reputação tem neste segmento, visto que existe uma tendência natural à concentração nesse mercado devido à importância da reputação, porém, é preciso atuar para se adquirir reputação.

Existe também o perigo de que ocorra conflito de interesses entre uma determinada empresa que passe pela avaliação da agência de rating e a própria agência. Schettini (2010) afirma: “Um problema central na atuação dessas agências é a existência de uma série de conflitos de interesse. O fato de os serviços das agências de classificação de risco serem pagos diretamente pelos emitentes avaliados, claramente gera um cenário intrigante e pode resultar em situações do tipo 'rating shopping', em que a empresa emitente pesquisa entre as agências de rating e escolhe aquela que deve fornecer a melhor avaliação ou a que tem o critério menos exigente."

Pode-se afirmar também que existe uma relevante pressão sobre as empresas para que estas resolvam adquirir outros serviços oferecidos pelas agências de rating, além do tradicional. As principais agências de rating têm fornecido diversos outros serviços, como consultoria de gestão e administração de risco, avaliações 
pré-rating, pesquisas de mercado, etc. Com isso, os emissores podem ser influenciados a adquirir outros serviços além da notação do risco de crédito.

Sendo assim, ao mesmo tempo, as agências de rating querem ampliar ainda mais os seus mercados e tentam melhorar a imagem do seu segmento, que foi arranhada após tantas crises financeiras.

\section{(e) Regulação das agências de rating}

A primeira iniciativa de formulação de normas e princípios para regular o funcionamento das agências de classificação de risco foi proposta pela IOSCO International Organization for Securities Commissions (Organização Internacional das Comissões de Valores Mobiliários) - com a divulgação do Code of Conduct Fundamentals for Credit Rating Agencies (Código de Condutas Fundamentais para Agências de Classificação de Risco ou Código IOSCO), o qual estabeleceu padrões de comportamento recomendáveis para as agências de rating. Assim como mencionado no próprio código, este trata da qualidade e integridade das avaliações, das situações de conflitos de interesses, da transparência na divulgação das informações e da independência dos analistas.

Uma das características principais do Código é seu caráter não obrigatório. Em consonância com o que havia sido mencionado anteriormente - em um relatório produzido em 2007 - a IOSCO verificou que as três principais agências de rating, dominantes no mercado e anteriormente citadas, adotaram os Códigos de Conduta de acordo com os modelos divulgados pela IOSCO.

Pelo o que se pode perceber, as iniciativas da regulação das agências de classificação de risco de crédito, bem como do mercado financeiro como um todo, não partem do governo ou de instituições internacionais tradicionais do mercado financeiro, mas sim de organizações formadas por instituições privadas ou entidades reguladoras dos governos, e a partir daí começam a se relacionar diretamente com instituições representantes em outros países.

São exemplos de instituições reguladoras a IOSCO, IAIS - International Association of Insurance Supervisors (Associação Internacional de Supervisores de Seguro) e a HFA Hedge Funds Association (Associação dos Fundos de Hedge). 
O objetivo principal destas instituições se refere à formulação de regras que modelam o funcionamento do mercado financeiro dos países que desejam ser orientados por tal regulação, mostrando mais uma vez a importância das agências reguladoras nacionais, que em um momento posterior, implementam as normas definidas por meio de instrumentos normativos, de forma a facilitar a convergência e integração dos mercados financeiros nacionais e internacionais.

Pode-se falar também em autorregulação, que é o ato ou efeito de regular a si próprio, bem como os integrantes presentes no mesmo mercado. A grande vantagem da autorregulação no contexto inserido é que, segundo Marauhn (2006): "é melhor para uma entidade com atuação internacional ser regulada por seus pares do que por governos". Existem outras vantagens, como o fato de que a autorregulação incorpora expertise $e^{10}$ técnica no processo de regulação além da superior aceitabilidade de regras que são estabelecidas mediante um processo de participação direta das entidades reguladas.

\section{(f) Métrica e qualidade do rating}

Os ratings são elaborados pelas organizações denominadas agências de rating, que se especializam em avaliar o risco de crédito. Cada agência aplica sua própria metodologia para medir a qualidade de crédito e usa uma escala de ratings específica para publicar opiniões acerca das notações de risco. Normalmente, os ratings são expressos por meio de letras que variam, por exemplo, de 'AAA' a 'D' para comunicar a opinião da agência sobre o nível relativo de risco de crédito.

Os ratings de crédito expressam opiniões prospectivas sobre a qualidade de crédito de emissores e obrigações. Mais especificamente, os ratings de crédito expressam uma classificação relativa da qualidade de crédito. Consideramos que os emissores e obrigações com ratings mais elevados apresentam melhor qualidade de crédito do que aqueles com ratings de crédito mais baixos.

A qualidade de crédito é um fenômeno multifacetado. Embora não exista uma "fórmula" para combinar as várias facetas, os ratings de crédito buscam condensar seus efeitos combinados sem símbolos de rating distribuídos em uma escala simples e unidimensional.

\footnotetext{
${ }^{10}$ Conhecimento que se adquire pelo estudo, experiência e prática.
} 
O termo qualidade de crédito refere-se à questão do pagamento de um título de dívida ou de outro instrumento financeiro de acordo com seus termos contratuais. Em primeira análise, a ideia de qualidade de crédito parece ser totalmente objetiva. No entanto, uma análise mais profunda revela sua verdadeira natureza multidimensional.

\subsubsection{Conceitos Iniciais - Hirth (2014)}

Hirth (2014) analisou o comportamento das agências de rating de crédito competindo em um mercado com mais de duas agências e mostrou como investidores e agências reagem com relação ao comportamento de ambos.

A pergunta central do artigo examinado refere-se à maneira como a interação entre as agências de rating de risco de crédito, os investidores e os emitentes afeta a qualidade e a formação dos ratings de crédito.

$\mathrm{O}$ autor afirma que as agências de rating são consideradas as principais causadoras da crise econômica de 2008, mais conhecida como "a crise do subprime", e se baseia no fato de as agências terem tido um comportamento inflacionário - não honesto - com relação aos ratings concedidos. Com isso muitas agências de rating fornecem ratings bons para investimentos ruins, levando o investidor a acreditar que estaria realizando um investimento com retorno positivo.

Hirth (2014) considerou um mercado onde os emitentes fornecem dois tipos de investimentos, bons e ruins. Além dos emitentes, existem duas populações que interagem uma com a outra, a população dos investidores e a população das agências de rating, onde cada uma dessas populações possuem duas estratégias. Com relação à população dos investidores, uma fração da população é composta por investidores confiantes, enquanto o restante é composto por investidores sofisticados. A respeito da população das agências de rating, o autor considerou que uma fração da população refere-se às agências de rating não honestas, que inflam suas notações de risco, e a outra parte da população refere-se às agências de rating honestas, que classificam os investimentos de forma correspondente à qualidade destes. 
A parte restante do mercado foi tratada como variável exógena ao modelo, focando somente na interação entre os investidores e as agências de rating.

Sendo assim, para cada interação existe um investimento aleatório de um dado emissor para ser classificado, em que atribui-se uma probabilidade de o investimento ser classificado como bom ou ruim. Assim, a interação corresponde a um par de indivíduos composto por um indivíduo da população dos investidores, que podem ser de dois tipos, confiantes e sofisticados, e um indivíduo da população das agências de rating, que divide-se em inflacionárias e honestas. Os jogadores não podem reconhecer o tipo do seu par. As características dos indivíduos são conhecidas em um momento posterior.

A agência de rating cobra uma taxa do emitente para classificar o investimento. Essa taxa somente é recebida pela agência quando esta classificar investimentos como bons. Este pressuposto é comum na literatura e pode ser interpretado como um modelo de forma reduzida de compra de ratings em que o emitente em questão irá procurar agências que tenham a promessa de dar-lhe um rating classificado como bom (rating shopping). Entretanto podemos ter um entendimento diverso com relação ao comportamento do emitente, onde este estaria disposto a pagar somente para agências que estejam dispostas a fornecer somente o rating bom. Resumidamente, o autor considera em seu modelo que um investimento sem rating é equivalente a um investimento classificado com rating ruim. Hirth (2014) assume que as agências de rating podem perfeitamente observar se os investimentos são bons ou ruins. Uma agência de rating honesta confiavelmente informa o tipo do investimento, de forma que, se o investimento é ruim, a agência fica incapacitada de vender o rating para o emitente e não recebe a taxa. Uma agência inflacionária, em contraste, sempre informa o rating como sendo bom e recebe a taxa.

Pelo lado do investidor, investidores confiantes não estão aptos a julgar a qualidade dos investimentos. Eles são programados para comprar todo e qualquer investimento que seja classificado como bom. Em contrapartida, investidores sofisticados têm a capacidade de avaliar a qualidade dos investimentos. Devido a capacidade de julgar a qualidade dos investimentos, os investidores confiantes têm um custo específico para verificar o trabalho da agência de rating e fazer a avaliação do investimento. Caso encontrem uma agência de rating inflacionária 
com um investimento classificado como bom, eles não compram esse investimento, e ao mesmo tempo isso causa um custo de reputação para esta agência.

O autor também parte de um pressuposto forte que, agências de rating que mentem - como no caso anteriormente citado - podem ser imediatamente reconhecidas e punidas. Um pressuposto mais realista seria o de que cada comportamento possa ser detectado com atraso. Entretanto, o pressuposto é consistente com o pressuposto anterior que diz que investimentos se tornam bons ou ruins imediatamente após a tomada da decisão de investimento. Um fundamental pressuposto relacionado é o de que investidores sofisticados ainda possuem custos de monitoramento para observarem o comportamento das agências de rating, embora possam perfeitamente observar a qualidade dos próprios investimentos. Isto pode ser motivado assumindo que somente com a combinação da informação que os investidores sofisticados recebem da agência de rating e com seus próprios esforços, eles estejam aptos a realizarem um perfeito julgamento com relação aos investimentos.

Existem várias explicações econômicas para as ações da população se modificarem ao longo do tempo, dependendo dos payoffs realizados. Como um resultado dos payoffs realizados, indivíduos mudam seus comportamentos em direção à outra estratégia pura, os participantes sem sucesso deixam o mercado, ou novos participantes observam e imitam os comportamentos de maiores sucessos.

Segue abaixo a matriz de payoffs considerada com base no comportamento dos agentes discutido na seção anterior:

\begin{tabular}{lll}
\hline Investor/ CRA & Honest (H) & Inflating (I) \\
\hline Trusting (T) & $\lambda R, \lambda \varphi(\alpha, \beta)-E$ & $\lambda R-(1-\lambda), \varphi(\alpha, \beta)-(1-\lambda) \rho t$ \\
Sophisticated (S) & $\lambda(R-C), \lambda \varphi(\alpha, \beta)-E$ & $\lambda R-C, \varphi(\alpha, \beta)-(1-\lambda) \rho s$ \\
\hline
\end{tabular}

Figura 30 - Matriz de Pagamentos. Fonte: Hirth (2014). Adaptado. 
Sob a ótica da população de investidores, da matriz de payoffs, pode-se observar os seguintes pagamentos:

$$
\text { - } \mathrm{V}_{\mathrm{TH}}=\lambda \mathrm{R}
$$

Entende-se ' $\lambda$ ' como a probabilidade do investimento ser bom, e ' $R$ ' como o retorno líquido esperado por bons investimentos. Assim, percebe-se que quando os investidores confiantes competem com agências de rating honestas, estes recebem os retorrnos líquidos devido aos bons investimentos existentes. Dessa forma, somente haverá bons ratings, visto que a agência honesta não aceita conceder rating para investimentos ruins. Com isso, a probabilidade de o investidor realizar um mau investimento é nula.

$$
\text { - } \mathrm{V}_{\mathrm{TI}}=\lambda \mathrm{R}-(1-\lambda)
$$

Nesse caso, haverá notas boas tanto para bons quanto maus investimentos, visto que a agência sempre infla seus ratings. Como o investidor confiante não tem capacidade de julgamento e sempre confia no rating da agência, aquele realizará todos os investimentos classificados como 'bom'. Assim, o investidor considera como pagamento a ponderação dos lucros e prejuízos. Com isso, o investidor obtém um retorno positivo na fração dos investimentos bons e perde o dinheiro aplicado na fração dos investimentos ruins.

$$
\text { - } \mathrm{V}_{\mathrm{SH}}=\lambda \cdot(\mathrm{R}-\mathrm{C})
$$

Neste caso, o investidor - por ser sofisticado - incorre em um custo de monitoramento do investimento. Acontece que, como a agência de rating é honesta, só há custo para monitorar os investimentos bons, visto que os investimentos ruins já foram descartados pela agência. 


$$
\text { - } \mathrm{V}_{\mathrm{SI}}=\lambda \mathrm{R}-\mathrm{C}
$$

Aqui, diferentemente do caso anterior, o investidor sofisticado monitora os investimentos bons e ruins, visto que a agência fornece notas boas para todos investimentos.

Sob a ótica da população de agências de rating, a partir da matriz de payoffs, temos que:

$$
\text { - } \mathrm{X}_{\mathrm{HT}}=\mathrm{X}_{\mathrm{HS}}=\lambda \varphi(\alpha, \beta)-\mathrm{E}
$$

Neste caso, as agências de rating honestas recebem pagamento $\varphi(\alpha, \beta)$ somente por avaliar bons investimentos como 'bons'. Porém, existe um custo 'E' por avaliar todos os investimentos antes de classificá-los.

O autor define $\varphi(\alpha, \beta)$ como a taxa cobrada pela agência de rating ao emissor para conceder a avaliação do investimento como 'bom' - assumindo-se que o emissor não conhece seu próprio investimento. Esta taxa depende de $\alpha$ e $\beta$, que representam os estados das populações, ou seja, $\alpha$ corresponde à fração de investidores confiantes, enquanto que $\beta$ corresponde à fração de agências de rating honestas. Sendo assim, o emissor está disposto a pagar o fee completo caso todos os investidores comprem seus investimentos. A probabilidade do investidor comprar um investimento dado que este foi avaliado pela agência de rating como 'bom' é mostrada na figura abaixo:

$$
\operatorname{Pr}(\text { buy|"G" })=\frac{\overbrace{\operatorname{Pr}(\text { "G"|buy })}^{=1} \operatorname{Pr}(\text { buy })}{\operatorname{Pr}(\text { "G") }}=\frac{\lambda+(1-\lambda) \alpha(1-\beta)}{\lambda+(1-\lambda)(1-\beta)} \in[\lambda, 1]
$$

Figura 31 - Probabilidade do investidor comprar o investimento dado que este foi avaliado como 'bom'. Fonte: Hirth (2014).

onde a probabilidade do investimento ser avaliado como 'bom' dado que o investidor o comprou é igual a 1, visto que nenhum investidor compra um investimento sem avaliação ou que esteja avaliado como 'ruim'.

A probabilidade do investidor comprar é representada por: $\lambda+(1-\lambda) \cdot \alpha .(1-\beta)$. Entende-se que, qualquer investidor compra se o investimento for avaliado como 'bom', no entanto, para o caso do investimento ser avaliado como 'ruim', este é 
comprado pelo investidor confiante quando a agência de rating inflacionária concede boa avaliação ao investimento.

A probabilidade do investimento ser bom é representada pela parcela de bons investimentos somada à parcela dos investimentos ruins que são avaliados como 'bons' pelas agências de rating inflacionárias.

Dessa forma, a taxa cobrada pela agência de rating ao emissor para conceder a avaliação do investimento como 'bom' pode ser observada na figura abaixo:

$$
\varphi(\alpha, \beta)=\Phi \cdot \operatorname{Pr}(\text { buy } \mid \text { "G" })=\Phi \cdot \frac{\lambda+(1-\lambda) \alpha(1-\beta)}{\lambda+(1-\lambda)(1-\beta)} \in[\lambda \Phi, \Phi]
$$

Figura 32 - Taxa esperada pela agência de rating.

Fonte: Hirth (2014).

onde $\Phi$ representa a taxa que o emissor está disposto a pagar caso a avaliação concedida pela agência de rating faça com que todos os seus investimentos sejam comprados pelos investidores.

- $\mathrm{X}_{\mathrm{IT}}=\varphi(\alpha, \beta)-(1-\lambda) \cdot \rho_{\mathrm{t}}$

Nesta análise, pode-se observar que a agência inflacionária recebe por todos os investimentos, visto que ela classifica todos os investimentos como 'bons'. No entanto, a agência incorre em um custo de reputação $\left(\rho_{t}\right)$ imposto pelo investidor confiante na fração dos investimentos ruins que foram inflados.

- $\mathrm{X}_{\mathrm{IS}}=\varphi(\alpha, \beta)-(1-\lambda) \cdot \rho_{\mathrm{s}}$

Este caso é similar ao anterior. No entanto, nesta análise, o custo de reputação $\left(\rho_{\mathrm{s}}\right)$ é o custo imposto pelo investidor sofisticado.

\subsubsection{Modelagem para a estrutura espacial}

\section{(a) Caso base: ponto fixo interior e dinâmica cíclica}

Neste caso, o autor analisou o equilíbrio neutramente estável onde o ponto interior fixo é o centro da dinâmica evolucionária. Isto significa que os movimentos cíclicos da população no sentido horário, como mostrado na figura adiante, 
representam uma espiral que se movimenta periodicamente em torno do ponto fixo. O pressuposto teórico por trás disso prevê que os ratings são mais facilmente inflados em tempos econômicos muito bons, quando investidores possuem menores incentivos para realizarem due dilligence (auditoria e investigação das informações), e a qualidade ex-ante dos investimentos são, então, maiores. Com analogia ao presente artigo objeto de estudo, entende-se que isto corresponde a uma maior fração das agências de rating inflacionárias para uma fração menor de investidores sofisticados no mercado.

A conclusão para o caso base depende da estrutura de mercado. Vale a pena temporariamente que as agências de rating sejam honestas, mas somente se houverem investidores sofisticados suficientes no mercado, o que representa uma ameaça real à perda de reputação. Caso contrário, a melhor estratégia para as agências seria inflar seus ratings.

A seguir são apresentados os parâmetros de entrada e o diagrama de fases resultante do jogo evolucionário:

\begin{tabular}{|c|c|}
\hline Share of good investments & $\lambda=0.5$ \\
\hline Honest CRAs' effort & $E=0.3$ \\
\hline Fee if all investors buy & $\Phi=0.4$ \\
\hline Reputation cost (S) & $\rho_{S}=1.5$ \\
\hline Reputation cost (T) & $\rho_{T}=0.7$ \\
\hline Verification cost & $C=0.3$ \\
\hline Net payoff upon investment & $R=0.1$ \\
\hline
\end{tabular}

Figura 33 - Parâmetros para o Caso Base - Ponto fixo interior e dinâmica cíclica. Fonte: Hirth (2014). 


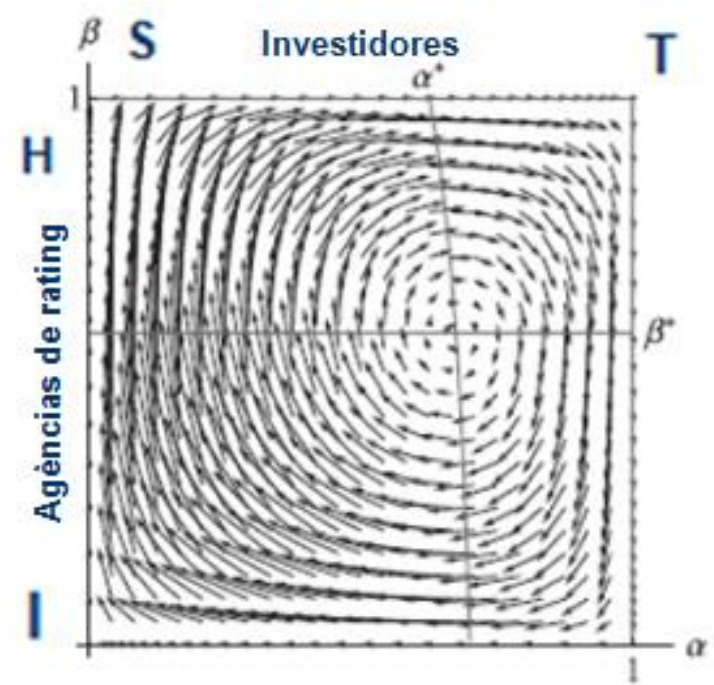

Figura 34 - Caso Base: ponto fixo interior e dinâmica cíclica. A figura representa a evolução dinâmica da fração da população, onde $\alpha$ representa a fração dos investidores confiantes (em vez dos sofisticados) e $\beta$ representa a fração das agências de rating honestas (em vez das inflacionárias). Fonte: Hirth (2014). Adaptado.

O diagrama de fases, representado acima, pode ser mais facilmente analisado ao ser dividido em áreas, conforme mostra a figura abaixo:

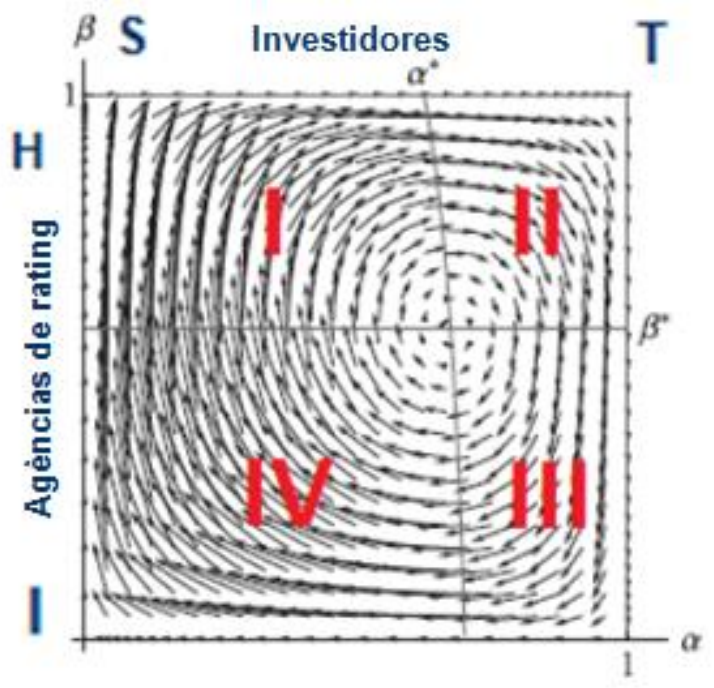

Figura 35 - Caso Base: ponto fixo interior e dinâmica cíclica. Fonte: Hirth (2014). Adaptado.

Assim, da área I entende-se que, a fração das agências de rating honestas é muito alta, de tal forma que não compensa para o investidor realizar o custo de monitoramento. Assim, a fração de investidores confiantes cresce nesse mercado. Porém, ainda existe uma quantidade suficiente de investidores sofisticados, o que faz com que o número de agências honestas aumente. 
Com relação à área II, entende-se que, os investidores se tornam cada vez mais confiantes, e com a alta fração de agências de rating honestas, ainda é atrativo realizar investimentos com boa classificação. Mas, a partir de um momento, as agências de rating percebem o incentivo de inflar seus ratings, visto que a fração de investidores confiantes é muito alta. Assim, a fração de agências de rating inflacionárias tende a aumentar.

Da área III, observa-se que, as agências de rating inflacionárias possuem desempenho melhor que as honestas, o que aumenta ainda mais sua fração no mercado. Porém, devido à grande quantidade de investimentos inflados no mercado, os investidores confiantes realizam muitos prejuízos, o que pode ser compreendido como incentivo para tornar-se sofisticado.

A partir da área IV, percebe-se que, a fração de investidores sofisticados continua a crescer devido ao alto número de agências inflacionárias. Em um determinado momento, as agências começam a ser penalizadas com os custos de reputação impostos pelos investidores sofisticados. Isto pode ser compreendido como um incentivo ao aumento de agências honestas no mercado, voltando assim à área I. Por fim, entende-se que existe uma recompensa temporária para a agência de rating ser honesta, mas somente se a fração de investidores sofisticados for alta, devido à ameaça à reputação.

\section{i. Resultados alcançados}

A fim de modelar este caso, analisado por Hirth (2014), para a dinâmica de estrutura espacial, foram considerados os mesmos parâmetros utilizados pelo autor.

Sendo assim, para tal análise, uma quantidade muito grande de pontos foram considerados como condições iniciais do jogo, de forma que todos os pontos convergiram para o mesmo resultado. Então, foi escolhido um determinado ponto para servir de exemplo nesta dissertação, visto que seria redundante apresentar os resultados para qualquer outro ponto, de forma que a explicação é análoga à vista adiante.

Com isso, seguem abaixo, como exemplo, os gráficos de frequência correspondentes à evolução do jogo espacial para ambas as populações, a partir da condição inicial $(\alpha=0.3 ; \beta=0.7)$. 


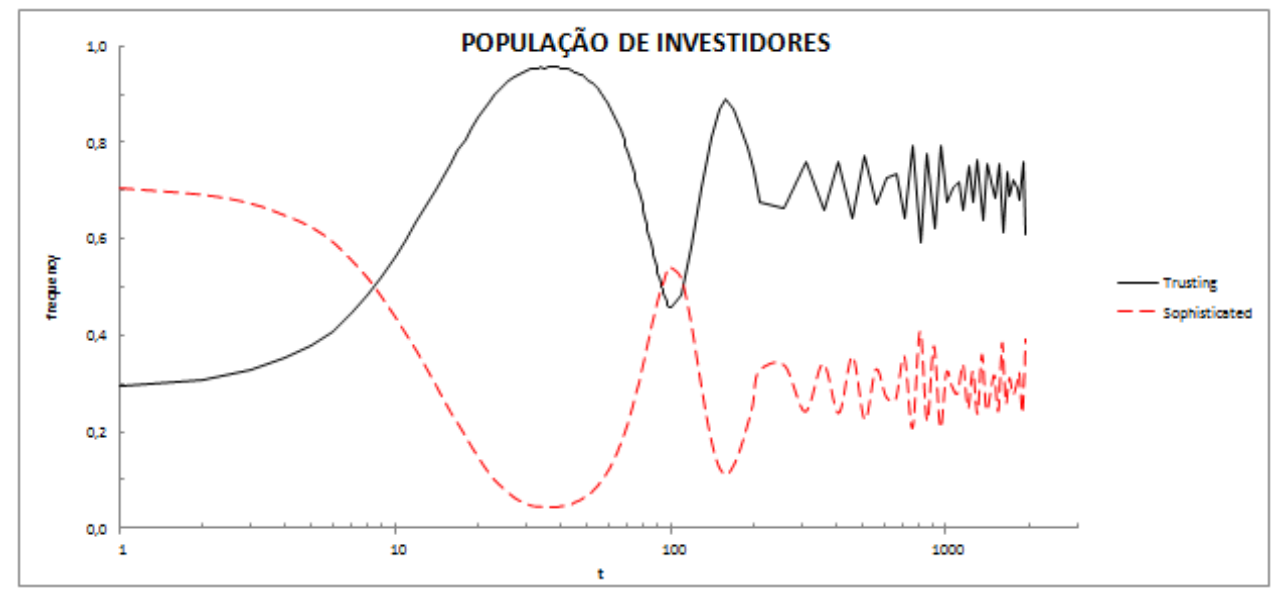

Figura 36 - Frequência da população de investidores.

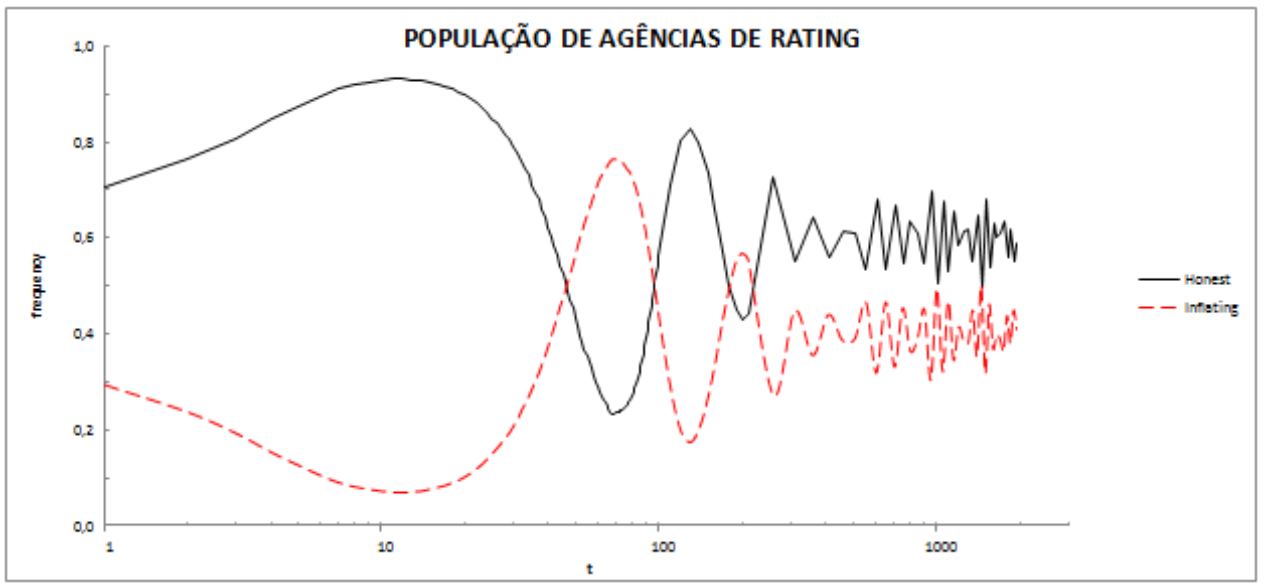

Figura 37 - Frequência da população de agências de rating.

Percebe-se que as frequências de ambas as populações têm comportamentos similares ao que foi observado no diagrama de fases, obtido como resultado do jogo evolucionário. Dessa forma, observa-se que as distâncias entre os pontos de máxima e mínima frequência para cada ciclo estão em consonância com as distâncias apresentadas no diagrama. Ou seja, tomando como exemplo a população de investidores, percebe-se que, no instante inicial, a fração de investidores confiantes é de $\alpha=0.3$. Esta fração aumenta de valor até, aproximadamente, $\alpha=0.95$, e depois reduz para, aproximadamente, $\alpha=0.5$. Comparativamente, comportamento similar pode ser observado ao realizar a mesma análise tomando como base o diagrama de fases obtido como resultado da solução analítica para populações well-mixed. 
Por fim, a fração de agências de rating honestas tende a variar minimamente em torno do ponto $\beta=0.57$, enquanto que a frequência de investidores confiantes tende a variar em torno do ponto $\alpha=0.7$, de forma similar ao observado na solução apresentada por Hirth (2014).

Segue abaixo a evolução do jogo, na representação espacial, para a população de investidores:
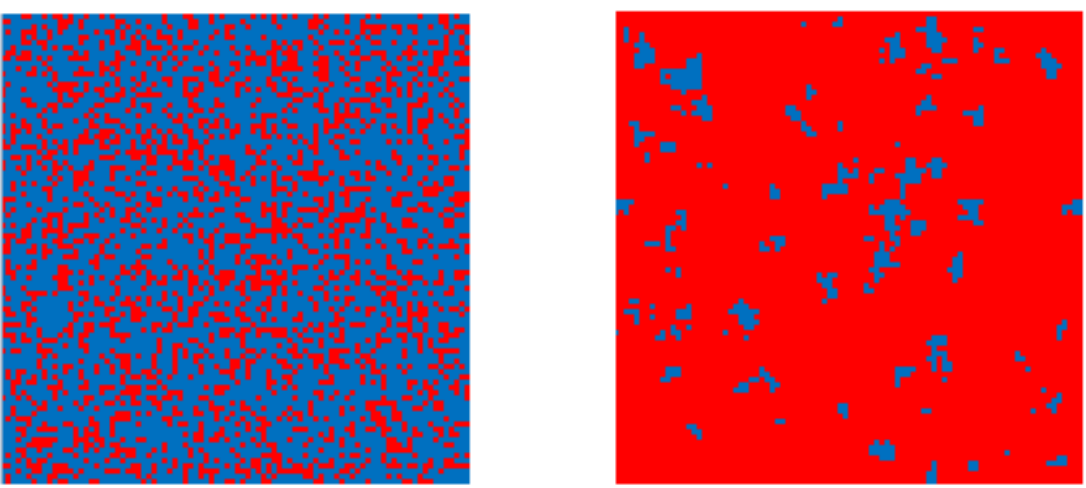

Figura 38 - Evolução espacial da população de investidores (investidores confiantes em vermelho e sofisticados em azul). PMC = 1 (à esquerda). PMC = 50 (à direita).
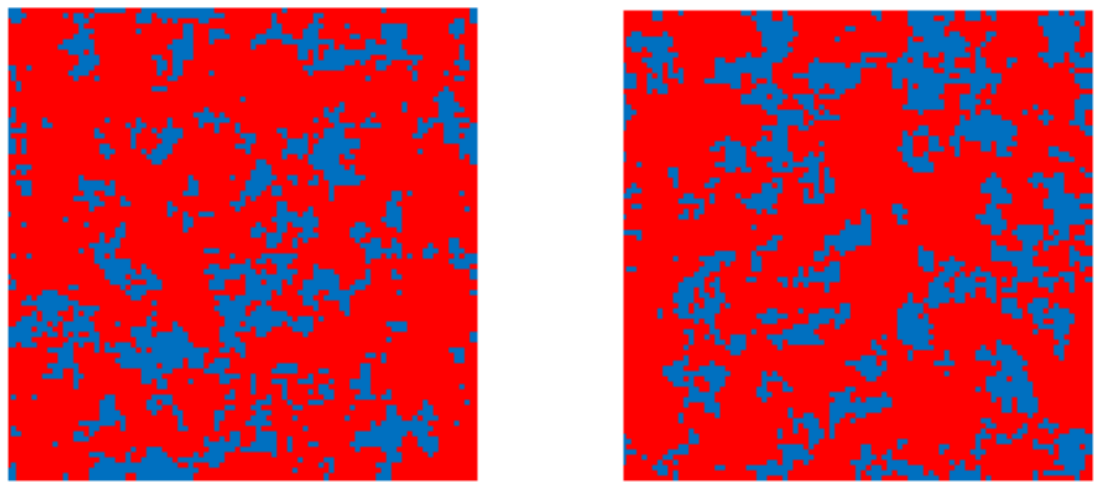

Figura 39 - Evolução espacial da população de investidores (investidores confiantes em vermelho e sofisticados em azul). PMC = 500 (à esquerda). PMC = 1000 (à direita).

Segue abaixo a evolução do jogo, na representação espacial, para a população de agências de rating: 

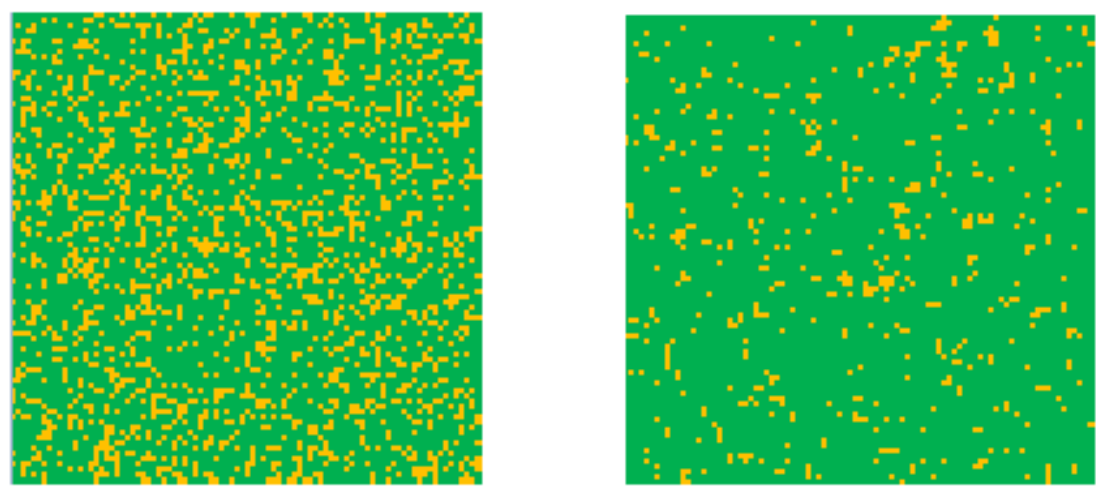

Figura 40 - Evolução espacial da população de agências de rating (agências honestas em verde e inflacionárias em amarelo). $\mathrm{PMC}=1$ (à esquerda). $\mathrm{PMC}=10$ (à direita).
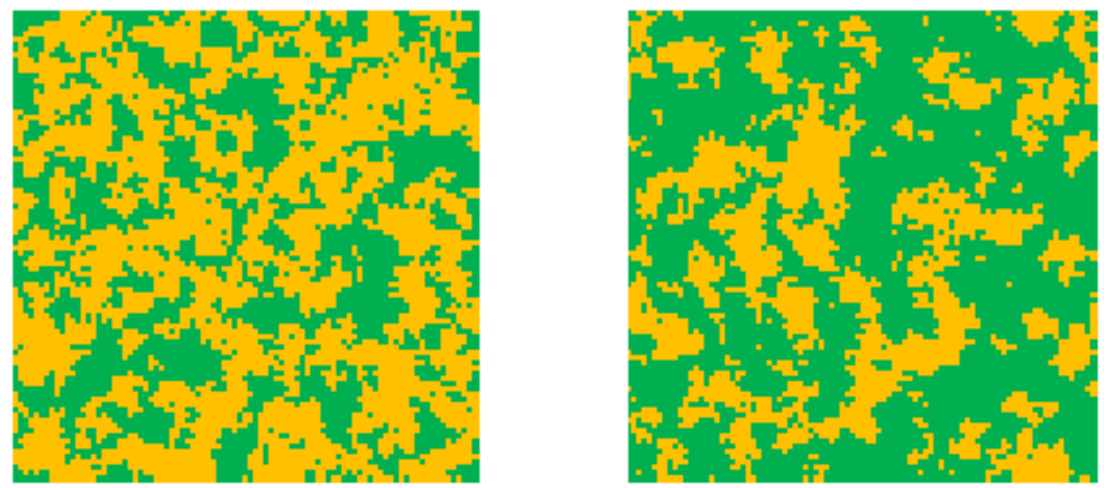

Figura 41 - Evolução espacial da população de investidores (agências honestas em verde e inflacionárias em amarelo). $\mathrm{PMC}=\mathbf{5 0}$ (à esquerda). $\mathrm{PMC}=\mathbf{5 0 0}$ (à direita).

Por fim, pode-se concluir que as frequências obtidas no equilíbrio neutramente estável, tanto no jogo com população well-mixed, quanto no jogo considerando a estrutura espacial, são as mesmas. Portanto, a inclusão da estrutura espacial não afeta o resultado.

\section{(b) Dinâmica sem ponto fixo interior}

O autor abordou quatro casos em que o resultado do jogo evolucionário, resolvido analiticamente, tende para um único equilíbrio assintoticamente estável. Diferentemente do caso base - com ponto fixo interior e dinâmica cíclica -, cada caso representa o efeito de alterar um dos parâmetros do caso base, o que conduz a quatro equilíbrios diferentes.

Todos os casos incorrem no mesmo tipo de modelagem, de modo que nesta dissertação - com a finalidade de não ser redundante - é apresentado um dos quatro casos, como exemplo de evolução do jogo espacial. 
Porém, é importante salientar que todos os casos foram extensamente analisados e convergiram para os resultados esperados de acordo com os resultados teóricos alcançados no artigo de referência que é base do presente estudo.

\section{i. Resultados alcançados}

Para o caso analisado, o autor variou o parâmetro que refere-se à proporção de bons investimentos existentes no mercado $(\lambda)$, mantendo todos os outros parâmetros inalterados com relação ao caso base. Dessa forma, com a recente parametrização, vamos focar no caso particular em que:

- $\quad \mathrm{E} \geq(1-\lambda)\left(\rho_{\mathrm{T}}-\Phi\right)$

- $\mathrm{C} \geq 1-\lambda$.

Nesse caso, o Equilíbrio de Nash do jogo na figura |28| é (T,I), o qual corresponde ao estado evolucionário da população $\alpha=1, \beta=0$.

Sob a ótica do investidor, infere-se que não há incentivo para monitorar a qualidade do investimento, já que o custo de monitoração relativamente excede a proporção de maus investimentos.

Assim, considerando que as agências de rating estão com comportamento desonesto, os investidores confiantes possuem o seguinte payoff:

- $\mathrm{V}_{\mathrm{TI}}=\lambda \mathrm{R}-(1-\lambda) \leq 0$.

Por outro lado, os investidores sofisticados possuem o seguinte payoff:

- $\mathrm{V}_{\mathrm{SI}}=\lambda \mathrm{R}-\mathrm{C} \leq 0$.

Porém, como: $\mathrm{C} \geq(1-\lambda)$; observa-se que $\mathrm{V}_{\mathrm{TI}} \geq \mathrm{V}_{\mathrm{SI}}$.

Assim, o autor apresentou o seguinte diagrama de fases: 


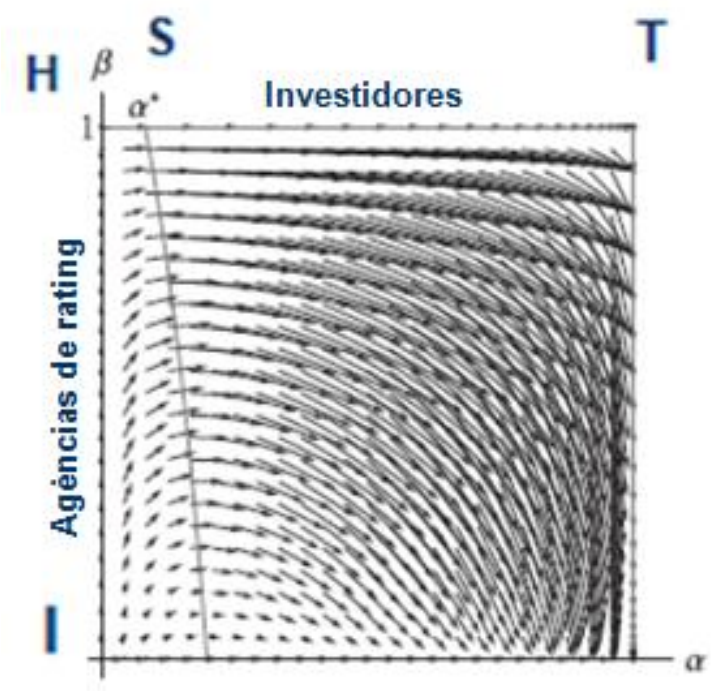

Figura 42 - Equilíbrio: Investidor confiante/ Agência inflacionária. $\boldsymbol{\lambda}=\mathbf{0 . 7 1}$.

Fonte: Hirth (2014). Adaptado.

Como resultado do jogo espacial, partindo-se da condição inicial representada

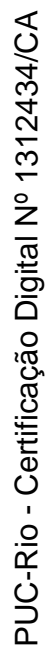

pelo ponto $(\alpha=0.1 ; \beta=0.4)$, foram obtidos como resultados, os seguintes gráficos de frequência:

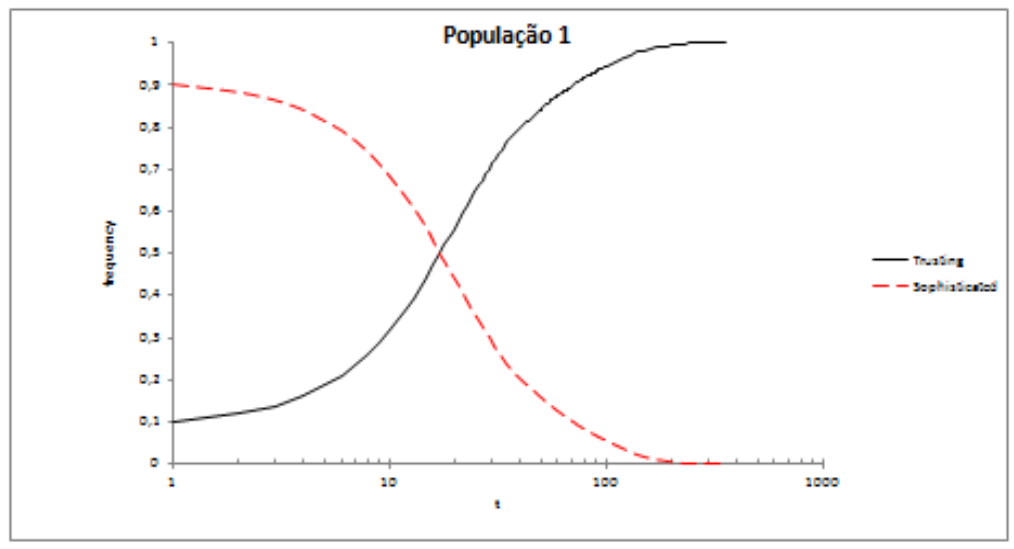

Figura 43 - Frequência da população de investidores. 


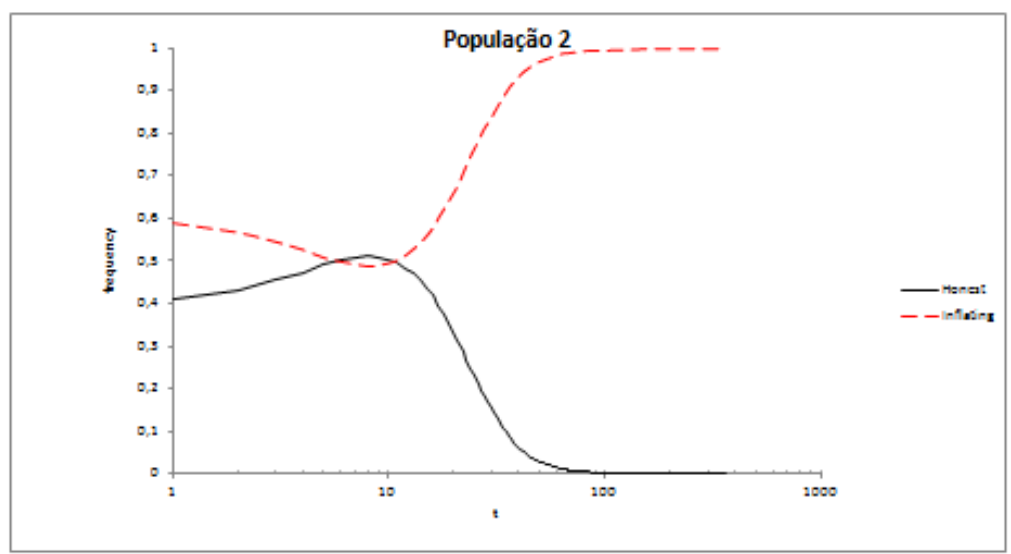

Figura 44 - Frequência da população de agências de rating.

A partir dos gráficos acima é possível observar que, o comportamento das frequências, para ambas as populações, é similar ao obtido analisando-se o diagrama de fases para a mesma condição inicial, no qual, no longo prazo, apenas investidores confiantes e agências de rating desonestas sobrevivem nas duas populações.

A seguir são apresentados os gráficos que correspondem à evolução das populações sob a ótica da estrutura espacial para a população de investidores:
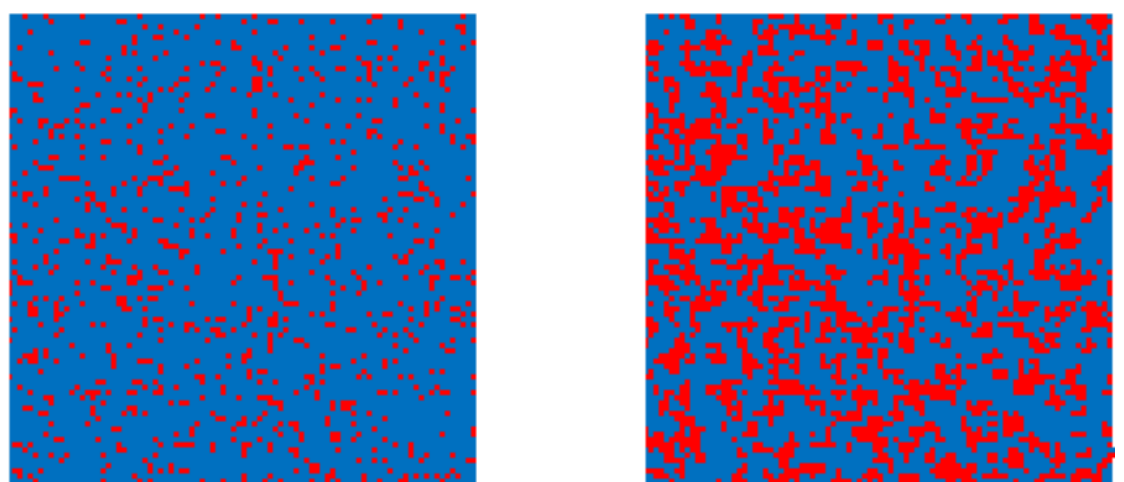

Figura 45 - Evolução espacial da população de investidores (investidores confiantes em vermelho e sofisticados em azul). PMC = 1 (à esquerda); PMC = 10 (à direita). 

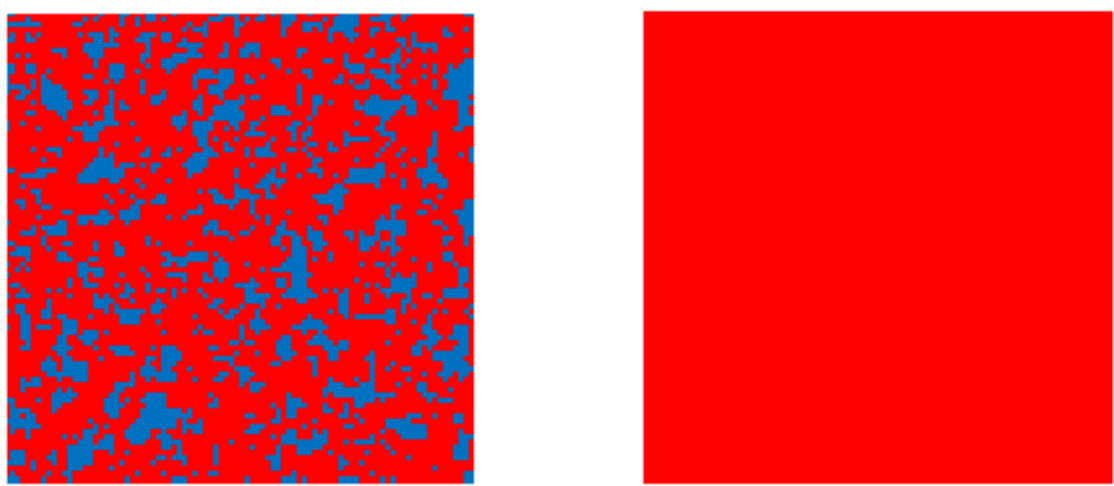

Figura 46 - Evolução espacial da população de investidores (investidores confiantes em vermelho e sofisticados em azul). PMC = $\mathbf{3 0}$ (à esquerda); $\mathrm{PMC}=\mathbf{3 0 0}$ (à direita).

Os gráficos a seguir representam a população de agências de rating:
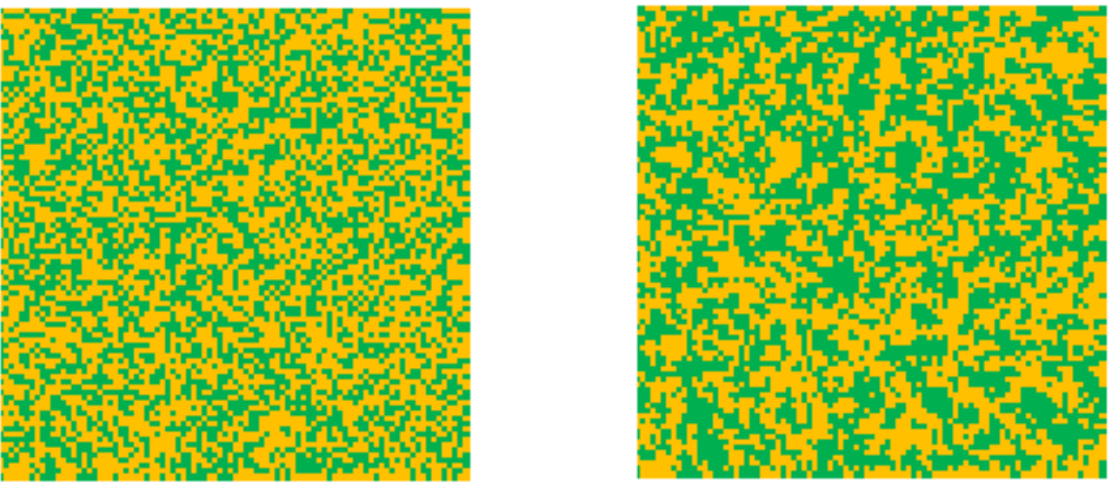

Figura 47 - Evolução espacial da população de agências de rating (agências honestas em verde e inflacionárias em amarelo). PMC = 1 (à esquerda); PMC = 10 (à direita).
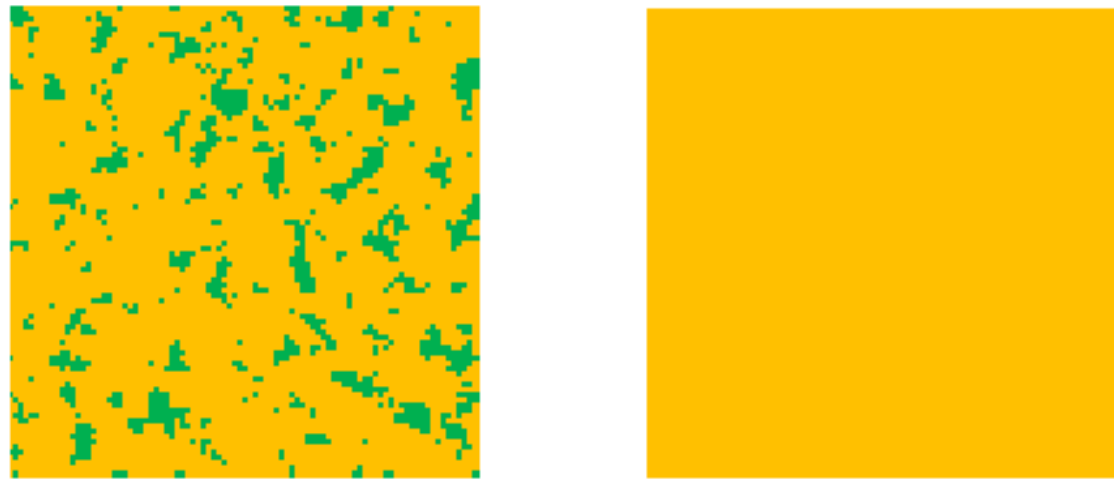

Figura 48 - Evolução espacial da população de agências de rating (agências honestas em verde e inflacionárias em amarelo). $\mathrm{PMC}=\mathbf{3 0}$ (à esquerda); $\mathrm{PMC}=\mathbf{3 0 0}$ (à direita).

Assim, da figura $|43|$ observa-se que os pontos em vermelho referem-se aos indivíduos confiantes da população de investidores, enquanto que os pontos em azul referem-se aos investidores sofisticados. Dessa forma, pode-se observar, para os citados passos de Monte Carlo, a evolução das frequências da população 
na forma espacial, em comparação ao gráfico de frequência apresentado anteriormente.

A partir da figura $|45|$ observa-se, para a população de agências de rating, que os pontos em verde referem-se às agências de rating honestas, enquanto que os pontos em amarelo referem-se às agências inflacionárias. Observa-se também que, a partir do $\mathrm{PMC}=1$, a população de agências de honestas apresenta um tênue crescimento em sua frequência, chegando ao valor máximo, aproximadamente, em $\mathrm{PMC}=10$, quando a frequência de agências honestas começa a reduzir tendendo ao desaparecimento.

\section{(c) Caso de sela: ponto fixo interior e duas bacias de atração}

\section{i. Considerações iniciais}

No caso considerado, os custos de reputação impostos pelos investidores confiantes - considerando as taxas que as agências de rating deixam de receber na proporção das classificações não concedidas - excedem os custos de reputação impostos pelos investidores sofisticados, conforme definido abaixo:

- $\rho_{\mathrm{S}}-\rho_{\mathrm{T}}+(1-\lambda) . \Phi<0$

Dessa forma, os investidores confiantes são mais dependentes da análise da agência de rating, visto que, quando se deparam com um investimento ruim classificado como 'bom', enfrentam prejuízos maiores do que enfrentados pelos investidores sofisticados.

Assim, os investidores confiantes, prejudicados, possuem incentivo maior em penalizar as agências de rating com o custo de reputação.

Para o caso estudado, o autor apresentou uma ilustração que mostra todos os Equilíbrios de Nash alcançados, considerando a premissa acima de que os custos de reputação impostos pelos investidores confiantes excedem os custos de reputação impostos pelos investidores sofisticados: 


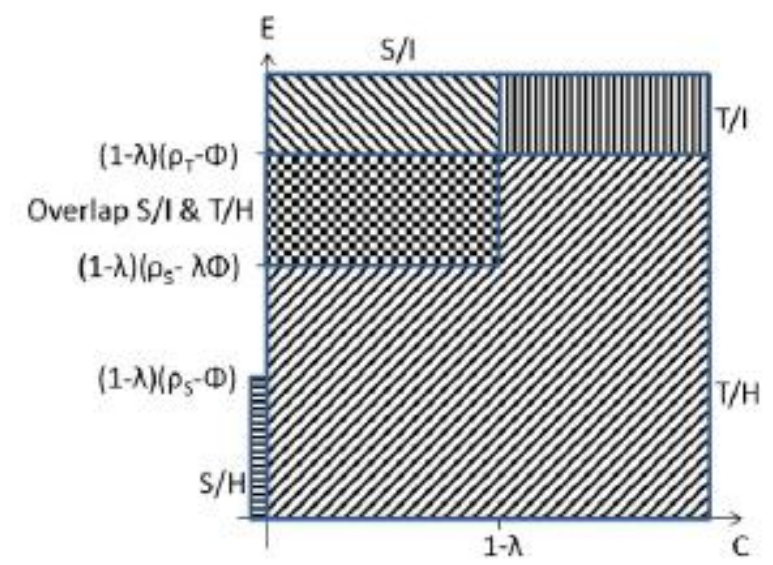

Figura 49 - Equilíbrios de Nash para o caso: $\rho_{\mathrm{S}}-\rho_{\mathrm{T}}+(1-\lambda) . \Phi<0$.

Fonte: Hirth (2014).

A partir da figura acima, observa-se que existe uma região de sobreposição, em que existem dois Equilíbrios de Nash ocorrendo de forma simultânea, conforme as condições abaixo:

- Equilíbrio (T,H):
○ $\mathrm{C} \geq 0$
$\circ \mathrm{E} \leq(1-\lambda)\left(\rho_{\mathrm{T}}-\Phi\right)$

- Equilíbrio (S,I):

$\circ \mathrm{C} \leq(1-\lambda)$

$\circ \quad \mathrm{E} \geq(1-\lambda)\left(\rho_{\mathrm{S}}-\lambda \Phi\right)$

Sendo assim, a dinâmica do jogo deve ser observada a fim de definir qual dos dois Equilíbrios de Nash será alcançado no longo prazo.

\section{ii. Resultados alcançados}

Para a modelagem do caso citado, o autor considerou os seguintes parâmetros: 


\begin{tabular}{ll}
\hline $\begin{array}{l}\text { Share of good } \\
\text { investments }\end{array}$ & $\lambda=0.5$ \\
Honest CRAs' effort & $E=0.3$ \\
Fee if all investors buy & $\Phi=0.2$ \\
Reputation cost (S) & $\rho_{\mathrm{S}}=0.6$ \\
Reputation cost (T) & $\rho_{\mathrm{T}}=0.9$ \\
Verification cost & $C=0.3$ \\
Net payoff upon & $R=0.1$ \\
$\quad$ investment & \\
\hline
\end{tabular}

Figura 50 - Parâmetros: caso de sela. Fonte: Hirth (2014).

A solução analítica resultou no seguinte diagrama de fases:

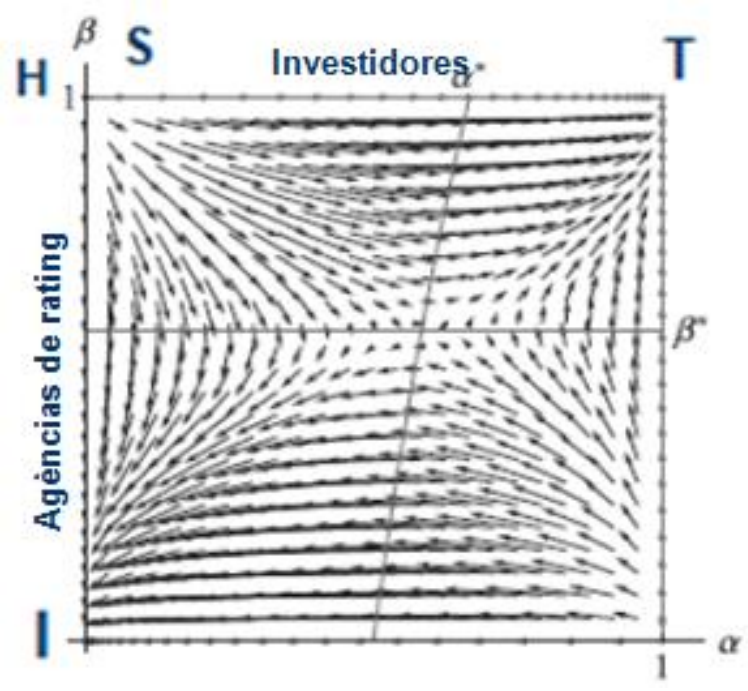

Figura 51 - Diagrama de fases. Caso de sela. Fonte: Hirth (2014). Adaptado.

A partir do diagrama de fases acima pode-se observar que existem duas bacias de atração, que levam a solução do jogo para um dos equilíbrios estáveis. Ou seja, caso a condição inicial do jogo seja tal que, um determinado ponto esteja situado na bacia à nordeste, o jogo irá evoluir até o ponto $(\alpha=1 ; \beta=1)$. Dessa forma, o equilíbrio estável para o mercado representará uma população composta somente por agências de rating honestas e investidores confiantes.

Por outro lado, caso a condição inicial seja tal que, o ponto corresponde às frequências das populações esteja situado na bacia de atração localizada à sudoeste, o equilíbrio estável para o jogo representará um mercado composto somente por agências de rating inflacionárias e investidores sofisticados. 
De forma a analisar a estrutura espacial, os seguintes pontos foram considerados:

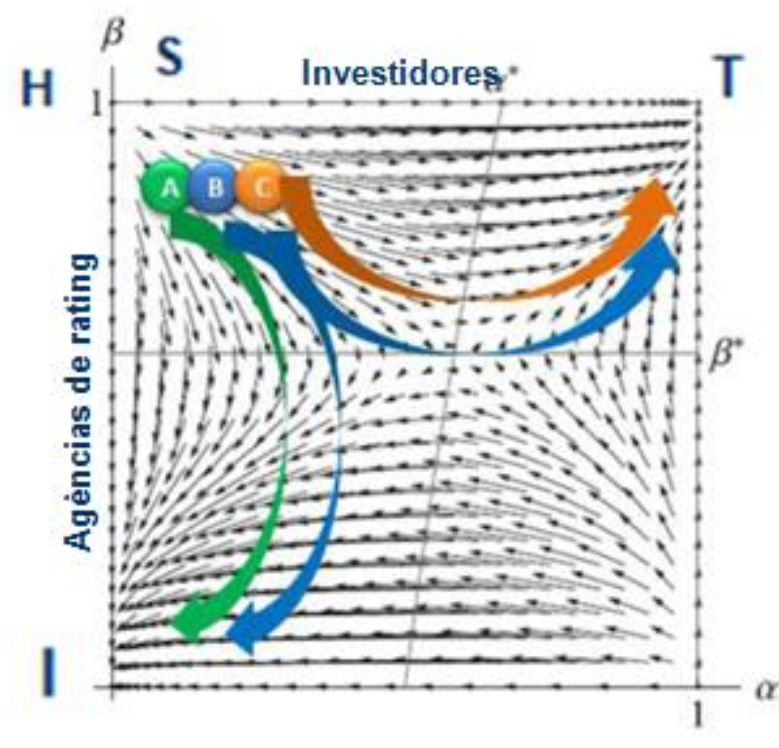

Figura 52 - Diagrama de fases para os pontos testados. Fonte: Hirth (2014). Adaptado.

A figura acima ilustra os pontos que serviram como base para este estudo. Conforme explicado anteriormente, sabe-se que qualquer ponto situado na bacia de atração de baixo convergirá para o ponto $(\alpha=0 ; \beta=0)$, e qualquer ponto situado na bacia de atração de cima convergirá para o ponto $(\alpha=1 ; \beta=1)$.

Sendo assim, os três pontos foram estrategicamente escolhidos de modo a verificar a evolução do jogo na estrutura espacial.

Da figura acima, observa-se que o ponto 'A', situado na bacia de atração de baixo, converge (de acordo com a solução analítica) para o ponto $(\alpha=0 ; \beta=0)$, enquanto que o ponto ' $\mathrm{C}$ ' converge para o ponto $(\alpha=1 ; \beta=1)$. O ponto ' $\mathrm{B}$ ' está localizado na separatriz existente entre as duas bacias de atração. Assim, de acordo com a estrutura espacial, qualquer distúrbio aleatório o faz convergir para qualquer um dos equilíbrios estáveis. É importante salientar que existe uma pequena probabilidade de que ponto ' $\mathrm{B}$ ' esteja situado exatamente sobre o autovetor que o levará até o ponto de sela.

Com isso, seguem abaixo os resultados obtidos, para cada ponto analisado, pela estrutura do jogo espacial: 
- Condição inicial: $(\alpha=0.13 ; \beta=0.8)$. Ponto 'A'.

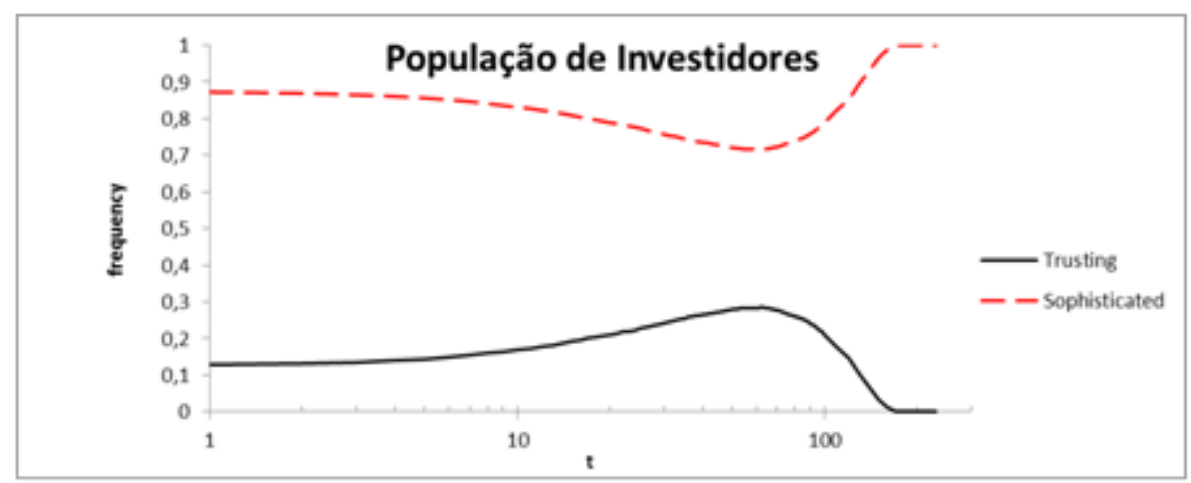

Figura 53 - Evolução das frequências para a população de investidores. Condição inicial: $(\alpha=0.13 ; \beta=0.8)$.

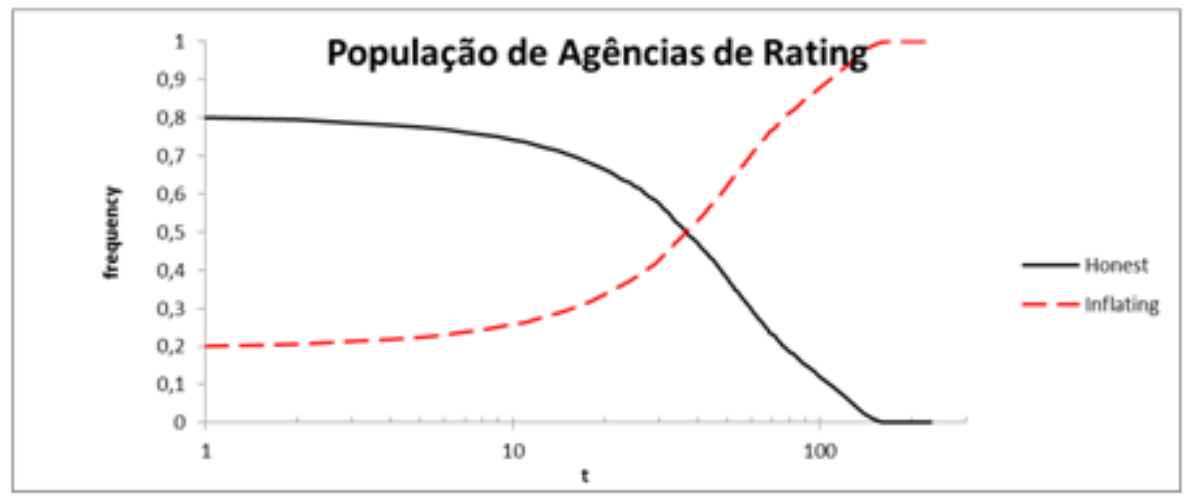

Figura 54 - Evolução das frequências para a população de agências de rating. Condição inicial: $(\alpha=0.13 ; \beta$ $=0.8$ ).

- Condição inicial: $(\alpha=0.15 ; \beta=0.8)$. Ponto ' $C$ '.

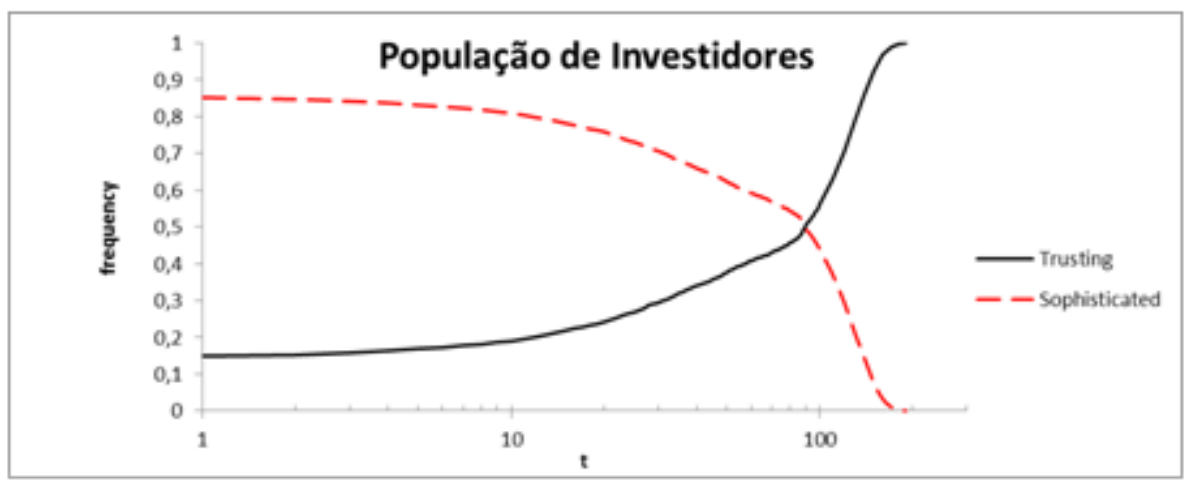

Figura 55 - Evolução das frequências para a população de investidores. Condição inicial: $(\alpha=0.15 ; \beta=0.8)$. 


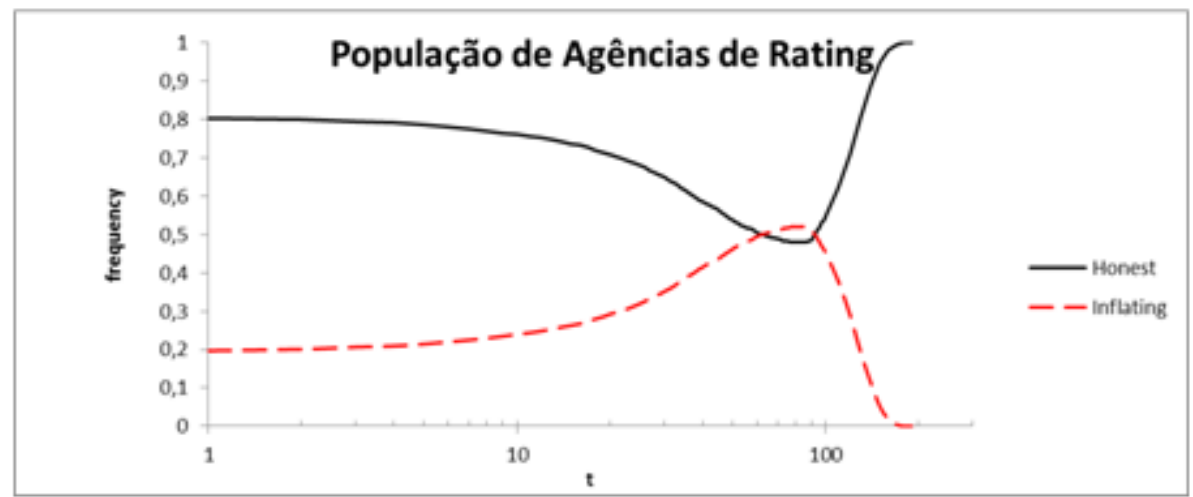

Figura 56 - Evolução das frequências para a população de agências de rating. Condição inicial: $(\alpha=0.15 ; \beta$ $=0.8$ ).

- Condição inicial: $(\alpha=0.14 ; \beta=0.8)$. Ponto 'B'.

○ Primeira simulação:

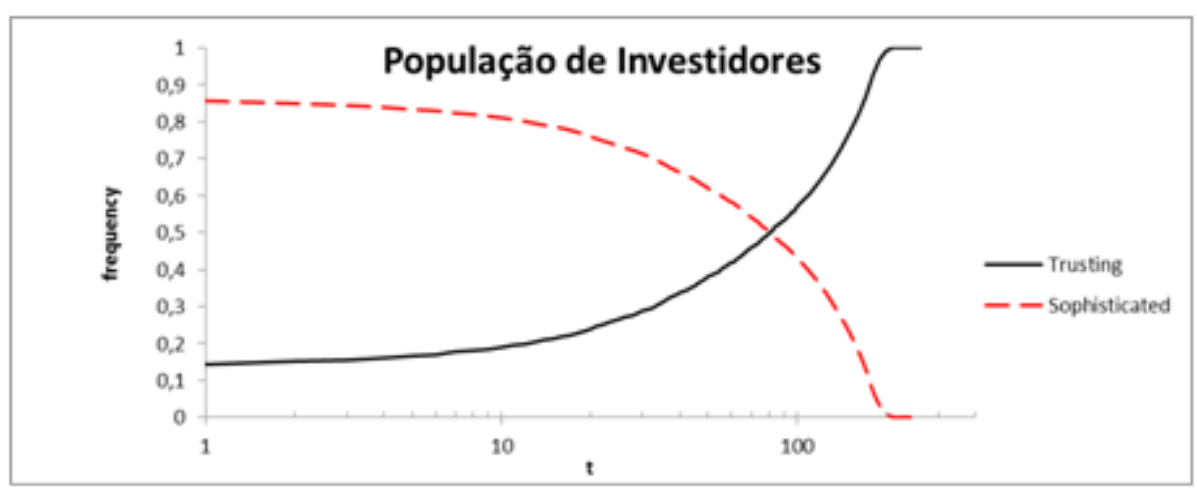

Figura 57 - Evolução das frequências para a população de investidores. Condição inicial: $(\alpha=0.14 ; \beta=0.8)$. Primeira simulação.

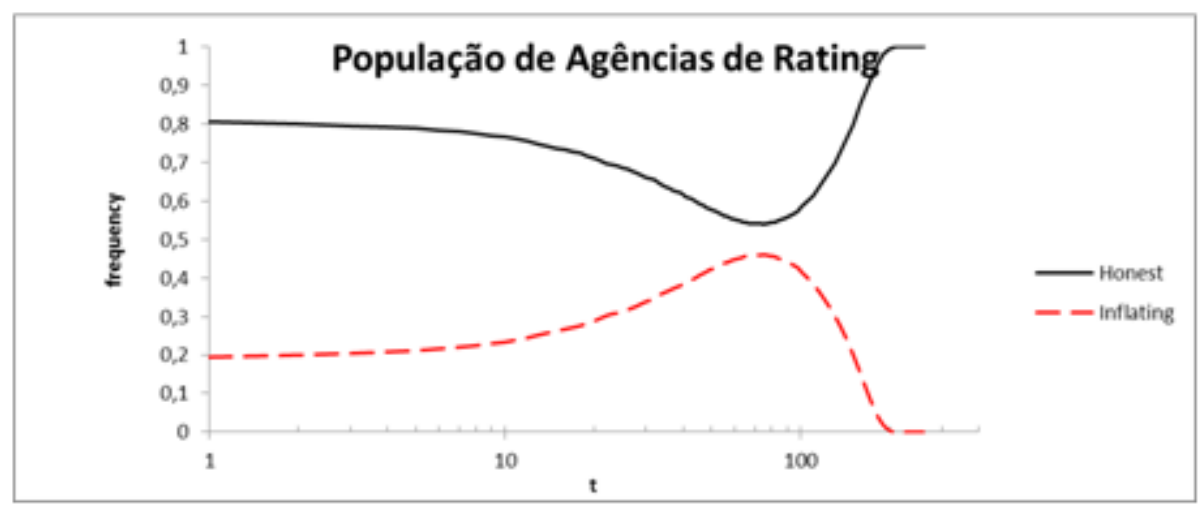

Figura 58 - Evolução das frequências para a população de agências de rating. Condição inicial: $(\alpha=0.14 ; \beta$ $=0.8$ ). Primeira simulação. 
- Segunda simulação:

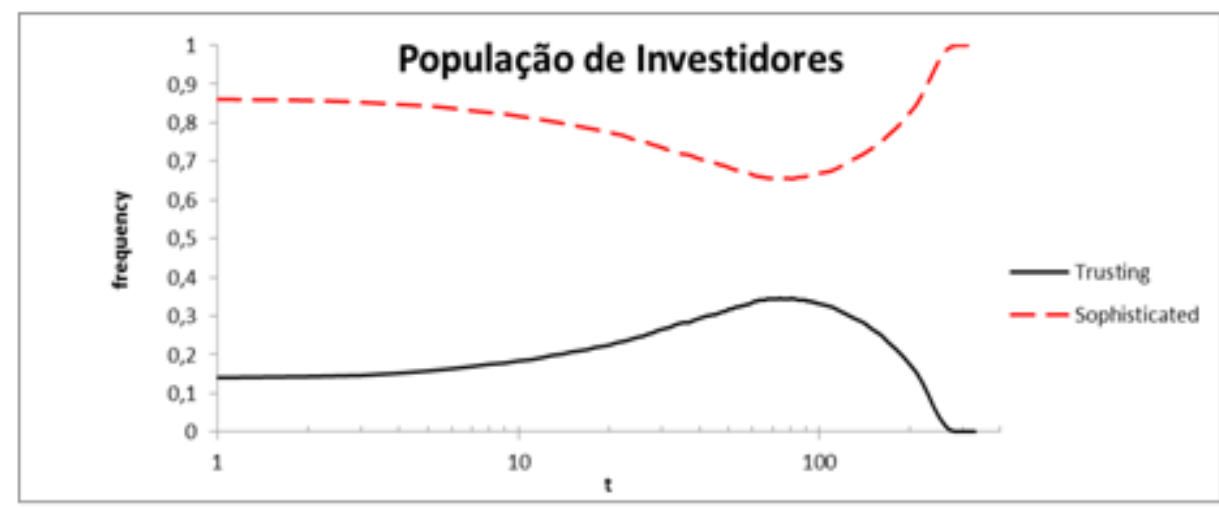

Figura 59 - Evolução das frequências para a população de investidores. Condição inicial: $(\alpha=0.14 ; \beta=0.8)$. Segunda simulação.

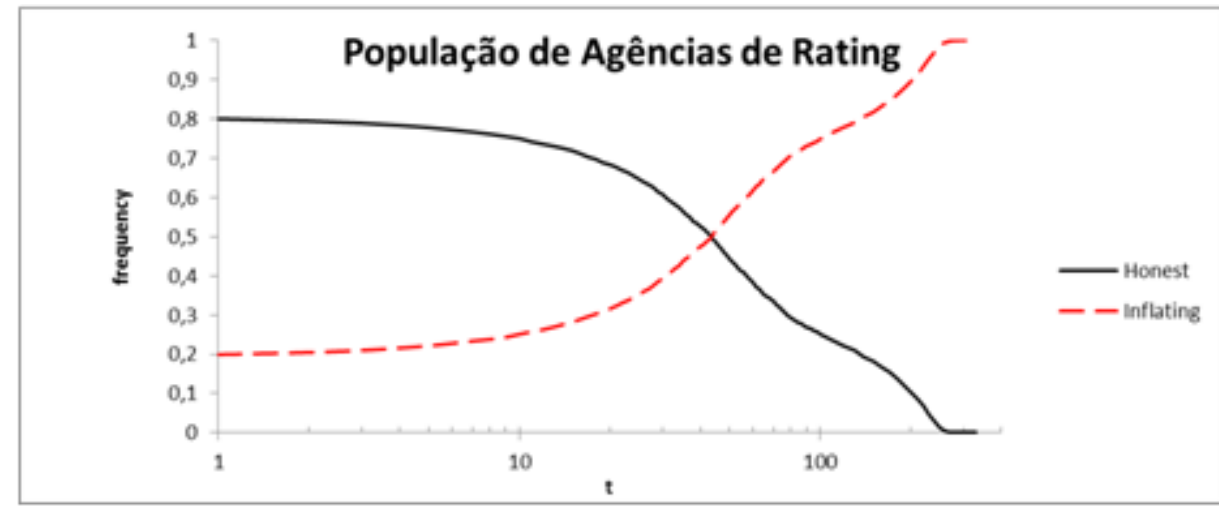

Figura 60 - Evolução das frequências para a população de agências de rating. Condição inicial: ( $\alpha=0.14 ; \beta$ $=0.8$ ). Primeira simulação.

A partir dos casos analisados acima, foi possível concluir que a estrutura espacial replicou o comportamento evolutivo apresentado pela solução analítica.

O caso analisado para o ponto 'B' (condição inicial: $(\alpha=0.14 ; \beta=0.8)$ ) é um dos mais importantes neste estudo. Esse caso mostra a aleatoriedade do jogo espacial, visto que o ponto 'B' está situado, aproximadamente, na fronteira entre as duas bacias de atração, conforme mostrado no diagrama de fases. Sendo assim, qualquer distúrbio aleatório faz com que o ponto 'B' se movimente para uma das bacias e assim convirja para o respectivo equilíbrio estável, conforme pode ser analisado nas duas simulações anteriormente apresentadas.

Segue abaixo a evolução da população na forma espacial para um dos pontos analisados: 
- Condição inicial: $(\alpha=0.15 ; \beta=0.8)$. Ponto 'C'.

○ População de investidores:
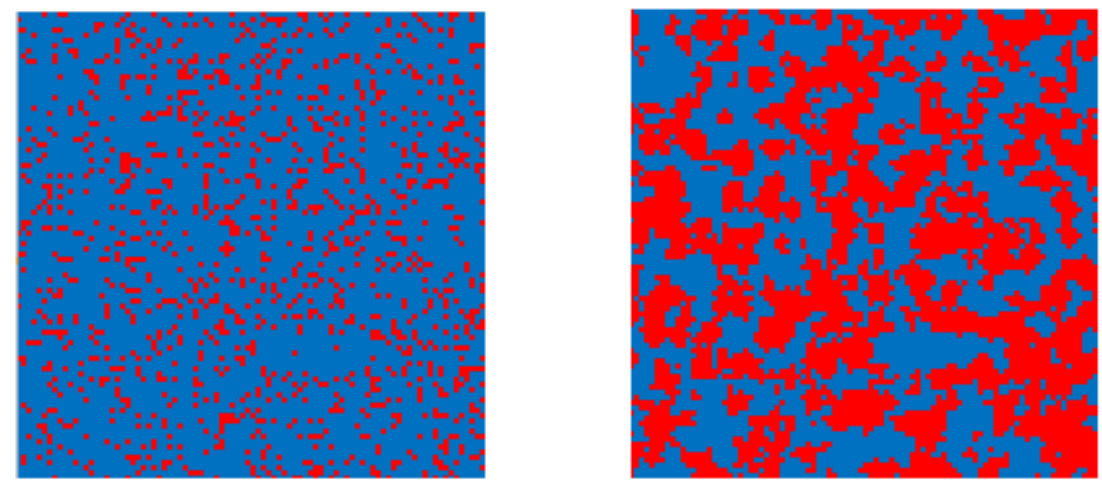

Figura 61 - População de investidores (investidores confiantes em vermelho e sofisticados em azul). PMC $=1$ (à esquerda). PMC = 80 (à direita).
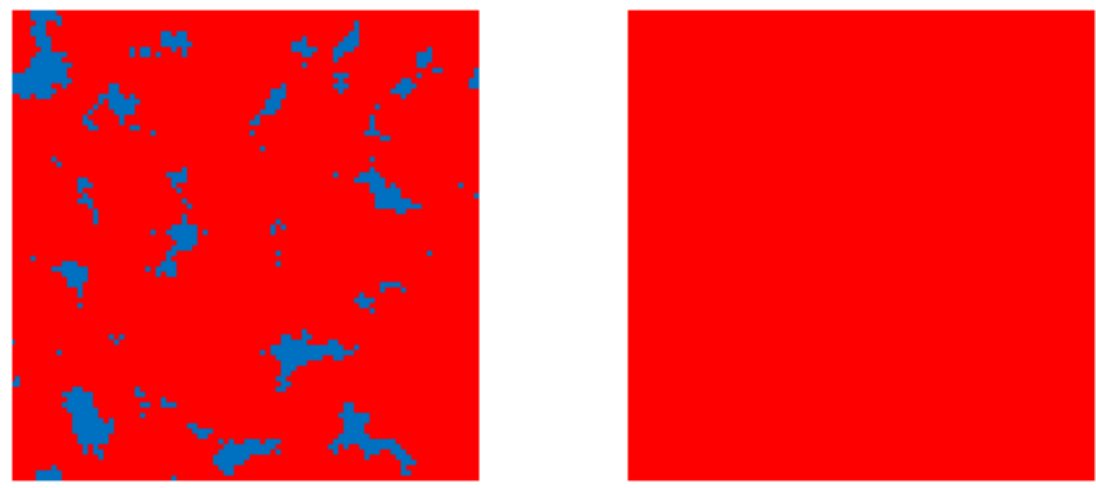

Figura 62 - População de investidores (investidores confiantes em vermelho e sofisticados em azul). PMC $=180$ (à esquerda). PMC $=250$ (à direita).

O População de agências de rating:
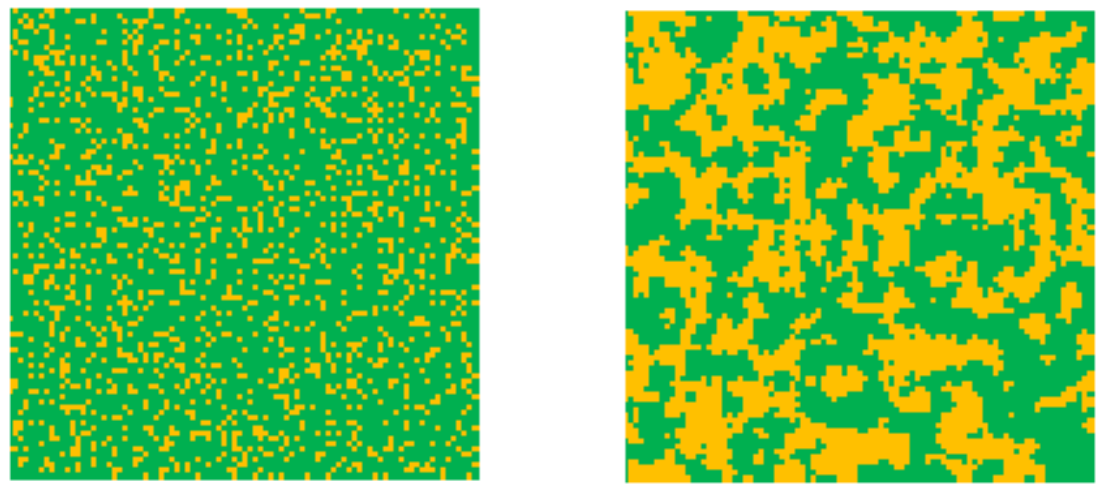

Figura 63 - População de agências de rating (agências de rating honestas em verde e inflacionárias em amarelo). PMC = 1 (à esquerda). PMC = 80 (à direita). 

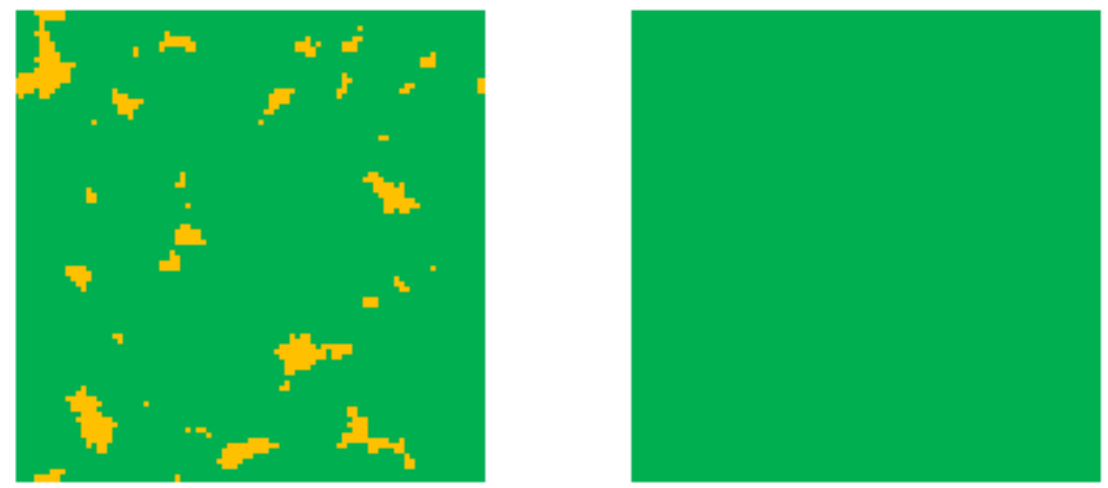

Figura 64 - População de agências de rating (agências de rating honestas em verde e inflacionárias em amarelo). PMC = 180 (à esquerda). PMC = 250 (à direita).

Das figuras acima, observa-se que os pontos em vermelho, para a população de investidores, representam os investidores confiantes, enquanto que, para a população de agências de rating, os pontos em verde, representam as agências de rating honestas. Então, em comparação aos gráficos de frequência, pode-se observar o comportamento da população de acordo com a estrutura espacial.

Dessa forma, pode-se concluir que os resultados alcançados representaram o que foi mostrado por Hirth (2014) de acordo com a solução analítica do jogo evolucionário. Ou seja, a solução do jogo evolucionário, obtida analiticamente, pode ser alcançada quando o problema é modelado na forma espacial.

\section{iii. Policy-maker}

Quando se tem um caso de sela, com duas bacias de atração, em geral pode-se considerar algum fator externo, como a figura do 'policy-maker', a fim de modificar o equilíbrio do jogo no longo prazo. Ou seja, a inserção de uma nova agência de rating no mercado pode alterar os parâmetros do modelo, e, portanto, todo o mercado pode ser levado a um novo equilíbrio. Essa inserção pode ocorrer em virtude da atuação do policy-maker, que fiscaliza e aplica severas punições às agências que estejam inflando suas avaliações, de modo a corrigir esta falha de mercado.

A figura abaixo ilustra tal situação ao representar a dinâmica do jogo considerando a entrada de uma nova agência de rating honesta no mercado: 


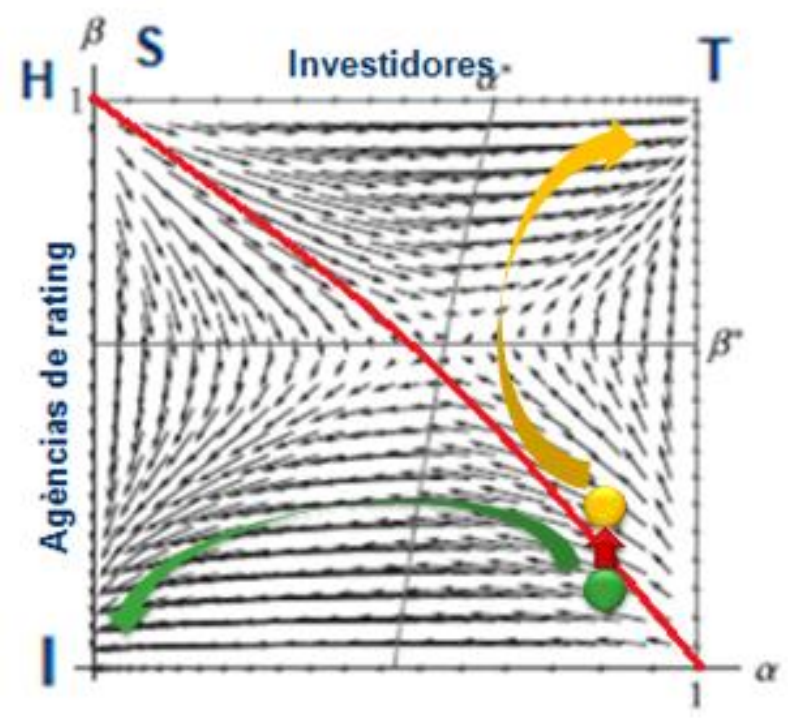

Figura 65 - Efeitos da consideração de uma nova agência de rating no mercado.

A partir da ilustração acima, assume-se que a entrada de uma nova agência de rating no mercado elevou a fração de agências honestas. Essa mudança pode ser crítica caso as frações de agências de rating honestas e investidores confiantes estejam próximas às frações que correspondem à separatriz.

Sendo assim, a entrada da nova agência de rating pode levar a dinâmica do jogo a saltar de uma bacia de atração para a outra, e, como no caso acima, atingir o equilíbrio de longo prazo com investidores confiantes e agências honestas, ao invés do equilíbrio com investidores sofisticados e agências inflacionárias, que seria o equilíbrio alcançado caso não fosse considerada a atuação do 'policymaker'. 


\section{Conclusão}

Nesta dissertação foi estudado o problema da imparcialidade das agências de rating na relação com investidores, conforme proposto por Hirth (2014).

A fim de analisar o problema proposto, fez-se uso da estrutura espacial em comparação à solução analítica apresentada como condição de equilíbrio para o jogo evolucionário com população well-mixed.

Foi desenvolvida uma ferramenta computacional que solucionou o problema proposto por Hirth (2014) utilizando a estrutura de Jogo Espacial para duas populações. Sendo assim, foi possível comparar os resultados apresentados pelo autor, como solução analítica para o jogo evolucionário com população wellmixed, com o obtido no presente estudo.

As simulações foram realizadas de modo a replicar os resultados alcançados por Hauert (2004) e Chan et al. (2013) para o jogo de uma população Snowdrift Game, bem como as suas adaptações. E posteriormente, foi desenvolvida uma extensão ao programa, de forma a considerar os jogos de duas populações, como o proposto por Hirth (2014), objeto do presente estudo.

Os resultados foram satisfatórios, de forma que a solução obtida pela estrutura espacial se aproximou da solução apresentada pelo autor.

A partir dos resultados alcançados, pode-se observar que a presença de investidores confiantes facilita as classificações infladas pelas agências de rating, principalmente quando o custo de reputação imposto pelo investidor confiante não é tão significativo. Por sua vez, a classificação inflada serve como incentivo para que os investidores confiem menos nas agências de rating. A interação entre os agentes, para ambos os efeitos podem levar a dinâmicas cíclicas na composição de ambas as populações quando vistas espacialmente.

Por outro lado, caso os custos de reputação impostos pelos investidores confiantes às agências seja significativo, a dinâmica do jogo espacial leva a solução do problema para um caso de sela, com um ponto interior fixo e duas bacias de atração. Dessa forma, qualquer distúrbio aleatório que afete a composição populacional das agências de rating ou dos investidores pode determinar equilíbrios estáveis diferentes para o resultado do jogo. O equilíbrio estável resultante pode ser tal que, a composição final das populações seja de agências de 
rating inflacionárias e investidores sofisticados, ou de agências honestas e investidores confiantes.

Por fim, a partir dos casos estudados, pode-se concluir que a estrutura de jogo espacial converge para o mesmo resultado obtido pela solução analítica do jogo evolucionário, ou seja, no caso do problema estudado, a população ser well-mixed ou estar disposta ao longo de uma grelha espacial não implica em diferenças significativas nos resultados para os mesmos valores dos parâmetros. 


\section{Referências bibliográficas}

BINMORE, K. G. Fun and Games: A Text on Game Theory. D.C. Heath, 1992.

BOLTON, P.; FREIXAS, X.; SHAPIRO, J. The Credit Ratings Game. The Journal of Finance. Volume 67, Issue 1, pages 85-111, 2012.

CHAN N. W. H. et. al. Evolutionary snowdrift game incorporating costly punishment in structured populations. Department of Physics, The Chinese University of Hong Kong, Shatin, Hong Kong. Physica A 392, pages 168 - 176, 2013.

DOEBELI, M.; HAUERT, C. Models of cooperation based on the Prisoner's Dilemma and the Snowdrift game, Ecology Letters. Pages 748-766, 2005.

FRIEDMAN, D. On economic applications of evolutionary game theory. Department of Economics, University of California at Santa Cruz, 212 Social Sciences I, Santa Cruz, CA 95064, USA, 1988.

GRAY, L. A Mathematician Looks at Wolfram's New Kind of Science. Notices of the AMS 50 (2): 200-211, 2003.

HAUERT, C; DOEBELI, M. Spatial structure often inhibits the evolution of cooperation in the snowdrift game. Departments of Zoology and Mathematics. University of British Columbia, Vancouver, British Columbia. Nature 428, 643646, 2004.

HAUERT, C. Effects of Space in $2 \times 2$ Games. Institut f"ur Mathematik, Universit“"at Wien, Strudlhofgasse 4, A-1090 Vienna, Austria, 2001. 
HIRTH, S. Credit Rating Dynamics and Competition. Aarhus University, School of Business and Social Sciences, Department of Economics and Business, Fuglesangs Allé 4, DK-8210 Aarhus V, Denmark. Journal of Banking \& Finance 49 (2014) 100112, 2014.

IOSCO. Code of Conduct Fundamentals for Credit Rating Agencies. The Technical Committee of international organization of securities commissions, 2014.

IVANOVIC, S; BARESA, S; BOGDAN, S. Role, Interests and Critics if Credit Rating Agencies. UTMS Journal of Economics, vol. 3, issue 1, pages 71-82, 2012.

MARAUHN, T. Introduction: The Regulatory Dilemma in International FinancialRelations. In.: Grote, Rainer and Marauhn, Thilo. The Regulation of International FinancialMarkets. Cambridge University Press, 2006

MAYNARD-SMITH, J. Evolution and the Theory of Games. Cambridge University Press, Cambridge, MA, 1982.

MAYNARD-SMITH, J., e Price, G. R. The logic of animal conflict. School of Biological Sciences. University of Sussex. Nature 246, 15 - 18, 1973.

NASH, J. F. Equilibrium Points in N-person Games. Proceedings of the National Academy of Sciences, 1950.

NASH, J. F. The bargaining problem, Econometrica 18 155-162, 1950.

NOWAK, M. A.; BONHOEFFER, S; MAY, R. M. Spatial games and the maintenance of cooperation. Department of Zoology, University of Oxford. United Kingdom. Proc. Nati. Acad. Sci. January 28, 1994. 
NOWAK, M. A; CORINA E. T.; ANTAL, T. Evolutionary dynamics in structured populations. Program for Evolutionary Dynamics, Department of Mathematics, Department of Organismic and Evolutionary Biology, Harvard University, Cambridge, USA, 2010.

PATTBERG, P. The institutionalization of private governance: how business and nonprofit organizations agree on transnational rules. Blackwell Publishing Ltd. 4. Ed. Pages: 589-610. Vol: 18, 2005.

ROCHA, A. B. S.; LARUELLE, A.; ZUAZO, P. Replicator Dynamics and Evolutionary Stable Strategies in Heterogeneous Games, IKERLANAK 2011-57, Universidad del País Vasco - Departamento de Fundamentos del Análisis Económico I, 2011.

TAYLOR, P. D.; JONKER L. Evolutionarily Stable Strategies and Game Dynamics. Mathematical Biosciences 40, 145-156, 1978.

UTZIG, S. The Financial Crisis and the Regulation of Credit Rating Agencies: A European Banking Perspective. Vol: 188. ADB Institute working paper series. Asian Development Bank Institute, 2010.

VON-NEUMANN, J.; MORGENSTERN, O. Theory of Games and Economic Behavior. Princeton University Press, 1944.

$X U, C$. et al. Costly punishment and cooperation in the evolutionary snowdrift game. Physica A: Statistical Mechanics and its Applications. Volume 390, Pages 1607-1614, 2011.

ZHONG, L. et al. Networking effects on cooperation in evolutionary snowdrift game. Europhysics letters 76 (4), pp. 724-730, 2006. 